EDGAR BORGES DE OLIVEIRA JÚNIOR

\title{
UMA NOVA ABORDAGEM PARA O ESTUDO DOS DEFEITOS GENÉTICO-MOLECULARES DA DOENÇA GRANULOMATOSA CRÔNICA E ANÁLISE DE SUASS RELAÇÕES GENÓTIPO-FENÓTIPO
}

Tese apresentada ao Programa de Pós-Graduação em Imunologia do Instituto de Ciências Biomédicas da Universidade de São Paulo, para obtenção do Título de Doutor em Ciências.

São Paulo

2010 
EDGAR BORGES DE OLIVEIRA JÚNIOR

\section{UMA NOVA ABORDAGEM PARA O ESTUDO DOS DEFEITOS GENÉTICO-MOLECULARES DA DOENÇA GRANULOMATOSA CRÔNICA E ANÁLISE DE SUAS RELAÇÕES GENÓTIPO-FENÓTIPO}

Tese apresentada ao Programa de Pós-Graduação em Imunologia do Instituto de Ciências Biomédicas da Universidade de São Paulo, para obtenção do Título de Doutor em Ciências.

Área de concentração: Imunolgia

Orientador: Prof. Dr Antonio Condino Neto

São Paulo

2010 
DADOS DE CATALOGAÇÃO NA PUBLICAÇÃO (CIP)

Serviço de Biblioteca e Informação Biomédica do Instituto de Ciências Biomédicas da Universidade de São Paulo

(C) reprodução total

Oliveira-Júnior, Edgar Borges de.

Uma nova abordagem para o estudo dos defeitos genéticomoleculares da doença granulomatosa crônica e análise de suas relações genótipo-

fenótipo / Edgar Borges de Oliveira-Júnior. -- São Paulo, 2010.

Orientador: Antonio Condino Neto.

Tese (Doutorado) - Universidade de São Paulo. Instituto de Ciências Biomédicas. Departamento de Imunologia. Área de concentração: Imunologia. Linha de pesquisa: Imunodeficiência de fagócitos

Versão do título para o inglês: A new approach to study of moleculargenetic defects of chronic granulomatous disease and analysis of its genotype-phenotype relationships.

Descritores: 1. Doença granulomatosa crônica 2. Fagócitos 3. NADPH oxidase 4. Gene CYBB 5. Gene NCF1 6. dHPLC I. Neto, Antonio Condino II. Universidade de São Paulo. Instituto de Ciências Biomédicas. Programa de Pós-Graduação em Imunologia III. Título. 


\section{UNIVERSIDADE DE SÃO PAULO \\ INSTITUTO DE CIÊNCIAS BIOMÉDICAS}

Candidato(a):

Título da Tese:

Orientador(a):
Edgar Borges de Oliveira-Júnior.

Uma nova abordagem para o estudo dos defeitos genéticomoleculares da doença granulomatosa crônica e análise de suas relações genótipo-fenótipo.

Antonio Condino Neto.

A Comissão Julgadora dos trabalhos de Defesa da Tese de Doutorado, em sessão pública realizada a ........... considerou

\section{( ) Aprovado(a) \\ ( ) Reprovado(a)}

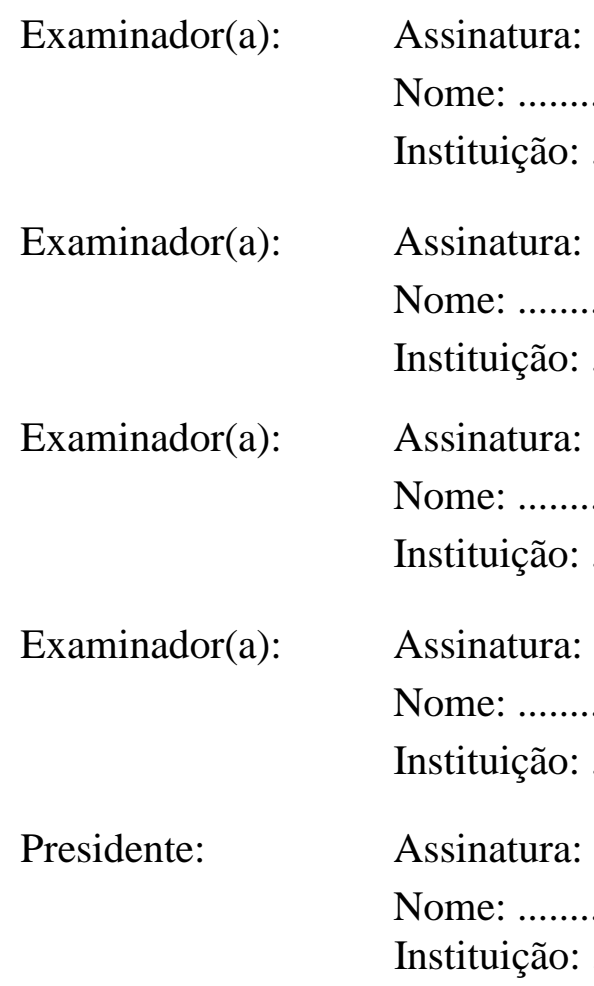




\section{PARECER 881/CEP}

Prezado Senhor,

Atendendo sua solicitação, a comissão de Ética em Pesquisas com seres Humanos do ICB, em sua $93^{\text {a }}$ reunião realizada em 24.003 .09 , analisou o projeto de sua responsabilidade intitulado: "Espectro clínico e defeitos genético-moleculares de pacientes com doença granulomatosa crônica".

Informo a V.Sa. que, após análise e discussão, o referido projeto foi aprovado por esta Comissão.

Lembramos que cabe ao pesquisador elaborar e apresentar a este comitê, relatórios anuais (parciais ou final), de acordo com a resolução 196/06 do Conselho Nacional da Saúde, item IX.2 letra c.

O primeiro relatório deverá ser encaminhado à Secretaria deste CEP em

\section{4 de março de 2010.}

Atenciosamente,

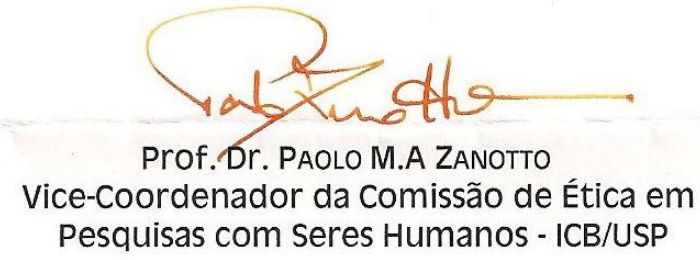

IImO.Sr.

EDAGR BORGES DE OLIVEIRA JÚNIOR

Departamento de Imunologia

Instituto de Ciências Biomédicas -USP

Comissão de Ética em Pesquisa com Seres Humanos do Instituto de Ciências Biomédicas / USP Aprovada pela Comissão Nacional de Ética em Pesquisa - CONEP, em 10 de fevereiro de 1998. 
À minha mãe, uma guerreira na luta contra o câncer de mama, pela sua paz e alegria apesar de tudo. 


\section{AGRADECIMENTOS}

À minha esposa Renata, grande amor e inspiração da minha vida, pelo seu imenso amor e carinho, por me acompanhar em todos os momentos da minha vida

Ao meu orientador Dr Antonio Condino Neto, pelas oportunidades e incentivos, mas acima e tudo pela amizade e confiança

À pesquisadora Dra Jacinta Bustamante, do Laboratório de Genética Humana da Faculdade de Medicina Necker, Paris, França, pelo apoio científico

Aos meus pais Edgar e Maria Helena, pelo dom da vida

Aos meus irmãos Juliana e Júlio, pela amizade e carinho

Aos meus sogros Joaquim Geraldo e Maria, pelo grande carinho e alegria.

Aos meus cunhados James e Roberta, pelos momentos de alegrias nos dias de descontração e lazer

Aos amigos Paulo Vitor, Josias e Walmir, pelo acolhimento durante minhas estadias em São Paulo

Aos amigos do Laboratório de Imunologia Humana (LIH), Angela, Otávio, Stefanie, Marília, Patrícia, Julieta, Sara, Soraya e Éric, pelo imenso carinho de todos

Às amigas, Cris e Silvana, pelo apoio técnico e administrativo

À Jussara, Dra Bia, Fabiana, Carolina Prando, Caru, Maiara, Mayra e Márcia, pelo apoio e carinho nos experimentos realizados na Universidade Estadual de Campinas (Unicamp)

A todos os médicos que colaboraram com este projeto

Aos pacientes e seus pais, por acreditarem em nosso trabalho

À Fundação de Amparo à Pesquisa do Estado de São Paulo (Fapesp), pelo apoio financeiro 
"Um pouco de ciência nos afasta de Deus. Muito, nos aproxima."

Louis Pasteur 


\section{RESUMO}

Oliveira-Júnior EB. Uma nova abordagem para o estudo dos defeitos genético-moleculares da doença granulomatosa crônica e análise de suas relações genótipo-fenótipo. [Tese (Dourando em Imunologia)] São Paulo (Brasil): Instituto de Ciências Biomédicas da Universidade de São Paulo; 2010.

A Doença Granulomatosa Crônica é uma imunodeficiência grave e rara, de manifestação precoce, na qual os quadros infecciosos por bactérias e fungos, ocorrem predominantemente nas barreiras naturais do organismo. O defeito molecular da DGC reside em mutações que afetam um dos componentes do sistema NADPH oxidase. Assim, na forma ligada ao sexo, é afetado o componente gp91-phox, ou NOX2 (56\% dos casos), e nas formas autossômicas recessivas é afetado um dos componentes citosólicos, sendo a p47-phox a mais frequente (33\% dos casos). A diversidade dessas mutações e os múltiplos genes afetados, explicam a heterogeneidade clínica e genética da DGC. A proposta deste trabalho foi identificar as alterações genético-moleculares de pacientes com DGC comparando dois métodos de triagem e avaliar a correlação genótipo-fenótipo das alterações encontradas. O método dHPLC mostrou-se mais sensível que o SSCP, sendo eficaz na detecção de alterações em $\mathbf{1 0 0 \%}$ dos casos. Identificamos sete mutações diferentes no gene $C Y B B$, sendo quatro delas inéditas. Identificamos as mutações: R226X (exon 7); R290X (exon 8); e C537R (exon 13). Dentre as mutações inéditas identificamos: T302fsX46 (exon 9); c.141+5 G>T (intron 2); C185R ( exon 6); e H222L (exon 6). Em duas pacientes identificamos a mutação c. V25fsX51 (exon 2) no gene NCF1 na forma homozigota em duas pacientes. Estabelecemos uma correlação entre genótipo e fenótipo clínico por meio de cálculo matemático baseado em seleção e classificação de 18 manifestações clínicas mais relevantes e comuns entre estes pacientes, nos fornecendo dados importantes como pontos gerais de cada manifestação clínica e um Índice de Gravidade Clínica (IGC) para cada tipo de mutação envolvida na DGC (CYBB "nonsense", $C Y B B$ "missense", $C Y B B$ "splicing" e $N C F 1$ "nonsense"). Os resultados contribuem para o avanço do conhecimento sobre o sistema NADPH oxidase fagocítico humano, para a construção de estratégias que permitam a identificação dos defeitos genéticomoleculares relacionados à DGC e, sobretudo no desenvolvimento e diferenciação clínica para cada tipo de mutação na DGC, podendo este modelo ser adaptado para o estudo de outras imunodeficiências.

Palavras-chave: DGC. Fagócitos. NADPH oxidase. CYBB. NCF1. dHPLC. Índice de Gravidade Clínica. 


\begin{abstract}
Oliveira-Júnior EB. A new approach to study of molecular-genetic defects of chronic granulomatous disease and analysis of its genotype-phenotype relationships. 2010. [Ph. D. Thesis (Immunology)]. São Paulo (Brasil): Instituto de Ciências Biomédicas da Universidade de São Paulo; 2010.

Chronic granulomatous disease (CGD) is a primary immunodeficiency characterized by early onset of recurrent and severe infections, affecting the body barriers. In these patients, phagocytes present a failure in the respiratory burst characterized by the total absence or low levels of reactive oxygen species production caused by a deficiency of the NADPH oxidase system, and a severe microbicidal defect. Mutations affecting one of the components of the NADPH oxidase system lead to CGD. The most frequent is the $\mathrm{X}$-linked form due to mutations in gp91phox (NOX2), encoded by $C Y B B$ gene. SSCP is a method for screening mutations widely used in investigating the $C Y B B$ gene, mostly in Latin America due to its low cost. dHPLC is a method that has been described and used for detection of mutations in PCR products by high-performance liquid chromatography under partially denaturing conditions. We compared the efficacy of dHPLC (denaturing high-performance liquid chromatography) and SSCP (Single Strand Conformation Polymorphism) for screening mutations in $C Y B B$ gene in 12 patients with X-linked chronic granulomatous disease (CGD). We found seven different mutations, four of which are original. Interestingly, the four novel mutations were identified only by dHPLC screening. Both methods detected the following alterations: R226X and R290X CYBB mutations. However, the novel mutations T302fsX46, $141+5 \mathrm{G}>\mathrm{T}$, C185R and H222L, were only detected by dHPLC. We concluded that dHPLC revealed high sensitivity and proved to be a reliable method for screening mutations and polymorphisms in an extensive gene and with a lot of genetic heterogeneity, as it happens in the $C Y B B$ gene. Moreover, we have identified mutations in NCF1 gene in two patients (V25fsX5). We have established a correlation between clinical phenotype and genotype by means of mathematical calculation based on the selection and classification of 18 relevant clinical manifestations, indicating a Clinical Severity index (CSI) for each type of mutation involved in CGD (CYBB "nonsense", $C Y B B$ "missense", $C Y B B$ "splicing" and $N C F 1$ "nonsense"). We believe to be an innovative analysis conciliating clinical and molecular-genetics data. We propose to perfect this method and adopt it to study other immunodeficiencies.
\end{abstract}

Keywords: CGD. Phagocytes. NADPH oxidase. $C Y B B$. NCF1. dHPLC. Clinical severity Index. 


\section{LISTA DE ILUSTRAÇÕES}

Figura 1. Sistema NADPH oxidase

Figura 2. Posição do gene $N C F 1$ e pseudogenes localizados no cromossomo 7 do genoma humano

Figura 3. Versão modificada da predição entre genótipos do

NCF1 / భNCF1

Figura 4. Esquema representativo dos oligos que abrangem

todo o transcrito do gene $C Y B B$

Figura 5. Heredogramas com representação das famílias dos

pacientes DGC ligada ao $\mathrm{X}$

Figura 6. Análise molecular do exon 7 (pacientes 1 e 2), uma mutação tipo "nonsense"

Figura 7. Análise molecular do exon 8 (pacientes 3, 4 e 5), uma mutação tipo "nonsense"

Figura 8. Análise molecular do exon 9 (paciente 6), uma inserção levando a um "frameshift" e códon de parada prematuro 38

Figura 9. Análise molecular do exon 2 (paciente 7), uma mutação tipo erro de "splicing"

Figura 10. Análise molecular do exon 6 (paciente 8), uma mutação tipo "missense"

Figura 11. Análise molecular do exon 6 (paciente 9), uma mutação tipo "missense"

Figura 12. Análise molecular do exon 13 (paciente 10), uma mutação tipo "missense"

Figura 13. Análise adicional do método dHPLC (controles)

Figura 14. Análise molecular no exon 2 - gene $N C F 1$ (pacientes P1a e P2a) por sequenciamento direto, uma mutação "nonsense"

Figura 15. Análise molecular do exon 2 - gene $N C F 1$ (pacientes P3a e P4a) por sequenciamento direto, possível alteração em heterozigose 46

Figura 16. Análise por SSCP do exon 4 do gene $N C F 1$ 46 
Figura 17. Análise molecular do exon 4 - gene $N C F 1$ (pacientes P3a e P4a) através sequenciamento: possível mutação em heterozigose

Figura 18. Análise cruzada da gravidade clínica entre as diferentes mutações no gene $C Y B B$

Figura 19. Análise cruzada da gravidade clínica entre os diferentes genes $(C Y B B / N C F 1)$

Figura 20. Análise do Índice de Gravidade Clínica entre os diferentes genótipos

Figura 21. Gráfico comparando as médias de idade (meses) entre diferentes mutações no gene $C Y B B$.

Figura 22. Gráfico comparando as médias de idade (meses) entre os genes $C Y B B$ e $N C F 1$

Quadro 1. Correlação genótipo-fenótipo clínico / Índice de Gravidade Clínica 
LISTA DE TABELAS

Tabela 1 - Oligos utilizados nos métodos SSCP e dHPLC

30

Tabela 2 - Mutações no gene $C Y B B$ e avaliação pelos métodos SSCP e dHPLC

Tabela 3 - Mutações no gene NCF1 identificados em pacientes DGC

Tabela 4 - Diagnóstico e Manifestações clínicas dos pacientes DGC 54 


\section{LISTA DE SÍMBOLOS}

\section{AMINOÁCIDO}

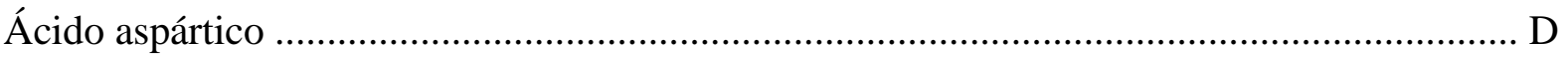

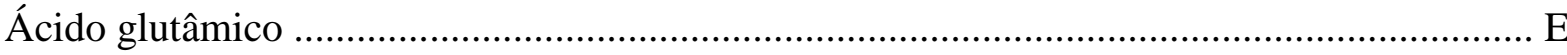

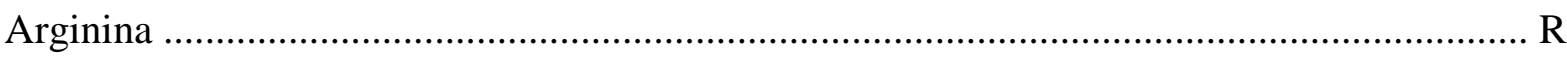

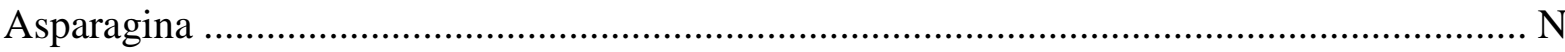

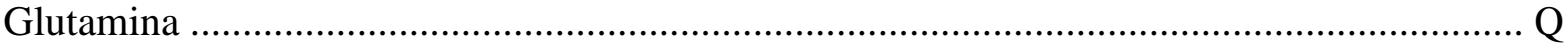

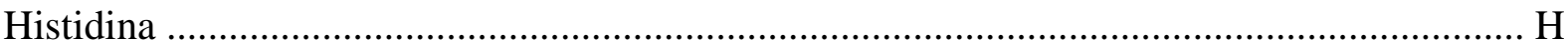

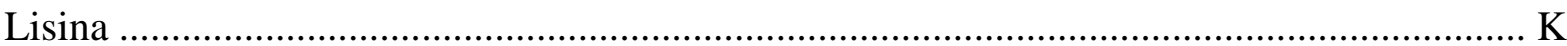

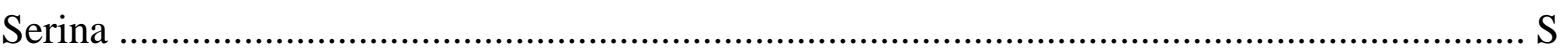

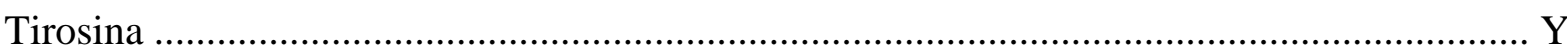

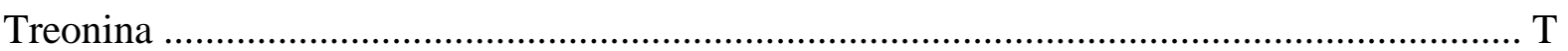

\section{BASES NITROGENADAS DOS NUCLEOTÍDEOS}

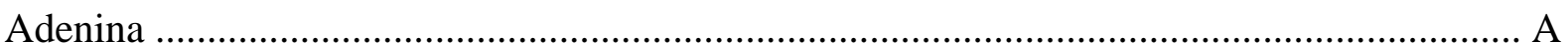

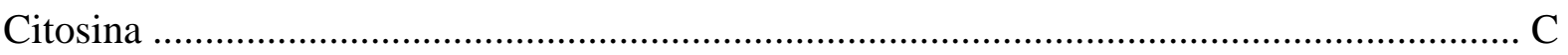

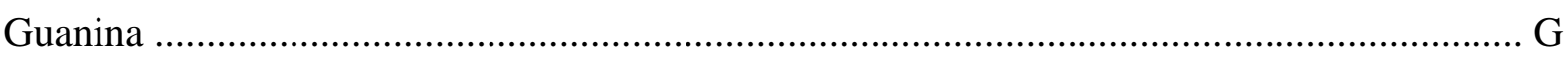

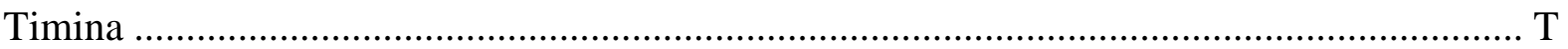




\section{SUMÁRIO}

1 INTRODUÇÃ

1.1 Conceito e Classificação da Doença Granulomatosa Crônica (DGC) ....................... 16

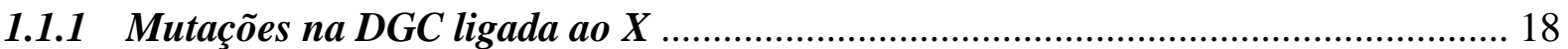

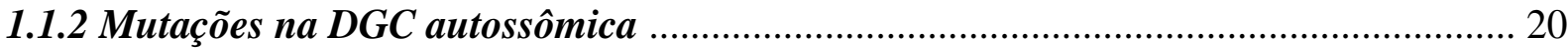

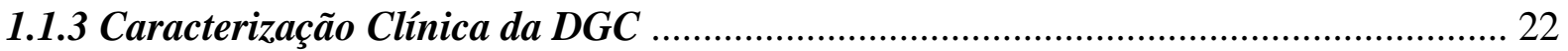

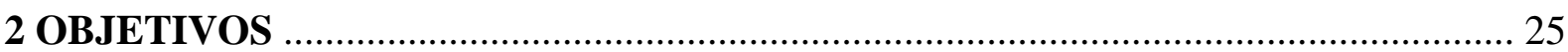

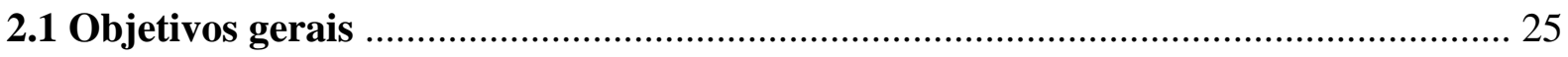

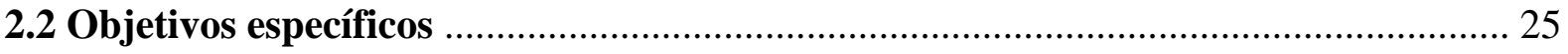

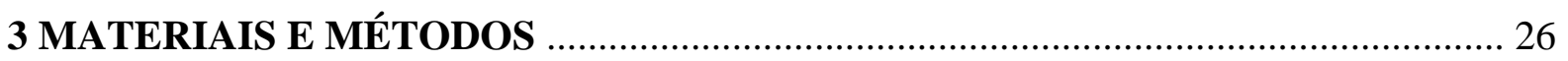

3.1 Avaliação clínica e bioquímica dos pacientes DGC ............................................... 26

3.1.1 Estabelecimento de linhagens celulares dos pacientes com DGC ........................... 26

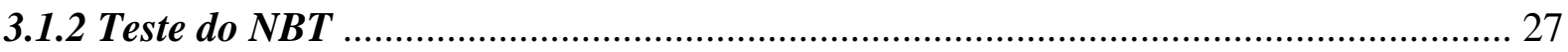

3.1.3 Redução do citocromo c - Liberação de ânion superóxido ……................................ 27

3.1.4 Avaliação da produção de peróxido de hidrogênio $\left(\mathrm{H}_{2} \mathrm{O}_{2}\right)$ por

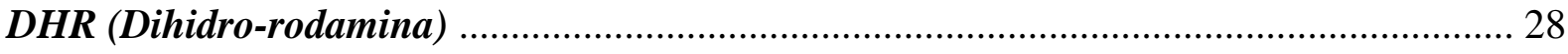

3.2 Caracterização genético-molecular dos pacientes DGC .......................................... 29

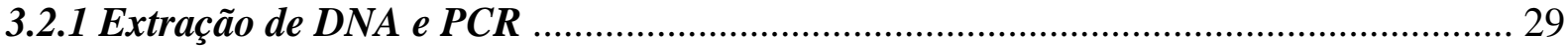

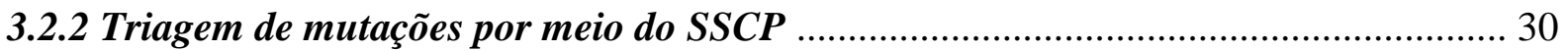

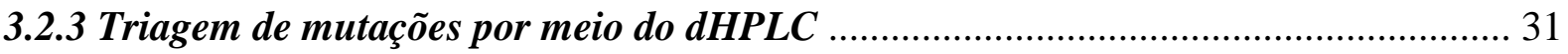

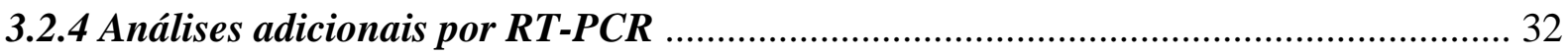

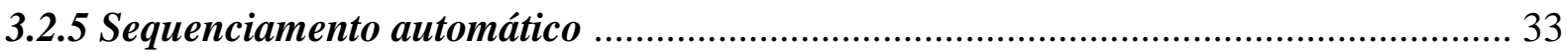

3.3 Correlação genótipo-fenótipo clínico dos pacientes DGC …..................................... 33

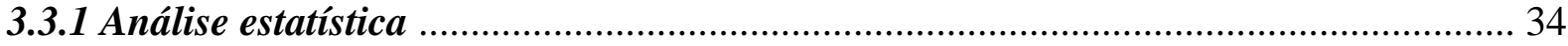

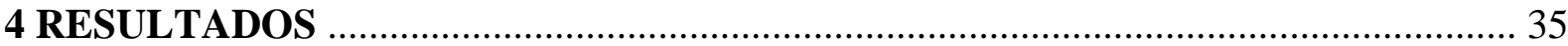

4.1 Estudo genético-molecular do gene CYBB: uso do dHPLC

e novas mutações

4.2 Estudo genético-molecular do gene NCF 1: interferência

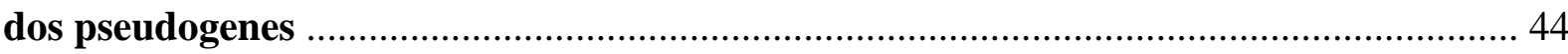

4.3 Correlação genótipo-fenótipo clínico: Índice de Gravidade Clínica ......................... 48

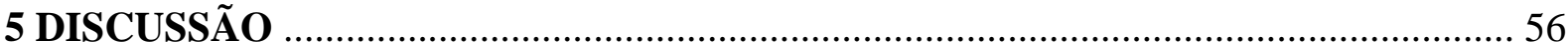


6 CONCLUSÕES

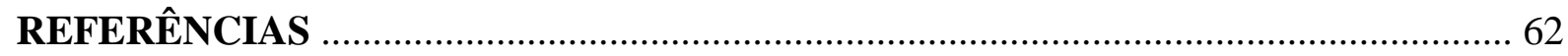

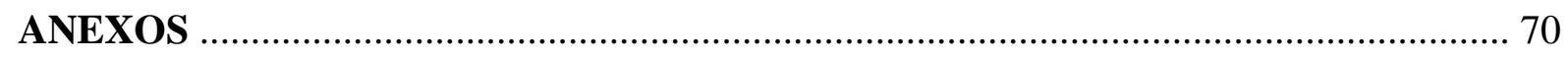

ANEXO A - Artigo no prelo (Olveira-Júnior, EB) .................................................... 70

ANEXO B - Estudo de Pacientes com Suspeita de Imunodeficiência Primária

Laboratório de Alergia e Imunodeficiências em Humanos ......................................... 90

ANEXO C.1 - Termo de Consentimento livre esclarecido (Grupo experimental) ......... 94

ANEXO C.2 - Termo de Consentimento livre esclarecido (menores de 18 anos) .......... 97

ANEXO D - Oligos (dHPLC / SSCP / Sequênciamento) ............................................. 100 


\section{INTRODUÇÃO}

\subsection{Conceito e Classificação da Doença Granulomatosa Crônica (DGC)}

A DGC (OMIM 306400) da infância foi descrita como uma entidade clínica em 1957, como uma enfermidade que acometia crianças do sexo masculino com pneumonia, linfadenite e abscessos localizados em diferentes áreas (Berendes et al., 1957; Landing e Shirkey, 1957; Bridges et al., 1959). Caracteriza-se clinicamente como imunodeficiência grave e rara (incidência estimada de 1: 250.000 nascidos vivos por ano), de manifestação precoce, na qual os quadros infecciosos por bactérias como Staphylococcus aureus e bacilos gram-negativos, e fungos como Aspergillus sp, Candida sp e Nocardia sp, ocorrem predominantemente em locais considerados barreiras naturais do organismo (Segal et al., 1983; Tauber et al., 1983). Desta maneira, o paciente apresenta infecções graves e recidivantes na pele, vias respiratórias, trato gastrointestinais, e respectivos linfonodos que drenam essas áreas. Outros alvos de infecções são: fígado, ossos, sistema nervoso central e pâncreas (Forrest et al., 1988; Segal et al., 2000; Winkelstein et al., 2000; Johnston, 2001; Movahedi et al., 2004; Agudelo-Florez et al., 2006; Oliveira-Júnior et al., 2010 - ANEXO A). Os reativos intermediários do oxigênio tiveram sua relevância clínica reconhecida, ao demonstrar-se que fagócitos de pacientes com DGC apresentam atividade microbicida defeituosa, resultado da baixa produção de superóxido, devido a mutações que afetam componentes do sistema NADPH oxidase (Holmes et al., 1966; Holmes et al., 1967; Babior, 2004; Holland, 2010), ilustrado na Figura 1.

O defeito molecular da DGC reside na ausência, baixa expressão ou mal funcionamento de um dos componentes do sistema NADPH oxidase. Assim, na forma ligada ao $\mathrm{X}$, é afetada a cadeia pesada do citocromo $b_{558}$, o componente gp91-phox, também chamado de NOX2 (56\% dos casos), e nas formas autossômicas recessivas é afetado um dos componentes citosólicos da NADPH oxidase, sendo a p47-phox ou p67-phox (respectivamente $33 \%$ e $5 \%$ dos casos); ou ainda a cadeia leve do citocromo $b_{558}$, o componente p22-phox (6\% dos casos) (Parkos et al., 1988; Clark et al., 1989; Dinauer et al., 1990; Segal et al., 2000; Segal et al., 2000; Stasia e Li, 2008). Uma mutação foi descrita em um paciente com DGC secundária a defeito no componente rac2 (Johnston, 2001), e recentemente foi descrita uma mutação na p40-phox resultando em defeito no "burst" oxidativo (Matute et al., 2009). Com base nestes achados, a classificação atual da DGC baseia-se nos defeitos moleculares específicos (Curnutte, 1988; Curnutte et al., 1994; Rae et 
al., 1998; Segal e Holland, 2000; Segal et al., 2000; Winkelstein et al., 2000; Heyworth et al., 2003; Babior, 2004; Stasia e Li, 2008).

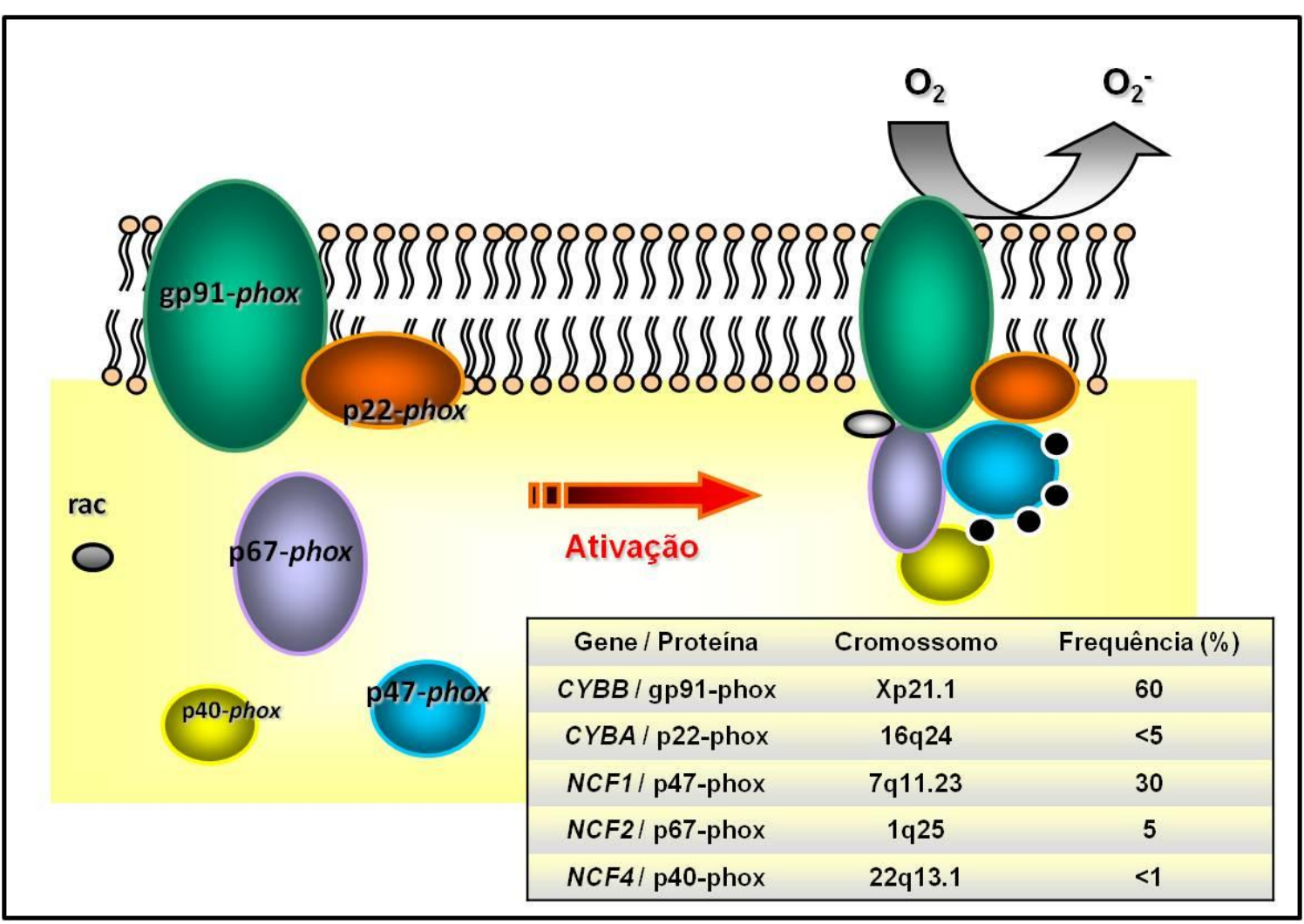

Figura 1. Sistema NADPH oxidase: Representação esquemática do Sistema NADPH oxidase com seus principais componentes: gp91-phox e p22-phox ligados a membrana celular formando o citocromo $\mathrm{b}_{558}$; $\mathrm{p} 67-$ phox, $\mathrm{p} 47-p h o x$, p40-phox e a proteína rac presentes no citoplasma do fagócito. A ativação do Sistema ocorre com a fosforilação da p47-phox seguida do agrupamento de todos os componentes junto ao citocromo $b_{558}$ reduzindo o oxigênio molecular $\left(\mathrm{O}_{2}\right)$ levando a formação do superóxido $\left(\mathrm{O}_{2}{ }^{-}\right)$.

O modo de herança da DGC é definido pela abreviação "A" para autossômico ou "X" para ligado ao sexo; o componente defeituoso da oxidase é representado pelo peso molecular da proteína afetada, “91,” “22,” “47,” “67” ou “40”; e o nível de expressão da proteína daquele componente é indicado pelo sobrescrito " 0 " para ausente, “+” para presente, e "-." para reduzido. $\mathrm{O}$ fenótipo $\mathrm{X} 91^{0}$ é o mais frequente, secundário a defeitos no gene $C Y B B$ no cromossomo $\mathrm{X}$, que codifica a proteína gp91-phox e resulta na ausência de citocromo $b_{558} \mathrm{e}$ atividade NADPH oxidase nula. O fenótipo X91 ${ }^{-}$é menos frequente, e refere-se à forma variante da DGC, laboratorialmente caracterizada por neutrófilos com baixa atividade NADPH oxidase, proporcional ao nível de citocromo $b_{558}$ expresso (Lew et al., 1981; Newburger et al., 1986; Roos et al., 1996; Rae et al., 1998; Holland, 2010). No fenótipo X91+, 
o citocromo $b_{558}$ encontra-se em níveis normais, entretanto sua atividade está diminuída ou ausente. A maioria das formas autossômicas recessivas de DGC não guarda expressão residual do componente afetado (fenótipos $\mathrm{A} 22^{0}, \mathrm{~A} 47^{0}, \mathrm{~A} 67^{0}$ e $\mathrm{A} 40^{\circ}$ ).

Dentre os defeitos genéticos de pacientes com DGC, ocorrem deleções, inserções e substituições. A maior parte destes pacientes tem mutações exclusivas de suas famílias. A diversidade destas mutações e os múltiplos genes afetados constituem uma explicação para a heterogeneidade clínica e genética da DGC (Curnutte, 1993; Roos et al., 1996; Patino et al., 1999; Patino et al., 1999; Agudelo-Florez et al., 2006; Agudelo-Florez et al., 2006; Holland, 2010; Oliveira-Júnior et al., 2010 - ANEXO A). Desta maneira, o estudo dos pacientes com DGC, além de ilustrar a relevância clínica dos reativos intermediários do oxigênio, possibilitou a identificação dos diversos componentes da NADPH oxidase, bem como seus mecanismos de ativação (Dinauer et al., 2000; Babior, 2004; Holland, 2010).

\subsubsection{Mutações na DGC ligada ao X}

O gene $C Y B B$, o qual codifica a grande subunidade glicosilada do citocromo $b_{558}$, denominada gp91-phox, contém 13 exons e ocupa aproximadamente $30 \mathrm{~kb}$ da região Xp21.1 do cromossomo X (Baehner et al., 1986). Diversos defeitos moleculares que levam a DGC ligada ao $\mathrm{X}$ foram identificados na região codante, introns e raramente nas regiões 5' reguladoras do gene $C Y B B$ (Patino et al., 1999; Heyworth et al., 2001; Heyworth et al., 2003; Barese et al., 2004; Jurkowska, et al., 2004; Oh et al., 2004; Barese et al., 2005; AgudeloFlorez et al., 2006; Agudelo-Florez et al., 2006; Lewis et al., 2008; Di Matteo et al., 2009; Oliveira-Júnior et al., 2010 - ANEXO A).

Os tipos de mutações que causam DGC ligada ao sexo incluem grandes deleções multigênicas, deleções e inserções menores, substituições do tipo "missense" e "nonsense", bem como defeitos de "splicing". Mutações nos sítios de "splicing" resultam no fenótipo X91 ${ }^{0}$ devido à deleção de um ou mais exons, que levam a DGC ligada ao X (Roos et al., 1996; Rae et al., 1998; Segal et al., 2000; Winkelstein et al., 2000; Barese et al., 2005; Agudelo-Florez et al., 2006; Agudelo-Florez et al., 2006; Oliveira-Júnior et al., 2010 ANEXO A). Entretanto, numa minoria de casos, tais mutações levam ao fenótipo X91-, devido à manutenção parcial do "splicing" normal (Rae et al., 1998). Vários estudos mostram que as mutações se distribuem com frequência similar entre os exons e as bordas dos genes (Roos et al., 1996; Rae et al., 1998; Winkelstein et al., 2000; Heyworth et al., 2001; Heyworth 
et al., 2003; Agudelo-Florez et al., 2006; Stasia e Li, 2008; Oliveira-Júnior et al., 2010 ANEXO A). Famílias não relacionadas nestes estudos serviram como base para os cálculos das frequências relativas de diferentes tipos de mutações. A heterogeneidade das mutações e a falta de um genótipo predominante mostram que a incidência mundial de DGC é consequência de muitos eventos mutacionais.

Rae et al. (1998) identificaram as mutações no gene $C Y B B$ que levaram ao fenótipo de DGC ligada ao sexo em 131 famílias consecutivas e independentes. O rastreamento por meio de SSCP ("single strand conformation polymorphism analysis") identificou mutações em 124 famílias. O sequenciamento completo dos exons e regiões próximas às bordas dos introns revelou outras 7 mutações. Neste estudo foi possível identificar 103 diferentes mutações específicas, sendo que nenhuma mutação isolada repetiu-se em mais de 7 famílias independentes. Os tipos de mutações foram grandes e pequenas deleções (11\%), "frameshifts" (24\%), mutações "nonsense" (23\%), mutações "missense" (23\%), mutações na região do "splicing" (17\%) e mutações nas regiões reguladoras (2\%). A distribuição das mutações ao longo do gene $C Y B B$ mostrou-se bastante heterogênea, não se identificando nenhum locus preferencial para sua ocorrência. Hoje, segundo base de dados e atualizações de mutações descritas no gene $C Y B B^{l}$, existem mais de 580 casos descritos, sendo 256 mutações diferentes dos quais $30 \%$ são do tipo "missense", 30\% "nonsense", $21 \%$ "frameshift" e $12 \%$ erros de "splicing".

Na América Latina, Patino et al. (1999) estudaram 7 famílias não relacionadas na Colômbia e no Brasil. Neste estudo do qual participamos, 6 mães eram portadoras de um alelo $C Y B B$ mutante, sendo que um dos casos deveu-se a mutação "de novo". Identificamos uma substituição A por $\mathrm{G}$ no penúltimo nucleotídeo do intron 12, quatro novas mutações "nonsense" (R91X, W106X, R157X, R290X), além de outras duas mutações "missense" (E225V, C244Y). Barese e colaboradores (Barese et al., 2005) estudaram 18 pacientes com DGC ligada ao X, tendo encontrado diversos tipos de mutações.

Nosso grupo estudou 14 pacientes, sendo 7 com a forma de DGC ligada ao X e 7 com DGC autossômica por defeito no componente p47-phox (Agudelo-Florez et al., 2006). Nesse estudo, os pacientes mostraram grande heterogeneidade clínica e genética, sendo os casos ligados ao X mais graves, além de relatar duas novas mutações e detectar três pacientes com mutações em sítios de "splicing”.

\footnotetext{
${ }^{1}$ (http://bioinf.uta.fi/CYBBbase)
} 


\subsubsection{Mutações na DGC autossômica}

O número de mutações identificadas em pacientes com DGC autossômica é menor que na DGC ligada ao X, devido à menor incidência de DGC autossômica. Alguns trabalhos indicam que as bases genético-moleculares das deficiências de p22-phox e p67-phox são tão heterogêneas quanto às observadas nas deficiências de gp91-phox, ligadas ao X, enquanto os casos de deficiência de p47-phox são mais homogêneos (Roos et al., 1996; Rae et al., 1998; Prando-Andrade et al., 2004; Stasia e Li, 2008).

Em 9 famílias com mutações na p22-phox, 10 diferentes mutações foram descobertas em 18 alelos, incluindo deleções e inserções, substituições próximas aos sítios de "splicing", e mutações missense (MIM 233690) (De Boer et al., 1992; Roos et al., 1996). Em 7 famílias os pacientes eram homozigotos para as mutações encontradas, enquanto em 2 famílias os pacientes eram heterozigotos compostos. Somente em 2 famílias não relacionadas, foram encontrados pacientes com a mesma mutação. Somente 4 polimorfismos da p22-phox foram identificados. Portanto, pequenas alterações na composição desta proteína parecem resultar em instabilidade intrínseca ou instabilidade secundária a baixa interação com a gp91-phox, ao compor o citocromo $b_{558}$ (Dinauer et al., 2000).

As mutações que levam a DGC autossômica por defeitos na p47-phox têm sido um enigma para os cientistas. Em 35 pacientes não relacionados com deficiência da p47-phox (MIM 233700), foi identificada uma deleção de 2 nucleotídeos na repetição GTGT, correspondente às 4 primeiras bases do segundo exon do gene NCF1 (Casimir et al., 1991; Volpp e Lin, 1993; Iwata et al., 1994; Vazquez et al., 2001). Em 31 destes casos a deleção GT foi homozigota e em um dos outros 4 pacientes, outra mutação de um nucleotídeo foi identificada além da deleção GT. Surpreendentemente no entanto, a amplificação por PCR do cDNA ou gDNA de indivíduos normais, também revelou a presença simultânea da sequência GTGT e do produto com a deleção GT. Isto sugeriu a existência de um pseudogene com a deleção GT, além do gene $N C F 1$, em parte do genoma de indivíduos sadios, e que a DGC autossômica por defeito da p47-phox se deve à recombinação entre o gene NCF1 e o pseudogene relacionado (Gorlach et al., 1997). Hoje sabemos que existem dois pseudogenes diferentes $N C F 1 \mathrm{~B}$ e $N C F 1 \mathrm{C}$, sendo o último o de sequência mais semelhante ao gene funcional (Figura 2). Num estudo com pacientes DGC, foi confirmado a mutação mais frequente na p47-phox em 7 casos. Os pacientes deste subgrupo apresentaram evolução clínica mais benigna quando comparados aos portadores da forma ligada ao X (PrandoAndrade, 2003; Agudelo-Florez et al., 2006). Recentemente, foram também descritos casos de 
DGC secundários a defeitos na p47-phox, por mutações não relacionadas ao pseudogene (Noack et al., 2001). Alguns trabalhos publicados mostraram que existe um novo tipo de pseudogene NCF1 que apresenta a mesma sequência GTGT do gene NCF1 funcional, classificado como pseudogene do Tipo II (Heyworth et al., 2002). Este novo tipo de pseudogene foi descoberto depois que o grupo de pesquisadores avaliou a razão entre a deleção GT versus GTGT entre indivíduos normais, portadores sãos e pacientes DGC A47º. Por meio do método de "scan-gene", (Dekker et al., 2001) revelaram um padrão diferente do normal entre a razão pseudogene (delGT) - 2:1 - gene (GTGT) que indica indivíduos normais, revelando também razões 1:1 e 1:2 dentro deste grupo. Além disso, em outros indivíduos com padrão 5:1 que indicaria os portadores neste método, encontraram também razão do tipo 2:1, semelhante aos indivíduos normais, mostrando complexidade em se avaliar indivíduos portadores da deleção GT no exon 2 do gene NCF1 (Figura 3).

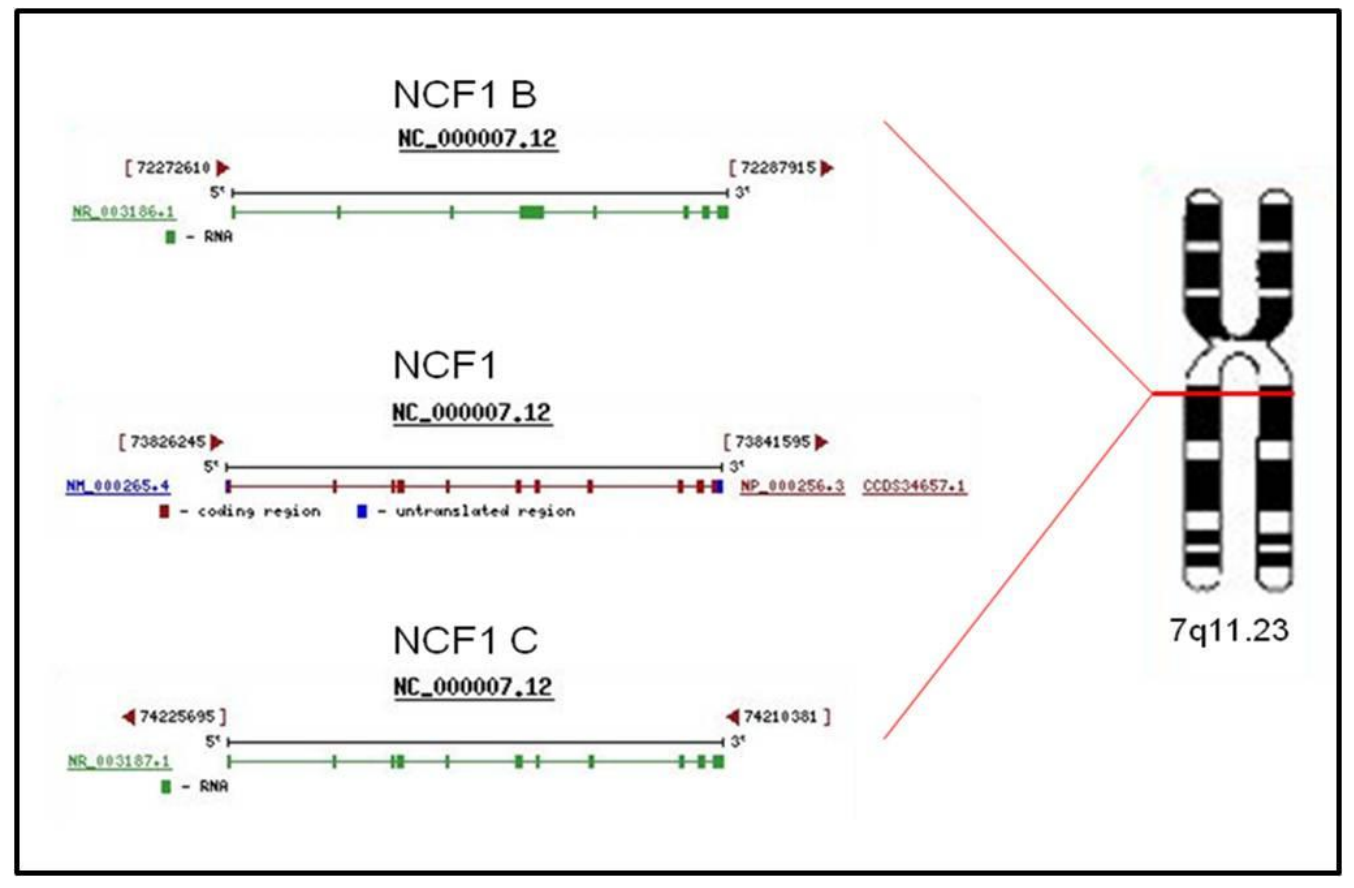

Figura 2. Posição do gene $N C F 1$ e pseudogenes localizados no cromossomo 7 do genoma humano. O pseudogene $N C F 1 \mathrm{C}$ é uma cópia quase exata do gene funcional $N C F 1$ (ao meio), o que dificulta a identificação de mutações por meio de ensaios simples e comuns de biologia molecular. 


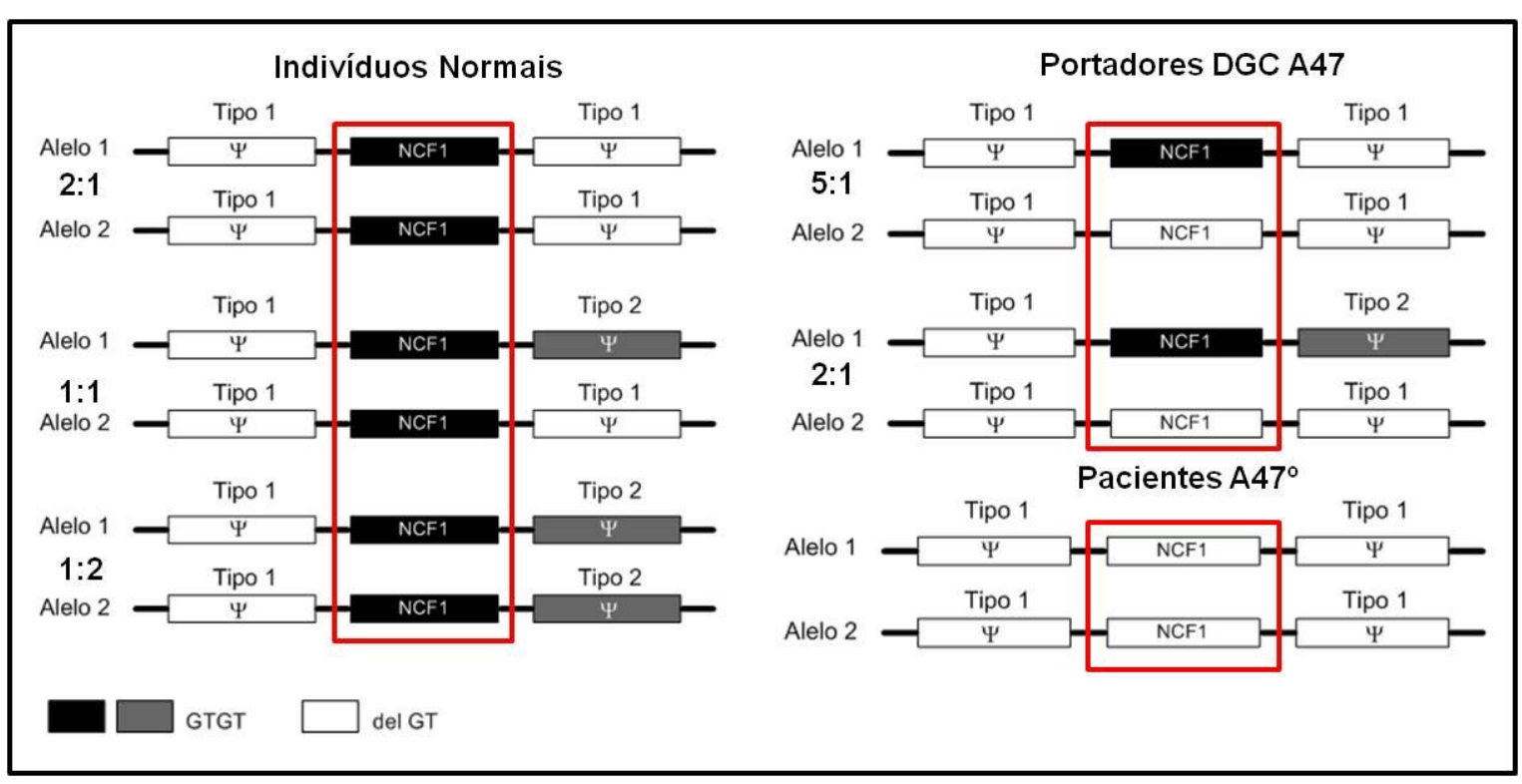

Figura 3. Versão modificada da predição entre genótipos do NCF1 / $\psi N C F 1$ mostrando combinações entre tipo 1 e o tipo 2 do pseudogene em indivíduos normais, portadores sãos e pacientes DGC. Nas barras fechadas estão representadas o gene NCF1 normal (preto) e o pseudogene tipo 2 (cinza) que possuem a sequência GTGT no exon 2. Nas barras abertas estão representadas o gene $N C F 1$ e o pseudogene tipo 1 que possuem a deleção GT no exon 2, que na forma homozigota leva a DGC autossômica A47 ${ }^{\circ}$. A seleção representa o gene $N C F 1$ funcional

FONTE: Adaptado de Heyworth et al. (2002).

\subsubsection{Caracterização Clínica da DGC}

No geral os casos de DGC autossômica p22-phox e p67-phox são tão graves quanto os casos de DGC ligada ao X gp91-phox. Por outro lado, diversas comparações clínicas entre DGC ligada ao X e DGC autossômica secundária a defeitos na p47-phox sugerem que esta última tem evolução mais benigna (Weening et al., 1985; Margolis et al., 1990; PrandoAndrade et al., 2004; Agudelo-Florez et al., 2006), o que pode ser atribuída à atividade NADPH oxidase residual (Cross et al., 1994; Bemiller et al., 1995; Cross et al., 1995; Winkelstein et al., 2000; Holland, 2010).

O prognóstico de pacientes com DGC melhorou significativamente desde que a doença foi descoberta na década de cinquenta, quando era denominada "granulomatose fatal da infância”. Os pilares do tratamento da DGC são: 1) prevenção das infecções por meio de imunizações e remoção das fontes de patógenos, 2) uso profilático de trimetoprinsulfametoxazol ou outro antimicrobiano com penetração intracelular, 3) uso profilático de IFN- $\gamma$, 4) uso precoce e agressivo de antibióticos parenterais, 5) drenagem cirúrgica ou 
ressecção de focos infecciosos persistentes. Dos cinco itens, o mais importante é a intervenção precoce nas infecções, antes que elas sobrepujem o comprometido sistema imunológico do paciente com DGC (Segal et al., 2000; Heyworth et al., 2003; Holland, 2010).

O IFN- $\gamma$ humano recombinante está indicado na dose de $50 \mu \mathrm{g} / \mathrm{m}^{2}$ de superfície corporal, por via subcutânea, três vezes por semana. Ele reduz o risco relativo de infecções graves em 70\%. Demonstrou-se que o IFN- $\gamma$ incrementa a fidelidade do "splicing" e a estabilidade dos transcritos do gene $C Y B B$, corrigindo parcialmente a expressão do componente gp91-phox, atenuando o fenótipo de DGC ligada ao X em uma família especialmente responsível ao IFN- $\gamma$ (Rae et al., 1998; Condino-Neto e Newburger, 2000; Errante et al., 2008). O IFN- $\gamma$ continua sendo uma terapia segura para a prevenção de infecções graves em pacientes com DGC (Marciano et al., 2004; Errante et al., 2008).

Transplante de medula óssea é uma técnica atraente porque pode levar a cura estável da DGC. Várias abordagens estão em uso, utilizando-se mieloblação total, que quando bemsucedido, há completo "engraftment" (Seger et al., 2002), e sem mieloblação, levando a quimerismo hematopoiético estável (Kamani et al., 1988). Baixa intensidade de transplantes "não-ablativos" ou "mini”" transplantes em irmãos HLA-idênticos de pacientes DGC tiveram um misto de sucessos (Horwitz et al., 2001). O sucesso dos transplantes de medula óssea é maior em crianças que em adultos. Relatórios recentes sobre independentes transplantes de medula óssea em Newcastle (Soncini et al., 2009) mostram uma taxa de sucesso global a longo prazo de $90 \%$. Estes investigadores britânicos também mostraram uma reconstituição impressionante pré-transplante, sugerindo que muito da demora visto na DGC e retardo de crescimento é de fato devido a vários aspectos da disfunção hematopoiética, variando de colite a infecção crônica. Apesar do transplante de medula óssea ser uma opção atraente para a cura definitiva da DGC, devemos ter em mente que a sobrevivência sem transplante de medula óssea é aproximadamente comparável (Holland, 2010). No entanto, nem todos os pacientes têm correspondência coligadas ou doadores, excluindo efetivamente um número substancial de pacientes desta opção (Seger, 2008). DGC ligada ao X é um alvo atraente para terapia genética por vários motivos: é um defeito num único gene, que pode ser reconstituído in vitro e a correção não precisa estar completa para oferecer proteção total (Kang e Malech, 2009). Este último ponto é comprovado por uma vida normal de muitas portadoras da DGC ligada ao $\mathrm{X}$, bem como pelas quimeras estáveis geradas em alguns protocolos de transplante.

Com base num estudo com 368 pacientes DGC nos EUA, as complicações mais comuns em DGC são pneumonia (79\%), abscesso subcutâneo (42\%), abscesso hepático 
(27\%), osteomielites (25\%), e sepse (18\%) (Winkelstein et al., 2000). Outro estudo envolvendo 60 pacientes com DGC na Itália demonstrou que pneumonia (47\%) e linfadenite (45\%) são as complicações mais comuns, seguidas por dermatite (26\%), abscesso subcutâneo (20\%), abscesso hepático (16\%) e osteomielite (16\%) (Martire et al., 2008). Com uma análise clínica profunda destes pacientes podemos identificar relações com o estado genético e futuramente direcionar estes pacientes para um melhor tratamento, e talvez exclusivos para cada grupo ou indivíduos de acordo com seu genoma. 


\section{OBJETIVOS}

\subsection{Objetivos gerais}

Identificar as alterações genético-moleculares de pacientes com DGC e avaliar a correlação genótipo-fenótipo de pacientes com Doença Granulomatosa Crônica.

\subsection{Objetivos específicos}

- Caracterização clínica e bioquímica dos pacientes com DGC.

- Localização da mutação no gene defeituoso dos pacientes com DGC, mediante análise por cromatografia de alta performance em condições denaturantes (dHPLC) e ou polimorfismo de conformação de fita simples (SSCP) e estabelecer melhor triagem.

- Identificação da mutação específica no gene alterado, por meio de sequenciamento do DNA amplificado.

- Correlação das alterações genético-moleculares com o fenótipo clínico dos pacientes estudados. 


\section{MATERIAIS E MÉTODOS}

\subsection{Avaliação clínica e bioquímica dos pacientes DGC}

Foram avaliados 26 pacientes (19 brasileiros, 4 mexicanos, 2 colombianos e 1 chileno)com quadro clínico compatível com DGC, transcritos para uma ficha de dados clínicos padrão (ANEXO B). Todos os procedimentos foram realizados após leitura e concordância com os termos de Consentimento Livre Esclarecido (ANEXO C) de acordo com o parecer 881/CEP. Considerando que somos um laboratório de referência neste assunto, investigamos pacientes brasileiros e latino-americanos com suspeita de DGC, conforme protocolo de cooperação científica estabelecido pelo Grupo Brasileiro de Imunodeficiências ${ }^{2}$ e Grupo Latino-Americano de Imunodeficiências Primarias ${ }^{3}$. O diagnóstico bioquímico de DGC foi confirmado conforme os critérios previamente estabelecidos, ou seja, a demonstração de uma falha bioquímica do sistema NADPH oxidase por meio do teste do NBT, dosagem de superóxido liberado por granulócitos e monócitos do sangue periférico e dosagem indireta por meio do DHR (Condino-Neto et al., 1993; Agudelo-Florez et al., 2006; Oliveira-Júnior et al., 2010 - ANEXO A).

\subsubsection{Estabelecimento de linhagens celulares dos pacientes com DGC}

Estabelecemos linhagens de linfócitos B dos pacientes, transformadas com vírus EpsteinBarr (Condino-Neto e Newburger, 1998, 2000). Com isto, obtemos uma fonte inesgotável de ácidos nucléicos dos pacientes para os estudos moleculares. Os linfócitos B transformados expressam o citocromo $b_{558}$, liberam superóxido e reproduzem fielmente os defeitos bioquímicos e moleculares dos pacientes com DGC (Volkman et al., 1984; Condino-Neto e Newburger, 1998, 2000). Evitamos com isto, repetidas coletas de sangue em pacientes de baixa idade. Para iniciar as culturas de linfócitos B, amostras de sangue periférico de indivíduos sadios ou de pacientes com DGC, foram fracionadas por meio de centrifugação em

\footnotetext{
${ }^{2}$ (www.imunopediatria.org.br)

${ }^{3}$ (Imunodeficiências LAGID, www.boletin-lagid.lsumc.edu/default.htm)
} 
Ficoll-Hypaque (Boyum, 1968). A fração de células mononucleares foi cultivada com sobrenadantes da linhagem B95-8, produtora de EBV (Nilsson et al., 1971; Volkman et al., 1984; Condino-Neto e Newburger, 1998, 2000). Após a transformação com EBV, os linfócitos B foram cultivados em meio RPMI 1640, suplementado com soro bovino fetal (10\%) inativado pelo calor $\left(60{ }^{\circ} \mathrm{C}-30\right.$ minutos $), 2 \mathrm{mM}$ L-glutamina, $100 \mathrm{U} / \mathrm{ml}$ penicilina, e $100 \mu \mathrm{g} / \mathrm{ml}$ de estreptomicina, a $37{ }^{\circ} \mathrm{C}$ em atmosfera úmida saturada com $5 \%$ de $\mathrm{CO}_{2}$. A viabilidade celular foi monitorada a cada três dias, e a cultura mantida indefinidamente durante os estudos. Alíquotas das linhagens celulares foram congeladas e mantidas em nitrogênio líquido, caso estudos adicionais fossem necessários.

\subsubsection{Teste do NBT}

O teste baseia-se na liberação de superóxido pelos leucócitos e redução do "nitro blue tetrazolium" (NBT), originando depósitos de formazan no interior das células (Ochs e Igo, 1973). Realizamos o ensaio do NBT conforme ensaio publicado anteriormente (Patino et al., 1999). Mais de $95 \%$ de 200 neutrófilos normais estimulados com PMA devem ser capazes de reduzir o NBT. Nos pacientes com DGC, a reação foi negativa ou abaixo de 5\%. O teste foi realizado com $5 \mathrm{ml}$ de sangue venoso colocados, imediatamente após a coleta, sobre lâmina de vidro previamente incubada a $37^{\circ} \mathrm{C}$ por 30 minutos. Para cada paciente foi montada uma lâmina para análise das células em repouso, sobre a qual foi adicionado o corante NBT (Sigma N-6876) e PBS a uma concentração de $1 \mathrm{mg} / \mathrm{ml}$ acrescido de $1 \mu \mathrm{l} / \mathrm{ml}$ de dimetilsulfóxido (DMSO), e outra lâmina em que as células foram estimuladas com acetato de forbol-miristato (PMA, $1 \mu \mathrm{g} / \mathrm{ml}$, concentração final). Todos os ensaios foram realizados simultaneamente com um controle sadio (Ochs e Igo, 1973; Patino et al., 1999).

\subsubsection{Redução do citocromo c - Liberação de ânion superóxido}

Granulócitos e leucócitos mononucleares foram fracionados do sangue periférico por meio de centrifugação em gradiente de densidades (Sigma Histopaque 1.077 g/ml e 1.119 g/ml, St. Louis, E.U.A.) (Boyum, 1968). A liberação de superóxido foi determinada em espectrofotômetro por meio da redução do citocromo $c$ especificamente inibida pela superóxido dismutase (SOD) (Mccord e Fridovich, 1969a,b) em ensaio modificado conforme 
publicado anteriormente (Condino-Neto et al., 1993; Condino-Neto et al., 1996; Dias-DaMotta et al., 1996). Resumidamente, as suspensões de neutrófilos e de células mononucleares numa concentração final de $2 \times 10^{6}$ células/ml em solução de Hank's $1 \mathrm{X}$ (pH 7,4, CaCl2 $1 \mathrm{mM}$ ), obtidas como descrito no item anterior, foram incubadas com forbol-miristato-acetato (PMA, $30 \mathrm{nM})$, na presença de citocromo C $(80 \mathrm{uM})$, durante 60 minutos a $37^{\circ} \mathrm{C}$. A liberação espontânea de ânion superóxido foi avaliada em solução sem PMA. Metade dos tubos continha superóxido dismutase (SOD, $90 \mathrm{U} / \mathrm{ml})$ no início do experimento, como controle da redução inespecífica do citocromo C. A reação foi interrompida, colocando-se todos os tubos em banho de gelo e adicionando-se SOD $(90 \mathrm{U} / \mathrm{ml})$ aos que não a continham. Após centrifugar os tubos a $2.200 \mathrm{xg}$ durante 15 minutos a $4{ }^{\circ} \mathrm{C}$, foi medida a absorbância de seus sobrenadantes a $550 \mathrm{~nm}$. A produção de ânion superóxido foi calculada usando-se um coeficiente de extinção de $21.100 \mathrm{M}^{-1} \mathrm{~cm}^{-1} \mathrm{e}$ os resultados expressos em nmol/ $10^{6}$ células/hora. Todos os experimentos foram realizados em duplicata.

\subsubsection{Avaliação da produção de peróxido de hidrogênio $\left(\mathrm{H}_{2} \mathrm{O}_{2}\right)$ por DHR (Dihidro- rodamina)}

Através da conversão da molécula não fluorescente (DHR-123) em molécula fluorescente (rodamina-123) analisamos a produção de $\mathrm{H}_{2} \mathrm{O}_{2}$ no interior dos monócitos e neutrófilos. A DHR-123 penetra nas células e na presença de $\mathrm{H}_{2} \mathrm{O}_{2}$ é oxidada convertendo-se em rhodamine-123, que é excitável por um comprimento de onda de $488 \mathrm{~nm}$ e emite uma florescência de $515 \mathrm{~nm}$ (Rothe et al., 1988) analisada por citometria de fluxo (FACs Canto II, software FACs Diva). Para realizar esta análise, em tubos de FACs contendo $100 \mu \mathrm{l}$ de sangue, foram adicionados $3 \mathrm{ml}$ de solução de lise de hemácias. Esta solução foi colocada em banho maria $37{ }^{\circ} \mathrm{C}$ durante 10 minutos. Em seguida as amostras foram centrifugadas a $1.250 x g$ durante 6 minutos. Após a centrifugação, o sobrenadante foi descartado, e ao tubo contendo o pellet foi adicionado dihidro-rodamina $(3 \mu \mathrm{g} / \mathrm{ml})$ e $2 \mu l$ de catalase $(140 \mathrm{U} / \mathrm{ml})$. Em seguida os tubos foram incubados à $37^{\circ} \mathrm{C}$ durante 5 minutos. Após este período um dos tubos foi incubado com $2 \mu \mathrm{l}$ de PMA $(200 \mathrm{ng} / \mathrm{ml})$ para ativação celular durante 1 hora à $37^{\circ} \mathrm{C}$ em estufa de $\mathrm{CO}_{2}$. Após a incubação, as amostras foram analisadas por citometria de fluxo realizando-se gates nas populações de neutrófilos e monócitos utilizando como parâmetro o tamanho (forward scatter, FSC) e granulosidade celular (side scatter, SSC). 


\subsection{Caracterização genético-molecular dos pacientes DGC}

\subsubsection{Extração de DNA e PCR}

As amostras de DNA foram extraídas de sangue periférico, usando um kit de extração Puregene DNA (Gentra Systems, Inc., Minneapolis, MN, EUA) de acordo com as instruções do fabricante. O PCR para os fragmentos de DNA fornecidas foram realizadas em um volume total de $50 \mu \mathrm{L}$ contendo $50 \mathrm{ng}$ de genoma de DNA, $0,3 \mu \mathrm{M}$ de cada oligo, 250 de $\mu \mathrm{M}$ dNTPs, 0,5 unidades de enzima recombinante Taq DNA polimerase e 2,5 $\mu \mathrm{L}$ do buffer de $\mathrm{x} 10$ PCR (10 mM tris- $\mathrm{HCl}, \mathrm{pH}=8,3 ; 50 \mathrm{mM} \mathrm{KCl}$ ), em $2 \mathrm{mM} \mathrm{Cl}_{2}$, fornecidas pelo fabricante (Invitrogen®). A amplificação foi executada num sistema de "multiblock thermocycler" (Applied Biosystems - GeneAmp ® PCR sistema 9100). A amplificação do PCR foi realizada com uma etapa de desnaturação inicial a $95{ }^{\circ} \mathrm{C}$ durante 3 minutos, seguido por 30 ciclos de desnaturação em $95{ }^{\circ} \mathrm{C}$ durante 30 segundos, anelamento entre $56{ }^{\circ} \mathrm{C}-60{ }^{\circ} \mathrm{C}$ (conforme o oligo) durante 45 segundos e extensão em $72{ }^{\circ} \mathrm{C}$ durante 1 min e, em seguida, um passo de extensão final em $72{ }^{\circ} \mathrm{C}$ durante $10 \mathrm{~min}$. Utilizamos 13 pares de oligos (Tabela 1), um para cada exon do gene $C Y B B$ amplificando também as bordas intrônicas (ANEXO D). Nas análises moleculares no gene $N C F 1$, para amplificação do DNA genômico e aplicação no sequanciamento direto e ou no SSCP, utilizamos os seguintes oligos: exon 2 - Ncf12F 5'-GTG CAC ACA GCA AAG CCT CT-3' / Ncf12R (p47phoxR) 5'-CTA AGG TCC TTC CCA AAG GGT-3' (211pb $65^{\circ} \mathrm{C}-30$ ciclos); exon 4 - Ncfl4F 5'-ACC TGC CCT CCC AGC C3' / Ncf14R 5'-GCA AAA CAC AGA AAG TCC CA-3' (267pb $60^{\circ} \mathrm{C}-30$ ciclos). 
Tabela 1 - Oligos utilizados nos métodos SSCP e dHPLC

\begin{tabular}{|c|c|c|c|c|}
\hline Exons & $\begin{array}{c}\text { Sequencia dos Oligos } \\
\text { Foward 5'-3' }\end{array}$ & $\begin{array}{c}\text { Sequencia dos Oligos } \\
\text { Reverse } 5^{\prime}-3^{\prime}\end{array}$ & $\begin{array}{c}\mathbf{T}^{\circ} \mathbf{C} \\
\text { anelamento }\end{array}$ & $\begin{array}{c}\text { Produto } \\
\text { (bp) }\end{array}$ \\
\hline 1 & gcaaggctatgaatgctgttc & gctttggtctattttagttcc & 56 & 545 \\
\hline 2 & tgttgaggaaagagctggct & taagtgactgttgcccagga & 58 & 420 \\
\hline 3 & gggcaaaaggtcaatttcagatg & tagtttgtcttagggagctcc & 56 & 466 \\
\hline 4 & tactggctgtttgacctgag & gaagtggcagaaagtgtggt & 60 & 446 \\
\hline 5 & acaactagagaggatcttaccc & tcagtgagtgaaaccctcct & 57 & 426 \\
\hline 6 & tgtctgtgagggatgattagg & tagcaattacatgggtgcatg & 58 & 566 \\
\hline 7 & acagaagtagaaattctccet & ttcttgaaccaaaacagcac & 56 & 675 \\
\hline 8 & cttgtcagtacagttccccat & gatgtccagaaagaacttggc & 58 & 553 \\
\hline 9 & gtatcccttaatcagcccatc & cggtgaccacagaaatagct & 58 & 602 \\
\hline 10 & aacccaacgttggcactaag & cccttcactaataggcctac & 56 & 548 \\
\hline 11 & gtgaaatgtccagagccttc & tggcgatactaaatgagagtg & 56 & 449 \\
\hline 12 & cgaagtctccetttctagac & ggaatcttctgttgggcatg & 56 & 449 \\
\hline 13 & gctcacacaaacaggctgaa & ccatagagctccacataaatg & 58 & 498 \\
\hline
\end{tabular}

\subsubsection{Triagem de mutações por meio do SSCP}

Para identificar a mutação responsável pelo fenótipo de DGC, nós investigamos a mutação subjacente por meio de SSCP (single strand conformation polymorphism), com desnaturação das amostras a $98{ }^{\circ} \mathrm{C}$ durante 8 minutos, seguida de resfriamento rápido a $4{ }^{\circ} \mathrm{C}$ até o momento de aplicá-las no gel de poliacrilamida 10\%. Após análise dos padrões de corrida eletroforética de cada amostra, enviamos para sequenciamento aquelas cujo padrão foi diferente do apresentado pelos controles sadios, indicando possível região afetada do gene em 
estudo, de acordo com procedimentos previamente publicados (Patino et al., 1999; AgudeloFlorez et al., 2006). Desenhamos primers apropriados para amplificação de todos os 13 exons do gene $C Y B B$ (gp91-phox). O ensaio de SSCP é baseado em mudanças na mobilidade eletroforética de produtos de PCR desnaturados indicando possíveis mudanças no DNA. Os géis de poliacrilamida foram corados com SYBR gold ® (Invitrogen) e a mobilidade eletroforética dos produtos de PCR dos pacientes DGC e controles saudáveis foi comparada.

\subsubsection{Triagem de mutações por meio do dHPLC}

Os produtos da amplificação por PCR (pacientes e controles sadios) foram aquecidos a $95{ }^{\circ} \mathrm{C}$ durante alguns minutos para permitir a desnaturação da dupla fita de DNA, seguidos de uma redução lenta de temperatura por 40 minutos (temperatura ambiente), permitindo que as fitas se renaturem lentamente, com suas ligações permanecendo levemente relaxadas. Durante a formação da dupla fita de DNA, as fitas podem juntar-se formando uma dupla fita sem alteração, ou ainda, formarem uma dupla fita sendo uma delas "normal" e outras com alteração, denominadas homoduplex e heteroduplex, respectivamente. Em razão do relaxamento das ligações entre as fitas pela baixa temperatura, as heteroduplexes permanecem mais fracamente ligadas do que as homoduplexes. Após a formação das "duplexes", os fragmentos de DNA foram passados por uma coluna de cromatografia líquida composta por partículas de poliestireno que foram carregadas positivamente pela passagem do tampão TEAA (acetato de trietilamônio). A carga negativa do DNA, em razão dos seus grupos fosfato permite que os fragmentos fiquem aderidos na matriz da coluna através dos grupamentos amônia do tampão TEAA. A eluição das moléculas de DNA foi feita pela passagem de um solvente orgânico, a acetronila ( $\mathrm{ACN}$ ), que na medida em que aumenta sua concentração, diminui a atração entre os fragmentos de DNA e o TEAA. Pela menor força de ligação entre as heteroduplexes, essas são eluídas primeiramente. Através de um detector ultravioleta a absorbância foi medida e os resultados processados em computador, que fornece gráficos com picos e permitem a análise de fragmentos com possíveis mutações (Xiao e Oefner, 2001; Xiao et al., 2001). Padronizamos os 13 exons do gene $C Y B B$, utilizando o equipamento de dHPLC situado no departamento de genética na Faculdade de Ciências Médicas, Unicamp (WAVE 4000 ®, Transgenomic). 


\subsubsection{Análises adicionais por RT-PCR}

Extraímos RNA total utilizando TRIZOL® (Invitrogem) segundo instruções do fabricante. As amostras foram conservadas a $-80{ }^{\circ} \mathrm{C}$ até sua utilização. $\mathrm{O}$ cDNA foi obtido utilizando-se o kit SuperScript III® RT (Invitrogem), seguindo instruções do fabricante. Para a reação, usamos $2 \mu \mathrm{g}$ de RNA total e hexâmeros randômicos (Amersham). O cDNA foi armazenado a $-20{ }^{\circ} \mathrm{C}$ até seu uso (Condino-Neto e Newburger, 2000). Para o ensaio de PCR foram utilizados 3 pares de oligos (Exons 1-5 Fwd.: 5'- T GAG GGG CTC TCC ATT TTT GTC A-3' / Rev.: 5'- AG TTC AGA GAG TGC TAC TGA ATA -3'; Exons 3-9 Fwd.: 5'-GCC TGC CTG AAT TTC AAC-3' / Rev.: 5'-TCA TCT GTA GCT CGA TG-3' ; Exons 7-13 Fwd.: 5'-GGA ATG CCC AAT CCC TCA G-3' / Rev.: 5'-GGG CCA GAC TCA GAG TTG G-3' ), desenhados para amplificar todo o transcrito do gene $C Y B B$ em três regiões estratégicas, e avaliar possíveis mutações que envolvam erros de "splicing” (Agudelo-Florez et al., 2004) (Figura 4).

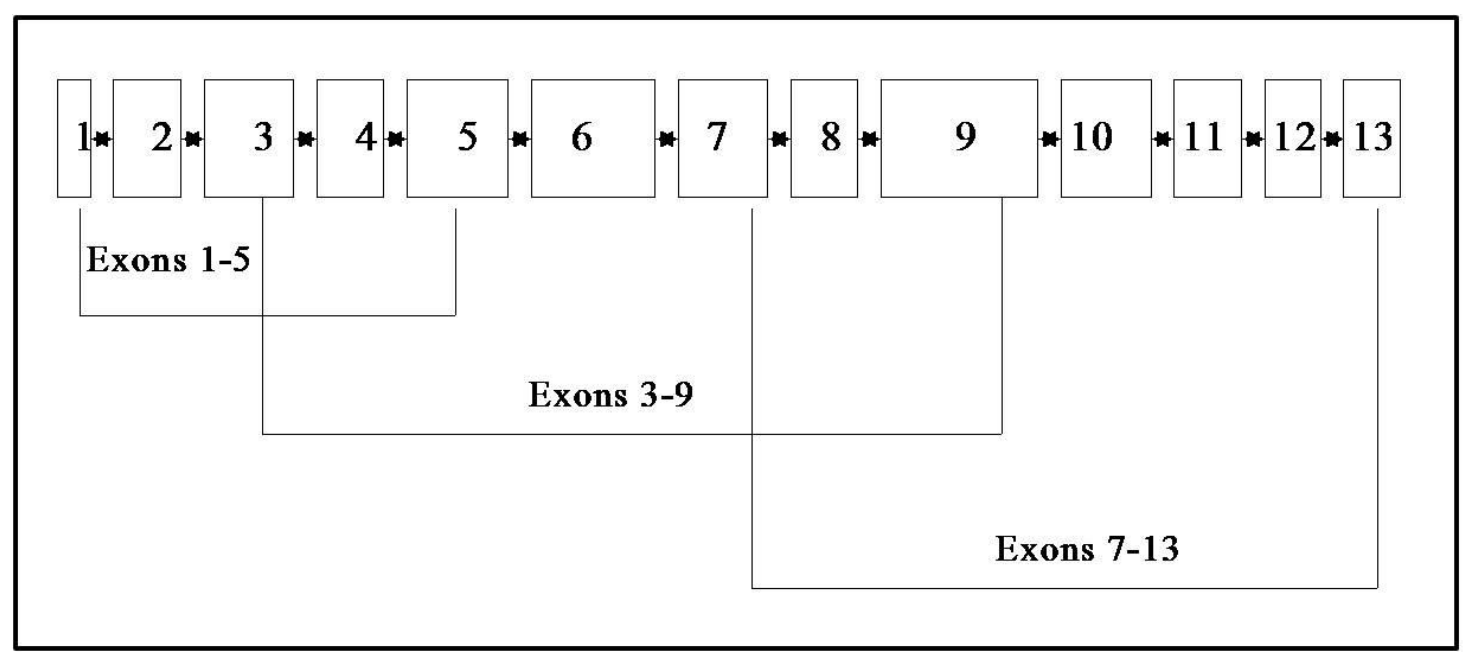

Figura 4. Esquema representativo dos oligos que abrangem todo o transcrito do gene $C Y B B$. Produtos de PCR das regiões: exons de $1-5=411 \mathrm{pb}$, exons de 3-9 $=766 \mathrm{pb}$ e exons de 7-13 $=909 \mathrm{pb}$. 


\subsubsection{Sequenciamento automático}

Após triagens por SSCP, dHPLC (CYBB) e PCR específico (NCF1), as amostras de gDNA selecionadas foram purificadas com o kit GFX ${ }^{\mathrm{TM}}$ PCR DNA e Gel Band Purification Kit e encaminhadas para sequenciamento no Centro de Estudos do Genoma Humano da Universidade de São Paulo (equipamento MegaBACE 1000 / DYEnamic ET Dye Terminator Kit com Thermo Sequenase ${ }^{\mathrm{TM}}$ II DNA Polimerase). Para análise dos cromatrogramas utilizamos os softwares Consed ou BioEdit. A montagem dos dados gerados foi realizada com o pacote de programas Phred/Phrap/Consed ${ }^{4}$ (Ewing e Green, 1998; Ewing et al., 1998; Gordon et al., 1998). O programa Phred atribuiu valores de qualidade a cada base de cada cromatograma, o Phrap realizou a montagem e o Consed permitiu visualização e edição da montagem, assim como o BioEdit. A determinação do efeito da alteração nas seqüência foi definida por NCBI-BLASTX ${ }^{5}$ (Altschul et al., 1990) das sequências possíveis de cada cluster contra o Banco de dados de proteínas NR.

\subsection{Correlação genótipo-fenótipo clínico dos pacientes DGC}

O quadro clínico dos pacientes com DGC e sua evolução foram analisados detalhadamente e correlacionados com os defeitos genético-moleculares encontrados. Analisamos todos os dados clínicos dos pacientes DGC com estudo genético conclusivo, e os separamos por tipos de mutações $(C Y B B$ "nonsense", $C Y B B$ "missense", $C Y B B$ "splicing" e NCF1 "nonsense"). Selecionamos 18 manifestações clínicas mais relevantes indicadas no histórico clínico dos pacientes DGC, e classificamos de forma gradual determinando uma “pontuação clínica (PC)" de 18 a 1, sendo manifestações consideradas graves <18 e manifestações consideradas leves $>1$. Com esta classificação gradual elaboramos um cálculo que leva em consideração o número absoluto de pacientes, dentro do grupo de mutações, que foi acometido por cada manifestação clínica. Os pontos obtidos para cada manifestação clínica foram somados e divididos por 18 (número de manifestações clínicas analisadas), criando um “ÍNDICE” pra cada tipo de mutação. Fórmula: (pontuação clínica ou PC) x (nº

\footnotetext{
${ }^{4}$ (www.phrap.org)

${ }^{5}$ (www.ncbi.nlm.nih.gov/BLAST)
} 
de indivíduos afetados $) / \mathrm{n}^{\circ}$ de pacientes afetados no grupo = pontos; $\left(\sum\right.$ pontos $) / 18=$ Índice de Gravidade Clínica (IGC). Elaboramos também uma apresentação gráfica gradual monocromática das correlações genótipo-fenótipo clínico, baseada nos pontos obtidos de cada uma das manifestações clínicas (software Microsoft Office 2007 - Excel). Além disso, analisamos as idades de primeira manifestação clínica e idade de diagnóstico de cada grupo de mutações, comparando as médias visualizadas em gráficos de barras desenhados no software GraphPad Prism versão5.01.

\subsubsection{Análise Estatística}

Para as análises estatísticas comparando dados clínicos e genéticos dos pacientes DGC, utilizamos "Kruskal-Wallis test" seguido de "Dunn's Multiple Comparison Test" além do "Mann Whitney test", dependendo dos grupos comparados conforme software GraphPad Prism versão 5.01. 


\section{RESULTADOS}

No total, 26 pacientes foram investigados, 17 casos envolvendo o gene $C Y B B$ (P1 a P10 somados a casos antigos, MF, JM, RS, GG, IC, Vin e PT - Tabela 2, pág. 43) e 9 casos envolvendo o gene NCF1 (P1a a P4a somados a casos antigos, MIS, MIN, ADE, ADR e RON - Tabela 3, pág. 47). Com as informações clínicas e todos os exames bioquímicos indicando falha no "burst" oxidativo dos fagócitos pela falta da liberação de superóxido, iniciamos nestes pacientes as investigações moleculares na busca de mutações no sistema NADPH oxidase que poderiam causar tal defeito, principalmente nos casos de suspeitas de mutações ligado ao gene $C Y B B$ (Figura 5) que proporcionou resultados conclusivos. Com os estudos genéticos concluídos iniciamos os estudos analisando detalhadamente todo o histórico clínico e familiar destes pacientes que passaram pelo nosso laboratório, a fim de correlacionar genótipo-fenótipo clínico. Para cada médico responsável, foi disponibilizada uma ficha com dados relevantes para os estudos destes pacientes, proporcionando elaborar estratégias de análises genéticas e clínicas.

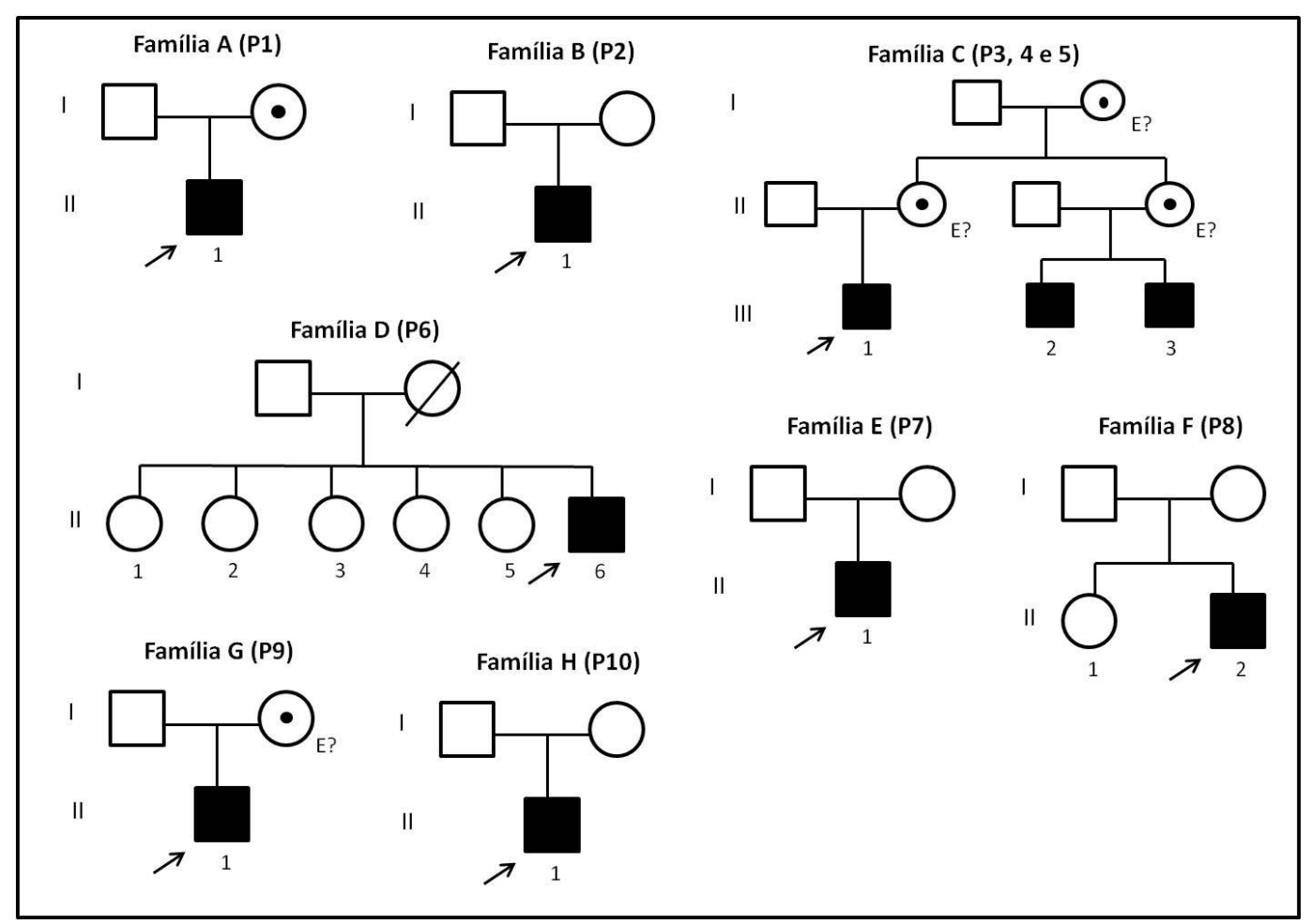

Figura 5. Heredogramas com representação das famílias dos pacientes DGC ligada ao $X$. As mães representadas como portadoras indicadas com o símbolo "E?" não foram avaliadas a nível genético, mas evidenciadas pelo teste do NBT. 


\subsection{Estudo genético-molecular do gene CYBB: uso do dHPLC e novas mutações.}

Nesta etapa utilizamos dois diferentes métodos para triagem inicial na busca por mutações, SSCP e dHPLC. Durante as investigações elucidamos 7 mutações diferentes, das quais 4 são inéditas na literatura. Interessantemente, essas 4 mutações foram identificadas na triagem somente pelo método dHPLC. Por meio de SSCP e dHPLC identificamos as seguintes mutações: c.688 C>T / R226X (exon 7), uma mutação do tipo "nonsense" nos pacientes 1 e 2 (Figura 6) já descrita na literatura (Heyworth et al., 2001); e c.880 C>T / R290X (exon 8), outra mutação do tipo "nonsense" nos pacientes 3, 4 e 5 (Figura 7) já descrita na literatura (Heyworth et al., 2001). Por outro lado, somente com o método dHPLC identificamos as 4 mutações inéditas no gene CYBB: c.904 InsC / T302fsX46 (exon 9), uma inserção que causa um "frameshift" que leva a um códon de parada prematura no paciente 6 (Figura 8); c.141 +5 G>T (intron 2), uma substituição de um nucleotídeo no sítio de "splicing" no paciente 7 (Figura 9A-C); c.553 T>C / C185R ( exon 6), uma mutação do tipo "missense" no paciente 8 (Figura 10A-C) e c.665 A>T / H222L (exon 6), uma mutação tipo "missense" no paciente 9 (Figura 11A-C). Em outro caso, identificamos a mutação c.1621 T>C / C537R (exon 13), uma mutação do tipo "missense" no paciente 10 (Figura 12A-B) já descrita na literatura (Heyworth et al., 2001). Neste último caso em especial, utilizamos como triagem somente o método dHPLC que identificou com precisão o fragmento alterado.

Para verificar o desempenho e eficácia das análises utilizando o método dHPLC, investigamos 2 casos DGC com genética confirmada pelo nosso grupo e colaboradores que utilizaram o método SSCP nas triagens, paciente 11 (exon 3) - c.229 C>T / R73X (AgudeloFlorez et al., 2006) e paciente 12 (exon 5) - c. 481 C>T / R157X (Patino et al., 1999), os quais serviram como nossos controles positivos durante padronizações iniciais do dHPLC, validando o método para análise do gene $C Y B B$ (Figura 13). O método dHPLC apresentou eficácia de $100 \%$ na deteç̧ão de alterações moleculares, enquanto que o método SSCP apresentou eficácia de 64\% nos casos estudados (Tabela 2), indicando portanto o melhor desempenho e confiabilidade do método dHPLC.

Complementamos nossas investigações moleculares do paciente 7 com análise dos transcritos (cDNA) através de eletroforese em gel de agarose que mostra um produto menor comparado ao controle, evidenciando deleção do exon 2 (Figura 9D). Realizamos também uma comparação filogenética entre as espécies (gp91-phox) especialmente nas mutações do tipo "missense" que apresentam uma substituição de aminoácido. No paciente 8 , a troca ocorre num aminoácido semi-conservado entre as espécies, porém altamente conservado entre 
os mamíferos (Figura 10D). No paciente 9, a troca ocorre num aminoácido altamente conservado entre as dez espécies comparadas (Figura 11D). No paciente 10, com mutação tipo "missense" já descrita na literatura, a troca também ocorre num aminoácido altamente conservado entre as espécies comparadas (Figura 12C).

Estes resultados também estão presentes no artigo em revisão (ANEXO A)

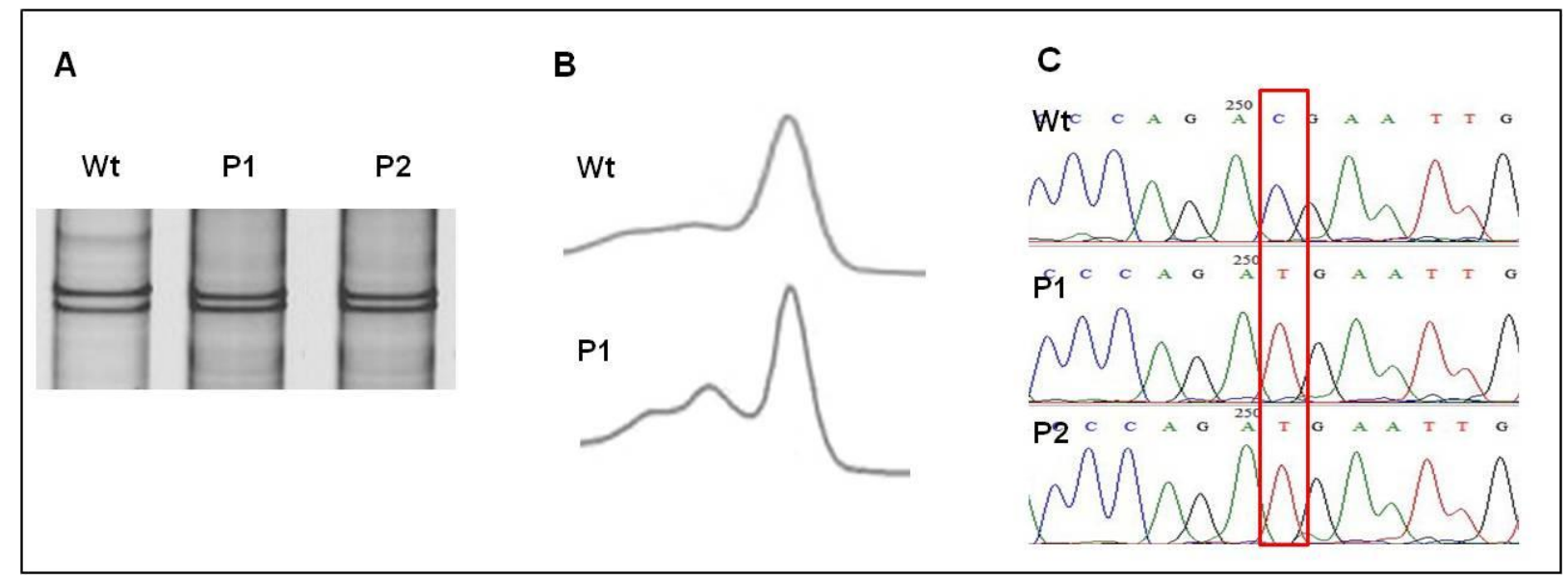

Figura 6. Análise molecular do exon 7 (pacientes 1 e 2), uma mutação tipo "nonsense". A: SSCP revelou alteração no padrão de corrida na região do exon 7. B: dHPLC confirmou a alteração molecular no exon $7\left(57{ }^{\circ} \mathrm{C}\right.$, tempo de retenção entre $3-5$ minutos). C: Cromatograma mostra a mudança dos nucleótidos C $>\mathrm{T}$ (gDNA). 


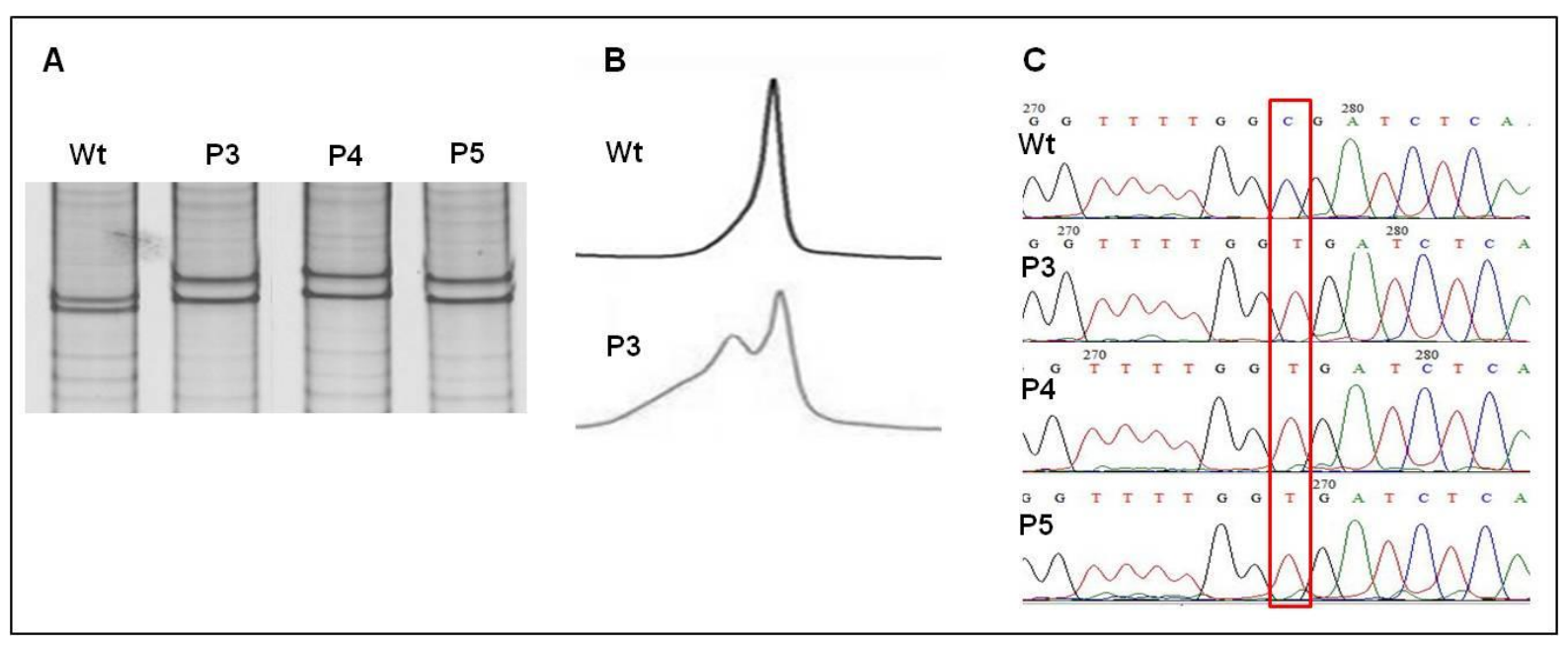

Figura 7. Análise molecular do exon 8 (pacientes 3, 4 e 5), uma mutação tipo "nonsense". A: SSCP revelou alteração no padrão de corrida na região do exon 8. B: dHPLC confirmou a alteração molecular no exon 8 (58,4 ${ }^{\circ} \mathrm{C}$, tempo de retenção entre $3-5$ minutos). C: Cromatograma mostra a mudança dos nucleótidos $\mathrm{C}>\mathrm{T}(\mathrm{gDNA})$.

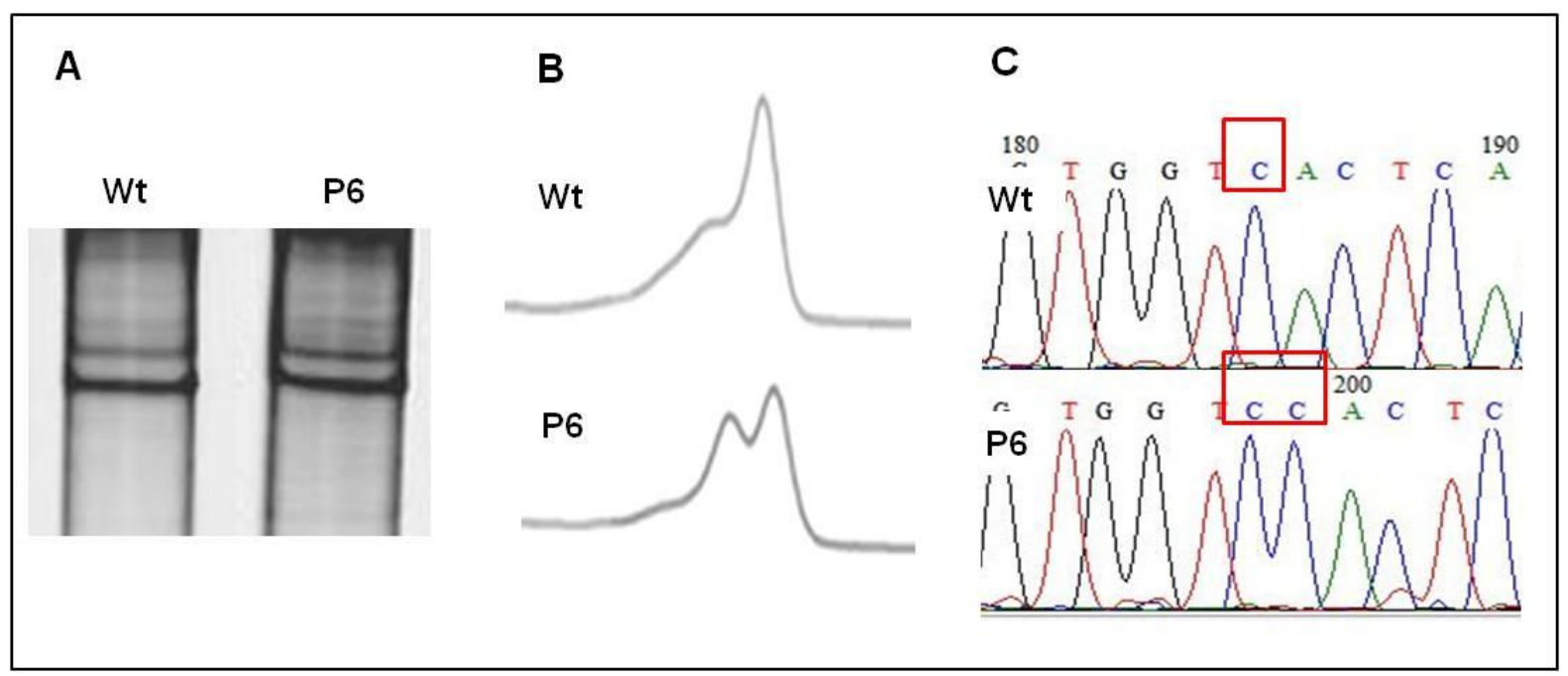

Figura 8. Análise molecular do exon 9 (paciente 6), uma inserção levando a um "frameshift" e códon de parada prematuro. A: SSCP mostra padrão normal de corrida na região do exon 9. B: dHPLC revela uma alteração molecular na região do exon $9\left(57{ }^{\circ} \mathrm{C}\right.$, tempo de retenção entre 3-5 minutos). C: Cromatograma mostra uma inserção de um nucleotídeo C (gDNA). 


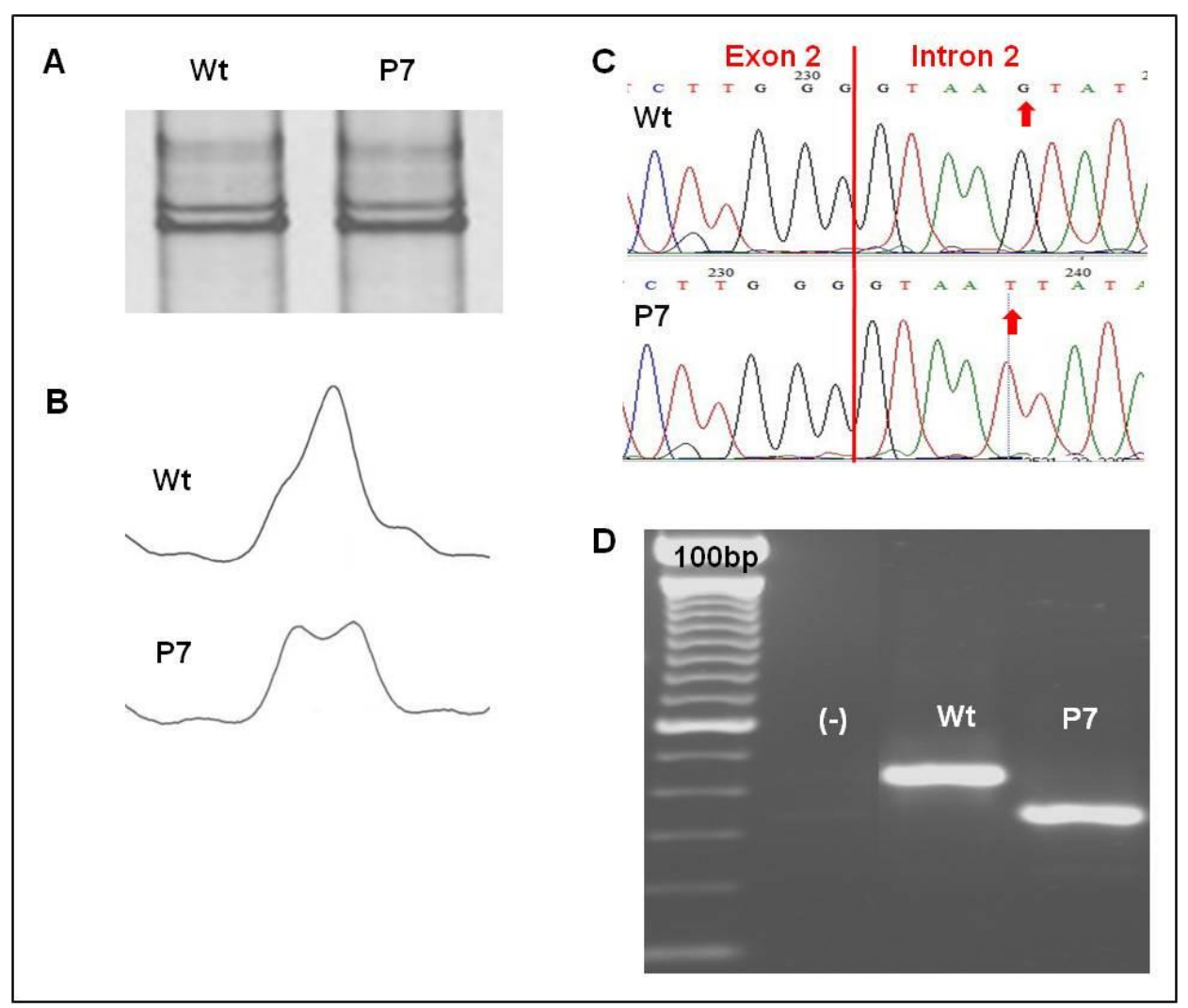

Figura 9. Análise molecular do exon 2 (paciente 7), uma mutação tipo erro de "splicing". A: SSCP mostra padrão normal de corrida na região do exon 2. B: dHPLC revela uma alteração molecular na região do exon $2\left(56,9^{\circ} \mathrm{C}\right.$, tempo de retenção entre $3-5$ minutos). C: Cromatograma mostra uma subtituição de nucleotídeo G>T na borda intrônica do intron 2. D: eletroforese em gel de agarose $2 \%$ corado com brometo de etídio mostrando diferença no tamanho dos produtos de PCR entre o paciente e o fragmento normal evidenciando deleção do exon 2 no transcrito do gene $C Y B B$ (cDNA). 


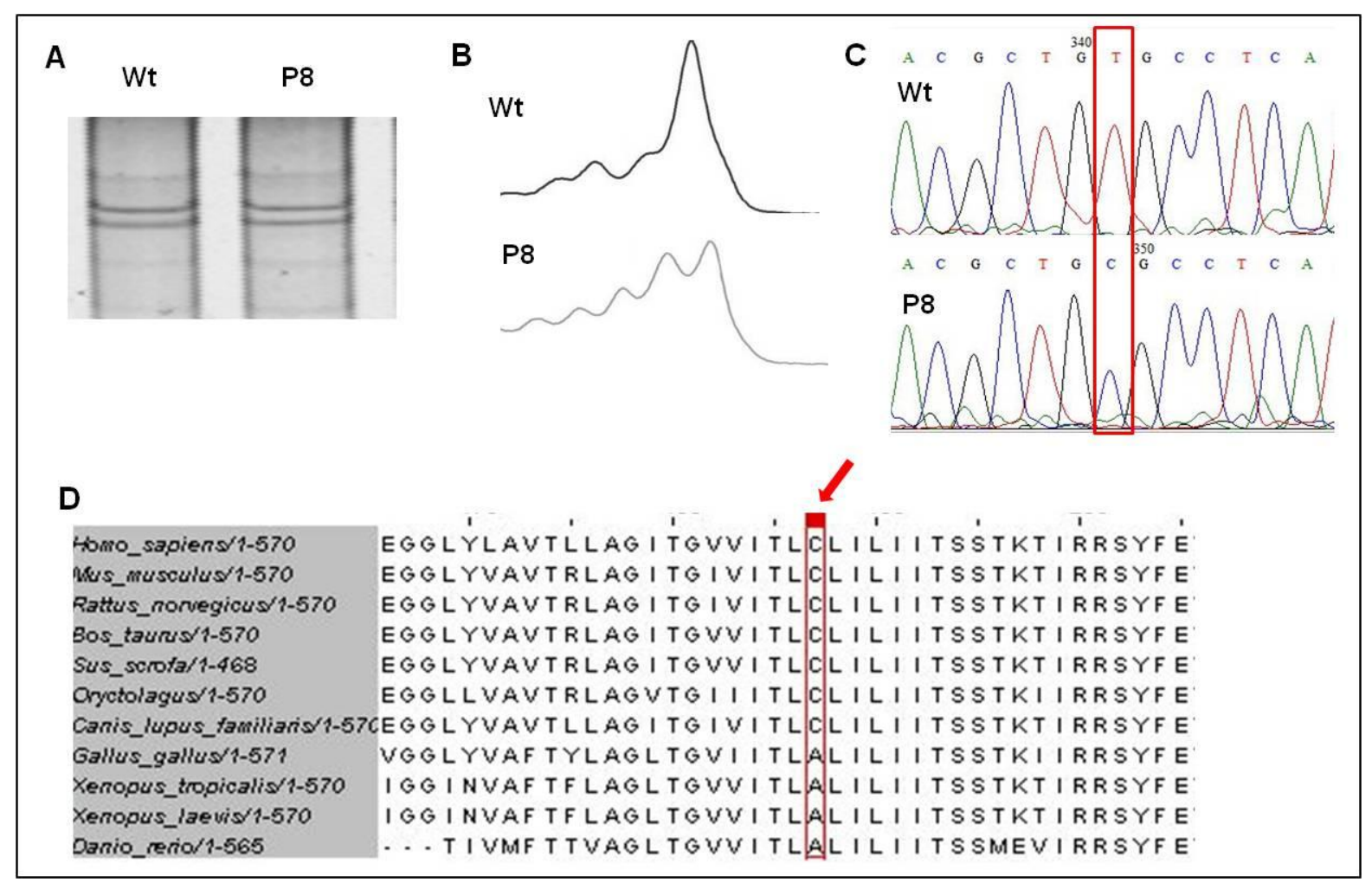

Figura 10. Análise molecular do exon 6 (paciente 8), uma mutação tipo "missense". A: SSCP mostra padrão normal de corrida na região do exon 6. B: dHPLC revela uma alteração molecular no exon $6\left(60{ }^{\circ} \mathrm{C}\right.$, tempo de retenção entre 3-5 minutos). C: Cromatograma mostra uma substituição de nucleotídeos $\mathrm{T}>\mathrm{C}$ (gDNA). D: Comparação filogenética entre espécies dos aminoácidos da gp91-phox evidenciando uma mutação "missense" no paciente 8 que gera uma substituição de aminoácidos (C185R) numa região semiconservada entre espécies, mas totalmente conservada entre os mamíferos. 


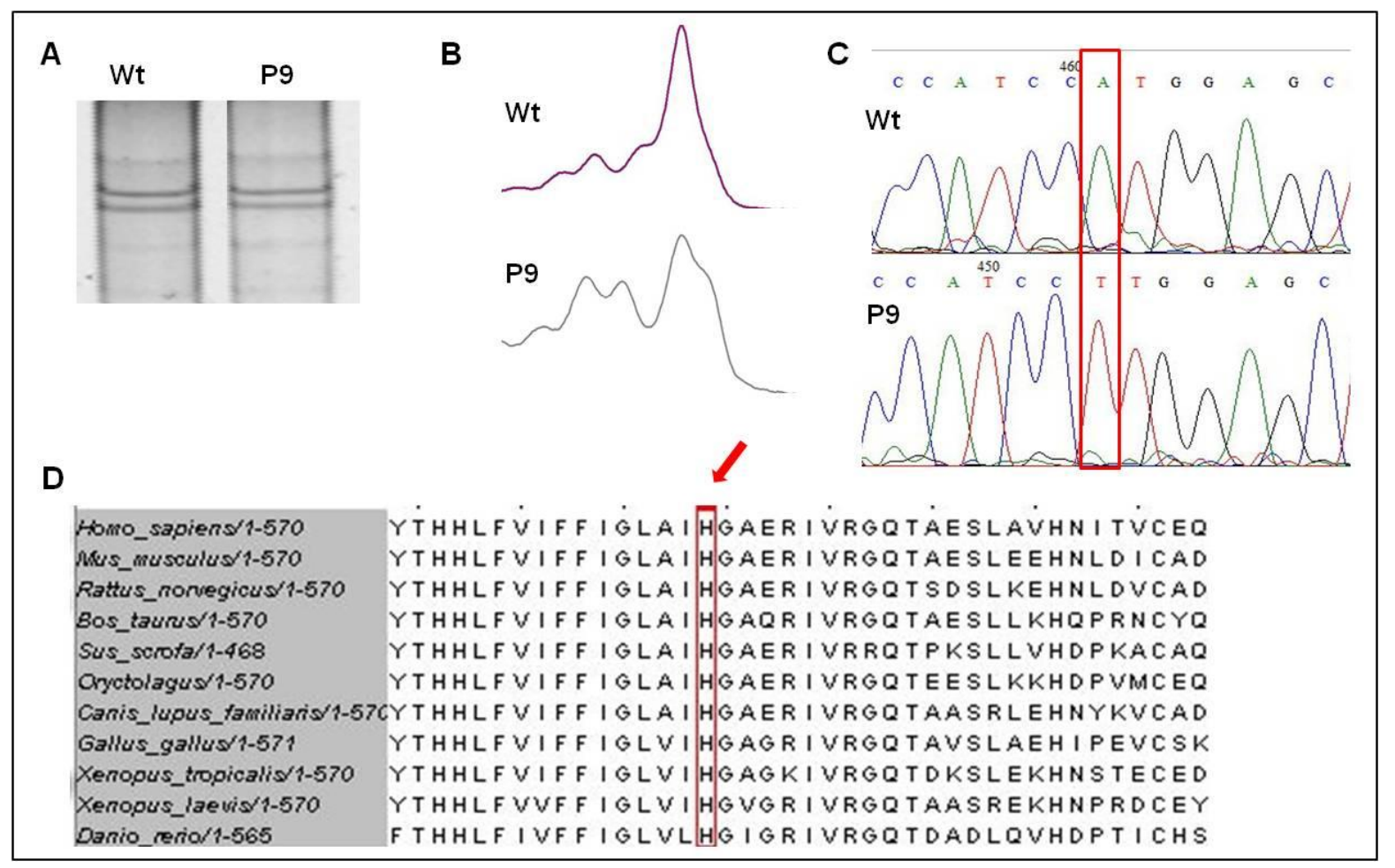

Figura 11. Análise molecular do exon 6 (paciente 9), uma mutação tipo "missense". A: SSCP mostra padrão normal de corrida na região do exon 6. B: dHPLC revela uma alteração molecular no exon $6\left(60{ }^{\circ} \mathrm{C}\right.$, tempo de retenção entre 3-5 minutos). C: Cromatograma mostra uma substituição de nucleotídeos $\mathrm{A}>\mathrm{T}$ (gDNA); D: Comparação filogenética entre espécies dos aminoácidos da gp91-phox evidenciando uma mutação missense no paciente 9 que gera uma substituição de aminoácidos (H222L) em uma região totalmente conservada entre todas as espécies analisadas. 


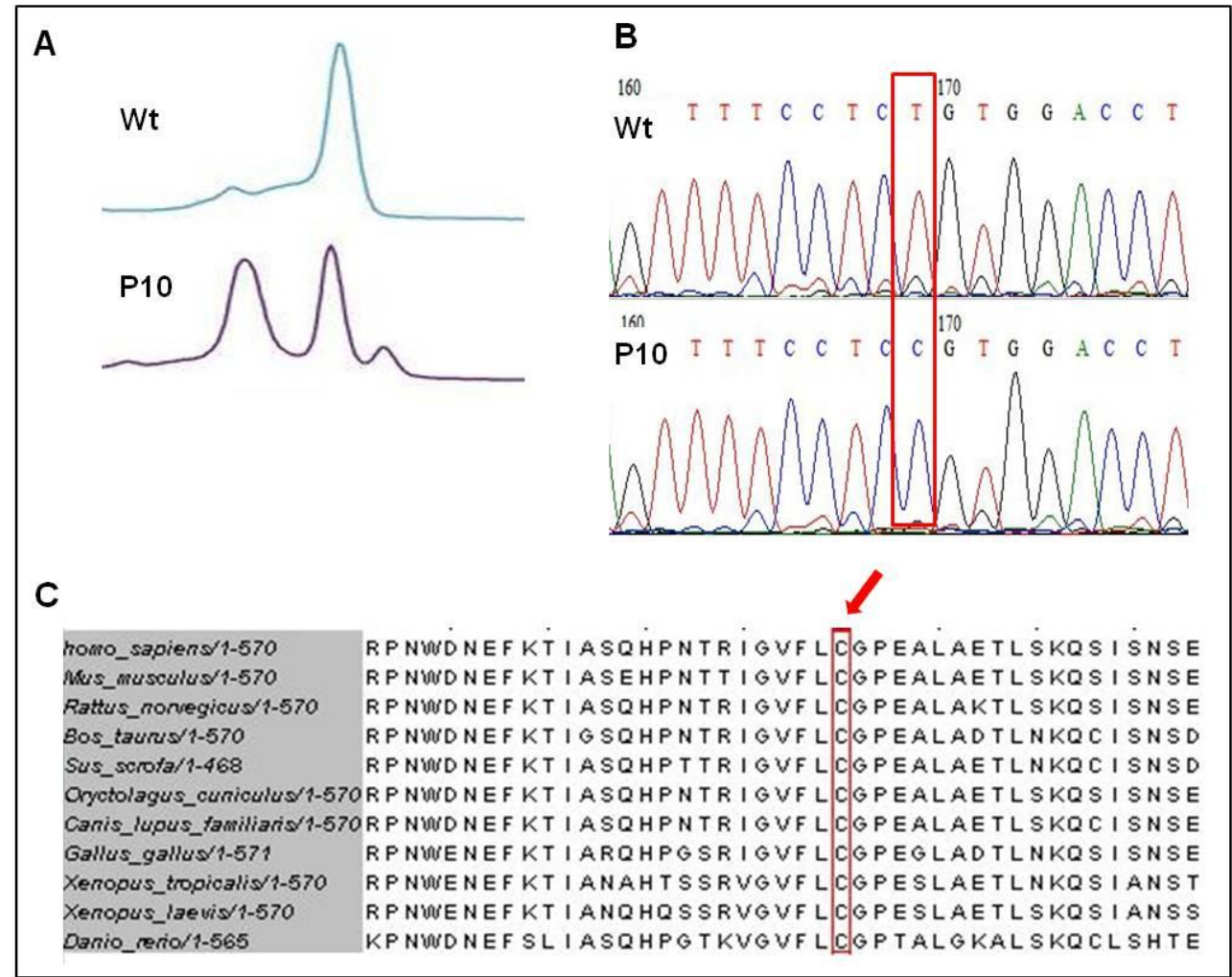

Figura 12. Análise molecular do exon 13 (paciente 10), uma mutação tipo "missense". A: dHPLC revelou uma alteração molecular no exon $13\left(58,9^{\circ} \mathrm{C}\right.$, tempo de retenção entre 35 minutos). B: Cromatograma mostra uma mudança de nucleotídeos $\mathrm{T}>\mathrm{C}$ (gDNA). C: comparação filogenética entre espécies dos aminoácidos da gp91-phox evidenciando uma mutação missense no paciente 10 que gera uma substituição de aminoácidos (C537R) em uma região totalmente conservada entre todas as espécies analisadas.

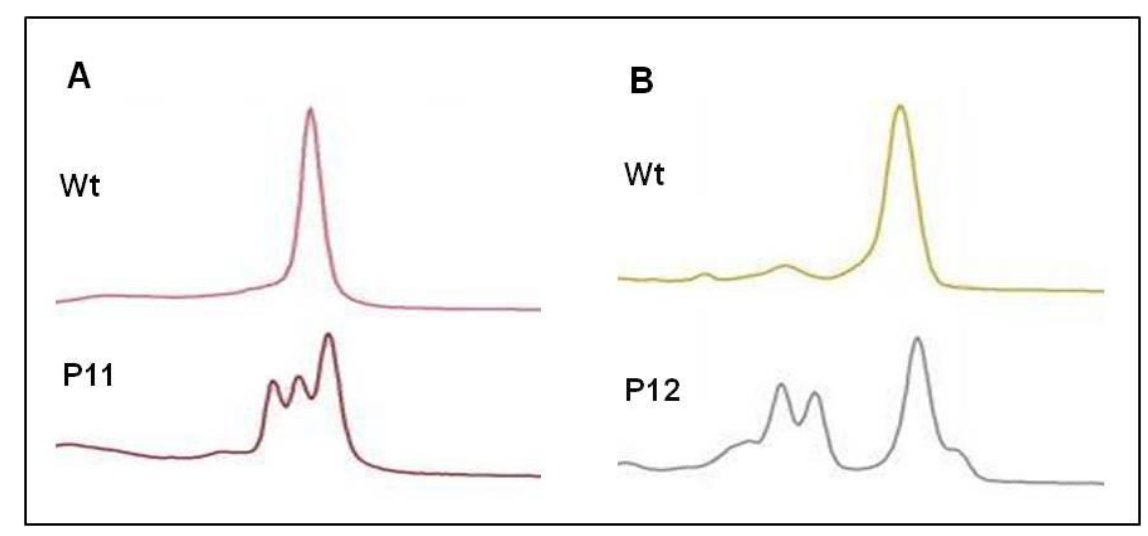

Figura 13. Análise adicional do método dHPLC (controles). Resultados de dois casos de pacientes DGC, confirmando a eficiência do método na detecção de alterações nos exons na sequência do gene $C Y B B$. A. Análise do paciente 11 mostra alteração na região do exon 3 (56,2 ${ }^{\circ} \mathrm{C}$, tempo de retenção 3-5 minutos) e B. Análise do paciente 12 mostra alteração na região do exon $5\left(57,2^{\circ} \mathrm{C}\right.$, tempo de retenção $3-5$ minutos). 
Tabela 2 - Mutações no gene $C Y B B$ e avaliação pelos métodos SSCP e dHPLC

\begin{tabular}{|c|c|c|c|c|c|c|c|c|}
\hline Pacientes & Expressão & Mutação & Local & $\begin{array}{l}\text { Nucleotídeo } \\
\text { (mRNA) }\end{array}$ & Produto & $\begin{array}{c}\text { SSCP } \\
\text { detectado }\end{array}$ & $\begin{array}{c}\text { dHPLC } \\
\text { detectado }\end{array}$ & Referência \\
\hline $\mathrm{P} 1$ & $\mathrm{X} 91^{0}$ & Nonsense & exon 7 & c. $688 \mathrm{C}>\mathrm{T}$ & R226X & $\operatorname{sim}$ & $\operatorname{sim}$ & $\begin{array}{c}\text { Heyworth et al. } \\
2001\end{array}$ \\
\hline $\mathrm{P} 2$ & $\mathrm{X} 91^{0}$ & Nonsense & exon 7 & c. $688 \mathrm{C}>\mathrm{T}$ & R226X & $\operatorname{sim}$ & NA & $\begin{array}{c}\text { Heyworth et al. } \\
2001\end{array}$ \\
\hline P3 & $\mathrm{X} 91^{0}$ & Nonsense & exon 8 & c. $880 \mathrm{C}>\mathrm{T}$ & R290X & $\operatorname{sim}$ & $\operatorname{sim}$ & $\begin{array}{c}\text { Heyworth et al. } \\
2001\end{array}$ \\
\hline $\mathrm{P} 4$ & $\mathrm{X} 91^{0}$ & Nonsense & exon 8 & c. $880 \mathrm{C}>\mathrm{T}$ & R290X & $\operatorname{sim}$ & NA & $\begin{array}{c}\text { Heyworth et al. } \\
2001\end{array}$ \\
\hline P5 & $\mathrm{X} 91^{0}$ & Nonsense & exon 8 & c. $880 \mathrm{C}>\mathrm{T}$ & R290X & $\operatorname{sim}$ & NA & $\begin{array}{l}\text { Heyworth et al. } \\
2001\end{array}$ \\
\hline P6 & $\mathrm{X} 91^{0}$ & Nonsense & exon 9 & c. 904 insC * & T302fsX46* & não & $\operatorname{sim}$ & - \\
\hline P7 & $\mathrm{X} 91^{0}$ & Splicing & intron 2 & c. $141+5^{*}$ & $\begin{array}{l}\text { Deleção } \\
\text { exon } 2\end{array}$ & não & $\operatorname{sim}$ & - \\
\hline P8 & $\mathrm{X} 91^{+}$ & Missense & exon 6 & c. $553 \mathrm{~T}>\mathrm{C} *$ & $\mathrm{C} 185 \mathrm{R} *$ & não & $\operatorname{sim}$ & - \\
\hline P9 & $\mathrm{X} 91^{-}$ & Missense & exon 6 & c. $665 \mathrm{~A}>\mathrm{T} *$ & $\mathrm{H} 222 \mathrm{~L} *$ & não & $\operatorname{sim}$ & - \\
\hline $\mathrm{P} 10$ & $\mathrm{X} 91^{+}$ & Missense & exon 13 & c. $1621 \mathrm{~T}>\mathrm{C}$ & C537R & NA & $\operatorname{sim}$ & $\begin{array}{c}\text { Heyworth et al. } \\
2001\end{array}$ \\
\hline $\mathrm{MF}(\mathrm{P} 11)$ & $\mathrm{X} 91^{0}$ & Nonsense & exon 3 & c. $229 \mathrm{C}>\mathrm{T}$ & $\mathrm{R} 73 \mathrm{X}$ & Ref. & $\operatorname{sim}$ & $\begin{array}{c}\text { Heyworth et al. } \\
2001\end{array}$ \\
\hline JM (P12) & $\mathrm{X} 91^{0}$ & Nonsense & exon 5 & c. $481 \mathrm{C}>\mathrm{T}$ & R157X & Ref. & $\operatorname{sim}$ & $\begin{array}{c}\text { Heyworth et al. } \\
2001\end{array}$ \\
\hline $\mathrm{RS}$ & $\mathrm{X} 91^{0}$ & Splicing & exon 3 & c. $264 \mathrm{G}>\mathrm{A}$ & $\begin{array}{l}\text { deleção do } \\
\text { exon } 3\end{array}$ & Ref. & NA & $\begin{array}{c}\text { Heyworth et al. } \\
2001\end{array}$ \\
\hline GG & $\mathrm{X} 91^{0}$ & Splicing & exon 3 & c. $264 \mathrm{G}>\mathrm{A}$ & $\begin{array}{l}\text { deleção do } \\
\text { exon } 3\end{array}$ & Ref. & NA & $\begin{array}{c}\text { Heyworth et al. } \\
2001\end{array}$ \\
\hline IC & X91? & Splicing & $\begin{array}{c}\text { intron } \\
10\end{array}$ & $\begin{array}{l}\text { c. } 1326+1 \\
\mathrm{G}>\mathrm{A}\end{array}$ & $\begin{array}{l}\text { deleção do } \\
\text { exon } 10\end{array}$ & Ref. & NA & $\begin{array}{c}\text { Heyworth et al. } \\
2001\end{array}$ \\
\hline Vin & X91- & Splicing & intron 9 & $\begin{array}{l}\text { c. } 1164-2 \\
\mathrm{G}>\mathrm{A}\end{array}$ & $\begin{array}{l}\text { deleção do } \\
\text { exon } 10\end{array}$ & Ref. & NA & $\begin{array}{c}\text { Agudelo-Florez, } \\
\text { et al., } 2006\end{array}$ \\
\hline PT & X91? & Nonsense & exon 2 & c. $95 \mathrm{G}>\mathrm{A}$ & W28X & Ref. & NA & $\begin{array}{c}\text { Heyworth et al. } \\
2001\end{array}$ \\
\hline
\end{tabular}

* mutação ainda não descrita neste gene; NA= não avaliado; Ref.= método aplicado em outros trabalhos 


\subsection{Estudo genético-molecular do gene $N C F 1$ : interferência dos pseudogenes}

Dentre 4 pacientes do sexo feminino estudadas, após sequencimento direto do exon 2 do gene NCF1, identificamos uma deleção dos nucleotídeos GT, na forma homozigota em duas pacientes (P1a e P2a) . No cromatograma normal, as sobreposições dos picos devem-se à interferência dos pseudogenes que possuem a mesma deleção GT, e por isso quando o paciente DGC apresenta deleção GT de forma homozigota, o cromatograma apresenta-se limpo sem esta interfência do pseudogene (Figura 14). Esta mutação devido a deleção de GT no exon 2 do gene $N C F 1$ provoca um "frameshift" que leva a um códon de parada prematuro TGA na região do domínio PX da p47-phox (c. 87 88del.GT / p.V25fsX51), a mutação mais comum na DGC autossômica $\mathrm{A} 47^{\circ}$.

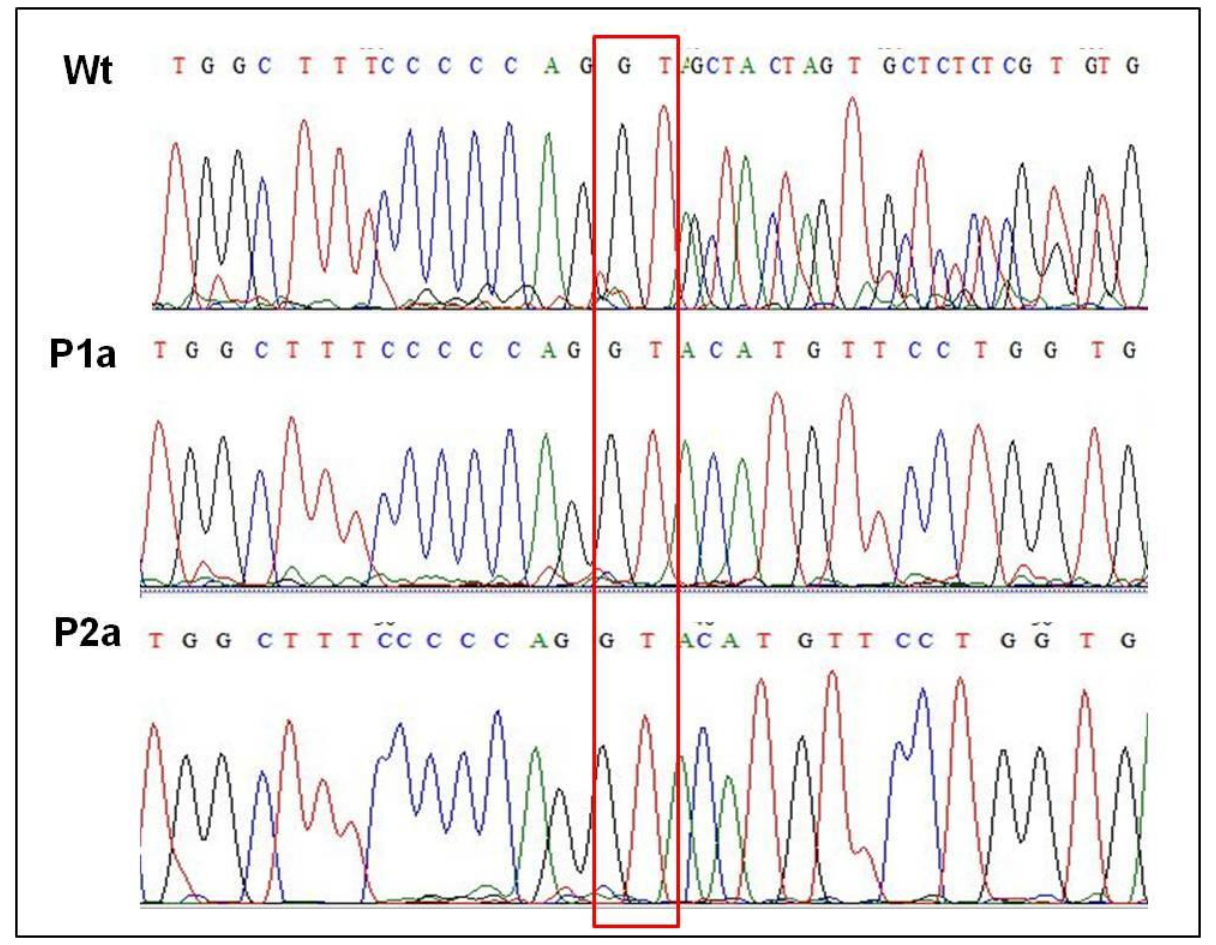

Figura 14. Análise molecular no exon 2 - gene $N C F 1$ (pacientes P1a e P2a) por sequenciamento direto, uma mutação "nonsense". O cromatograma mostra uma mutação devido a uma deleção de GT no exon 2 do gene NCF1 provocando um "frameshift" que leva a um códon de parada prematuro TGA na região do domínio PX da p47-phox (c. 87 88del.GT /p.V25fsX51). 
Entretanto, em outras 2 pacientes (P3a, P4a) em que aplicamos sequenciamento direto do exon 2 do gene $N C F 1$, apresentaram no cromatograma intensidade de picos diferentes na região dos nucleotídeos GT (Figura 15), que nos chamou atenção por manter esta baixa intensidade dos picos comparados aos controles normais em diversas tentativas de PCR e novos sequenciamentos, indicando deleção GT no gene NCF1 na forma heterozigota (GT_ / GTGT). Como nas bases de dados de mutações neste gene, existem casos com mutações nesta forma heterozigota associada a outras mutações em outras regiões do gene, principalmente exons 4, 6 e 7, também na forma heterozigota. Investigamos estas regiões por meio de triagem pelo método SSCP. Assim, identificamos alterações no exon 4 das pacientes P3a e P4a que apresentavam forma heterozigota da deleção GT no exon 2 (Figura 16). No sequenciamento do exon 4 destas pacientes, identificamos duas alterações que levavam a uma troca simples de aminoácido, c.268 G>A / p. R90H nas duas pacientes e c.295 G>A / p.G99S somente na paciente P3a (Figura 17), sendo esta última alteração descrita como polimorfismo no banco de dados do NCBI (refSNP ID: rs17856077). Neste caso, as pacientes P3a e P4a apresentam possíveis mutações do tipo c. 87 88del.GT (exon 2) no alelo 1 e c.268 G>A (exon 4) no alelo 2, que podem levar a alteração da proteína p47-phox devido a presença de mutações no mesmo gene, mas em diferentes alelos, afetando a proteína (Roos et al., 2006). Nestes dois últimos casos, portanto, não conseguimos concluir de forma segura a real causa da DGC, sendo necessários estudos mais complexos e aprofundados que anulem a interferência dos pseudogenes. 


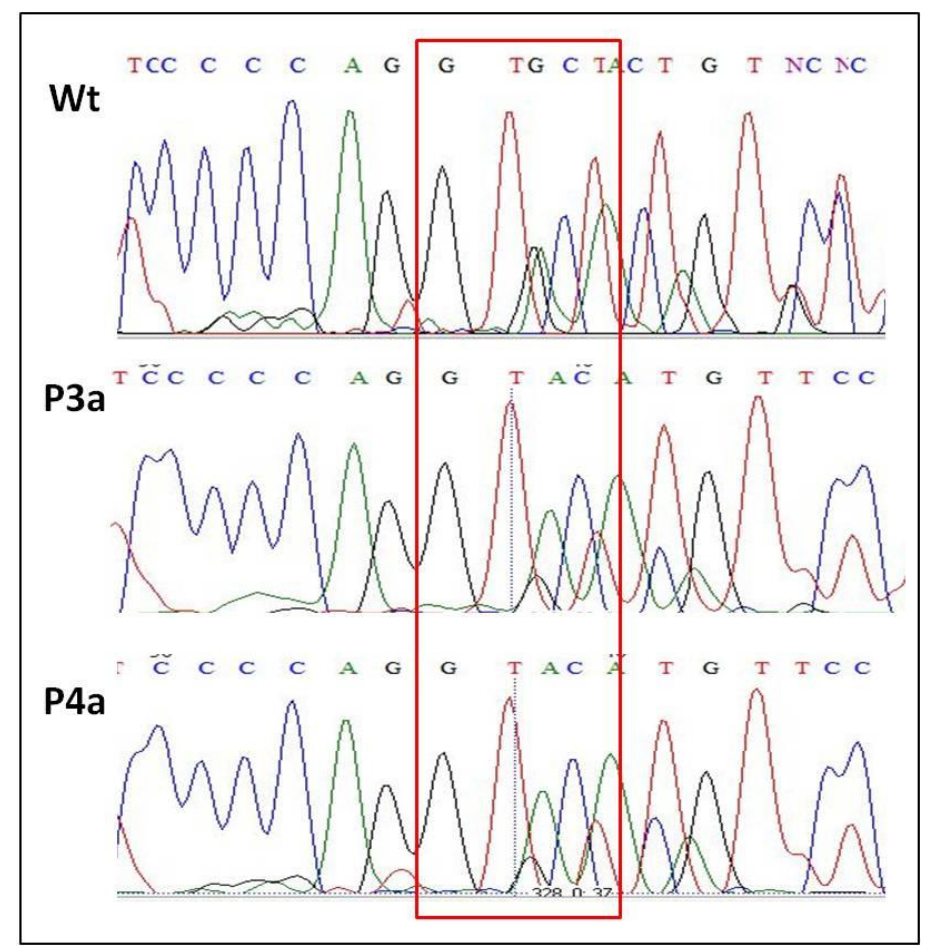

Figura 15. Análise molecular do exon 2 - gene NCF1 (pacientes P3a e P4a) por sequenciamento direto, possível alteração em heterozigose. $O$ cromatograma mostra a possibilidade de mutação em heterozigose devido a diferentes intensidades dos picos GT em relação ao controle na região da deleção de GT no exon 2 do gene $N C F 1$ indicando padrão heterozigoto para a mutação, c. 87 88del.GT / p.V25fsX51.

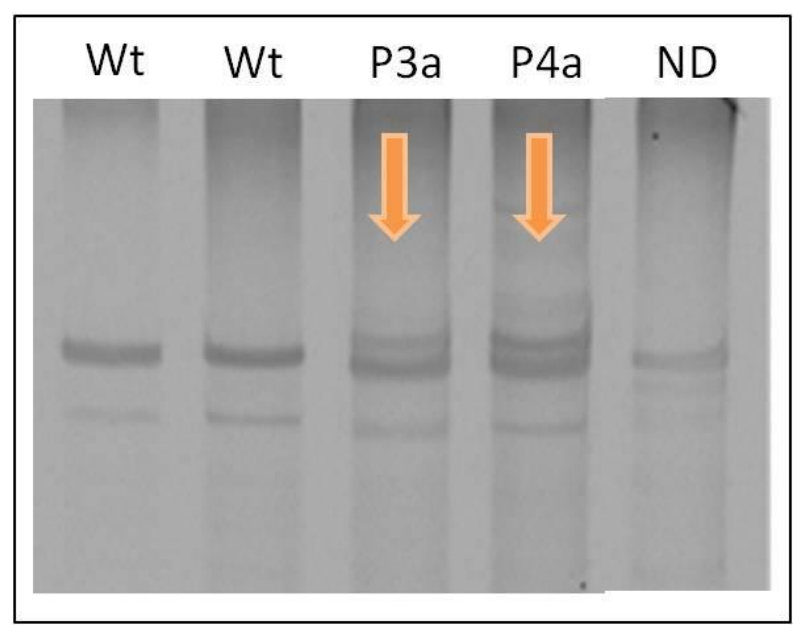

Figura 16. Análise por SSCP do exon 4 do gene $N C F 1$. Foram utilizados dois controles normais "Wt" (positivo). ND é o controle de uma amostra não submetida ao processo inicial de desnaturação (negativo). Observou-se alteração no padrão de mobilidade eletroforética nos pacientes $\mathrm{P} 3 \mathrm{a}$ e $\mathrm{P} 4 \mathrm{a}$. 


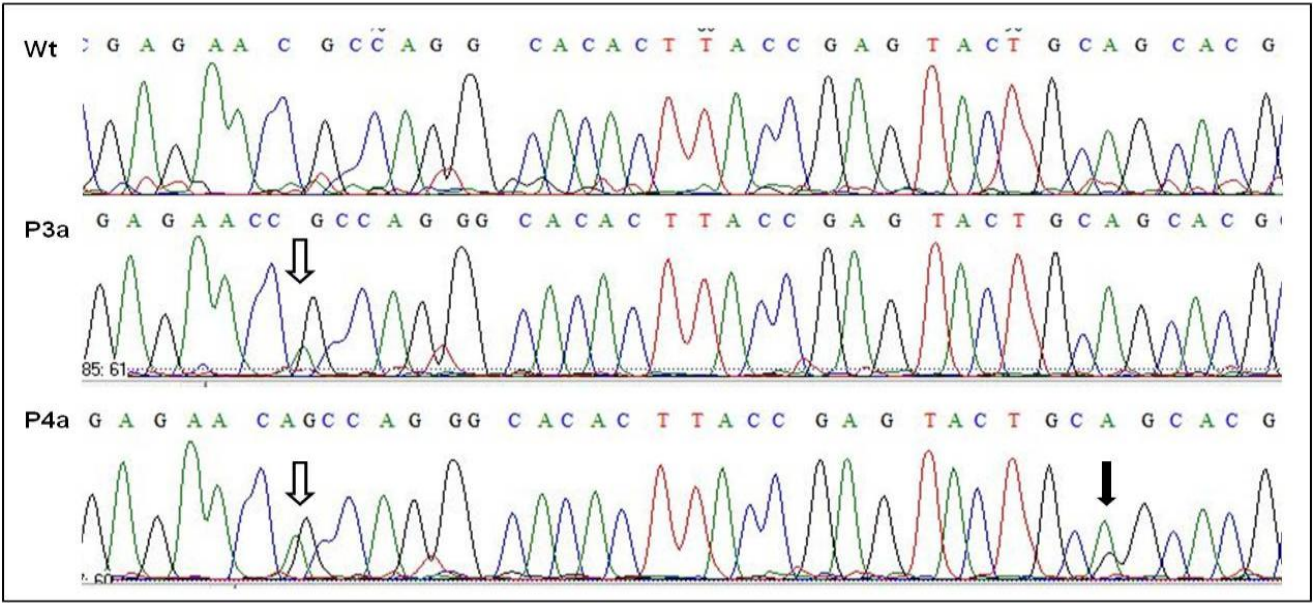

Figura 17. Análise molecular do exon 4 - gene NCF1 (pacientes P3a e P4a) através sequenciamento: possível mutação em heterozigose. Paciente $\mathrm{P} 3 \mathrm{a}$ apresentou picos sobrepostos G/A (c.268, p. R90H); paciente P4a apresentou dois pontos de sobreposição de picos G/A (c.268, p. R90H) e G/A (c.295, p.G99S), sendo este último já descrito como polimorfismo no banco de dados do NCBI (refSNP ID: rs17856077).

Tabela 3 - Mutações no gene NCF1 identificados em pacientes DGC

\begin{tabular}{|c|c|c|c|c|}
\hline Pacientes & Mutação & Localização & Mudança no nucletídeo & Produto \\
\hline P1a & Nonsense & exon 2 & c. 87 88del.GT & p.V25fsX51 \\
\hline \multirow[t]{2}{*}{$\mathrm{P} 2 \mathrm{a}$} & Nonsense & exon 2 & c. $8788 \mathrm{del} . \mathrm{GT}$ & p.V25fsX51 \\
\hline & & & (alelo1) c. 87 88del.GT & (alelo 1) p.V25fsX51 \\
\hline \multirow[t]{3}{*}{ P3a* } & Nonsense & exon 2 / exon 4 & & \\
\hline & & & (alelo 2)c.268 G>A & (alelo 2) p.R90H \\
\hline & & & (alelo1) c. 87 88del.GT & (alelo 1) p.V25fsX51 \\
\hline \multirow[t]{2}{*}{ P4a* } & Nonsense & exon 2 / exon 4 & & \\
\hline & & & (alelo 2)c.268 G>A & (alelo 2) p.R90H \\
\hline MIS & Nonsense & exon 2 & c. 8788 del.GT & p.V25fsX51 \\
\hline MIN & Nonsense & exon 2 & c. $8788 \mathrm{del} . \mathrm{GT}$ & p.V25fsX51 \\
\hline $\mathrm{ADE}$ & Nonsense & exon 2 & c. 8788 del.GT & p.V25fsX51 \\
\hline ADR & Nonsense & exon 2 & c. 8788 del.GT & p.V25fsX51 \\
\hline RON & Nonsense & exon 2 & c. $8788 \mathrm{del} . \mathrm{GT}$ & p.V25fsX51 \\
\hline
\end{tabular}

* pacientes com dados moleculares inconclusivos (não entraram nos estudos clínicos) 


\subsection{Correlação genótipo-fenótipo clínico: Índice de Gravidade Clínica}

Com os dados genéticos e clínicos dos pacientes DGC encaminhados ao nosso laboratório e que apresentaram DGC ligada ao X (Tabela 2) e DGC autossômica no gene NCF1 (Tabela 3), estabelecemos uma correlação entre genótipo e fenótipo clínico através de cálculo matemático baseado em seleção e classificação de 18 manifestações clínicas mais relevantes e comuns entre estes pacientes, nos fornecendo dados importantes como pontos gerais de cada manifestação clínica e um Índice de Gravidade Clínica, que chamamos de IGC para cada tipo de mutação envolvida na DGC (Quadro 1). 
Quadro 1. Correlação genótipo-fenótipo clínico / Índice de Gravidade Clínica

\begin{tabular}{|c|c|c|c|c|c|c|c|c|c|c|c|}
\hline & & $\mathrm{N}=8$ & & $\mathrm{~N}=3$ & & $\mathrm{~N}=4$ & & $\mathrm{~N}=15$ & & $\mathrm{~N}=7$ & \\
\hline $\begin{array}{c}\text { Manifestações } \\
\text { Clínicas }\end{array}$ & $P C$ * & $\begin{array}{c}\text { CYBB } \\
\text { nonsense }\end{array}$ & pontos & $\begin{array}{c}C Y B B \\
\text { missense }\end{array}$ & pontos & $\begin{array}{c}\text { CYBB } \\
\text { splicing }\end{array}$ & pontos & $\begin{array}{l}\text { CYBB } \\
\text { Geral }\end{array}$ & pontos & $\begin{array}{c}\text { NCF1 } \\
\text { nonsense }\end{array}$ & pontos \\
\hline Sepse & 18 & 1,00 & 2,25 & 1,00 & 6,00 & 1,00 & 4,50 & 3,00 & 3,60 & 0,00 & 0,00 \\
\hline Meningite & 17 & 1,00 & 2,13 & 0,00 & 0,00 & 0,00 & 0,00 & 1,00 & 1,13 & 0,00 & 0,00 \\
\hline Osteomie. & 16 & 1,00 & 2,00 & 0,00 & 0,00 & 0,00 & 0,00 & 1,00 & 1,07 & 0,00 & 0,00 \\
\hline Abscesso profundo & 15 & 7,00 & 13,13 & 1,00 & 5,00 & 1,00 & 3,75 & 9,00 & 9,00 & 3,00 & 5,63 \\
\hline Granulomas & 14 & 1,00 & 1,75 & 1,00 & 4,67 & 3,00 & 10,50 & 5,00 & 4,67 & 1,00 & 1,75 \\
\hline Pneu/DP & 13 & 0,00 & 0,00 & 0,00 & 0,00 & 2,00 & 6,50 & 2,00 & 1,73 & 1,00 & 1,63 \\
\hline Abscesso superficial & 12 & 6,00 & 9,00 & 0,00 & 0,00 & 0,00 & 0,00 & 6,00 & 4,80 & 1,00 & 1,50 \\
\hline Reação BCG & 11 & 0,00 & 0,00 & 1,00 & 3,67 & 1,00 & 2,75 & 2,00 & 1,47 & 0,00 & 0,00 \\
\hline Linfonodo & 10 & 7,00 & 8,75 & 2,00 & 6,67 & 2,00 & 5,00 & 11,00 & 7,33 & 1,00 & 1,25 \\
\hline Artrite & 9 & 1,00 & 1,13 & 0,00 & 0,00 & 0,00 & 0,00 & 1,00 & 0,60 & 0,00 & 0,00 \\
\hline Celulite & 8 & 1,00 & 1,00 & 1,00 & 2,67 & 0,00 & 0,00 & 2,00 & 1,07 & 0,00 & 0,00 \\
\hline Diarréia & 7 & 2,00 & 1,75 & 0,00 & 0,00 & 2,00 & 3,50 & 4,00 & 1,87 & 1,00 & 0,88 \\
\hline ITU & 6 & 0,00 & 0,00 & 1,00 & 2,00 & 1,00 & 1,50 & 2,00 & 0,80 & 0,00 & 0,00 \\
\hline Otite & 5 & 2,00 & 1,25 & 2,00 & 3,33 & 3,00 & 3,75 & 7,00 & 2,33 & 1,00 & 0,63 \\
\hline Pele & 4 & 2,00 & 1,00 & 1,00 & 1,33 & 4,00 & 4,00 & 7,00 & 1,87 & 4,00 & 2,00 \\
\hline Reação vacinas & 3 & 0,00 & 0,00 & 2,00 & 2,00 & 1,00 & 0,75 & 3,00 & 0,60 & 0,00 & 0,00 \\
\hline Amigda. & 2 & 0,00 & 0,00 & 1,00 & 0,67 & 1,00 & 0,50 & 2,00 & 0,27 & 0,00 & 0,00 \\
\hline Sinusite & 1 & 0,00 & 0,00 & 1,00 & 0,33 & 3,00 & 0,75 & 4,00 & 0,27 & 1,00 & 0,13 \\
\hline IGC & & & 2,51 & & 2,13 & & 2,65 & & 2,47 & & 0,85 \\
\hline
\end{tabular}

* $P C=$ Pontuação Clínica 
Quando cruzamos os dados dos pontos de cada manifestação clínica, obtidos pelo número de pacientes acometidos multiplicado pela pontuação de cada manifestação com os gráficos monocromáticos graduais, conseguimos visualizar dentro dos grupos de mutações que acometiam o gene $C Y B B$ menor intensidade de gravidade clínica no grupo dos pacientes com erros de "splicing" quando comparado com os grupos de mutações dos tipos "nonsense" e "missense" (Figura 18). Além disso, com esta mesma forma de análise, quando comparamos os grupos acometidos por mutações no gene $C Y B B$ com os grupos de pacientes acometidos por mutação no gene $N C F 1$, conseguimos visualizar menor intensidade da gravidade clínica neste último grupo (Figura 19). Porém, quando comparamos os dados obtidos pela somatória dos pontos de cada manifestação clínica, nos fornecendo um IGC (Índice de Gravidade Clínica) para cada tipo de mutação manifestada no gene $C Y B B$, verificamos que não há uma diferença significativa entre os grupos de mutações tipo "nonsense", "missense" e "splicing" (Figura 20A). Interessantemente, quando comparamos estes dados do IGC entre o grupo com mutações no gene $C Y B B$ com o grupo com mutação no gene $N C F 1$, verificamos menor índice de gravidade clínica significativo neste último grupo, $p=0,0022$ (Figura 20B). 


\section{CYBB nonsense}

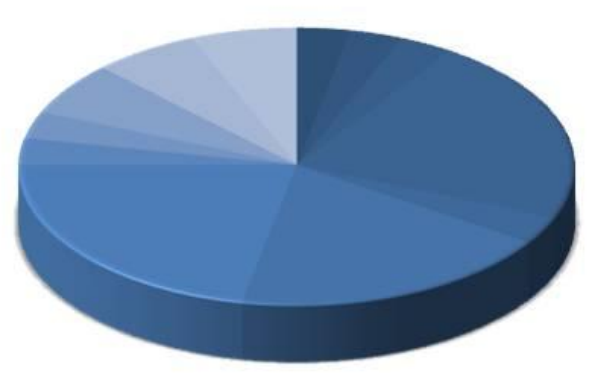

CYBB missense

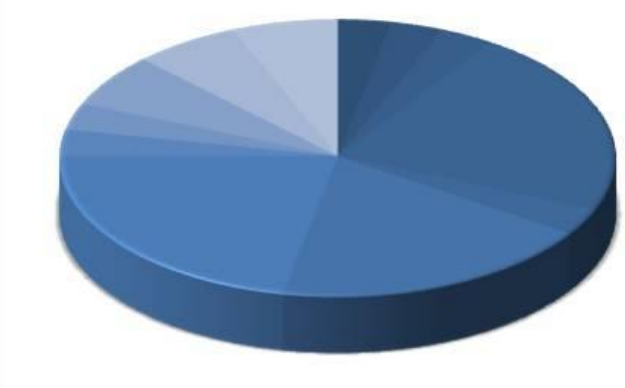

\section{CYBB splicing}

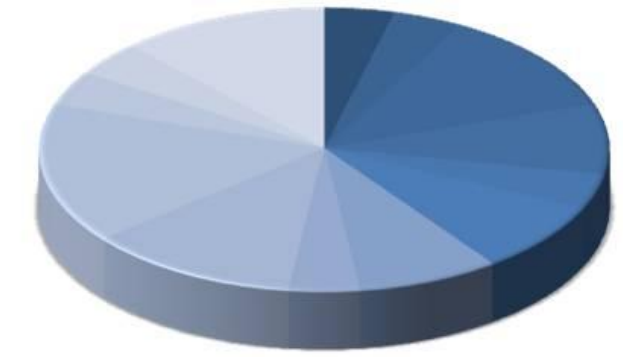

- Sepse

aeningite

口 Osteomie.

- Abscesso profundo

Granulomas

口 Pneu/DP

$\square$ Abscesso superficial

घeação BCG

- Linfonodo

口 Artrite

$\square$ Celulite

$\square$ Diarréia

그 ITU

口 Otite

$\square$ Pele

$\square$ Reação vacinas

$\triangle$ Amigda.

Figura 18. Análise cruzada da gravidade clínica entre as diferentes mutações no gene CYBB. O gráfico gradual mostra através do cruzamento entre os pontos e escala gradual monocromática comparando gravidade clínica entre mutações no gene $C Y B B$ ("nonsense", "missense" e "splicing"). O grupo com mutações tipo "splicing" visualmente revelou menor intensidade colorimétrica que os outros grupos de mutações, indicando menor intensidade clínica. 


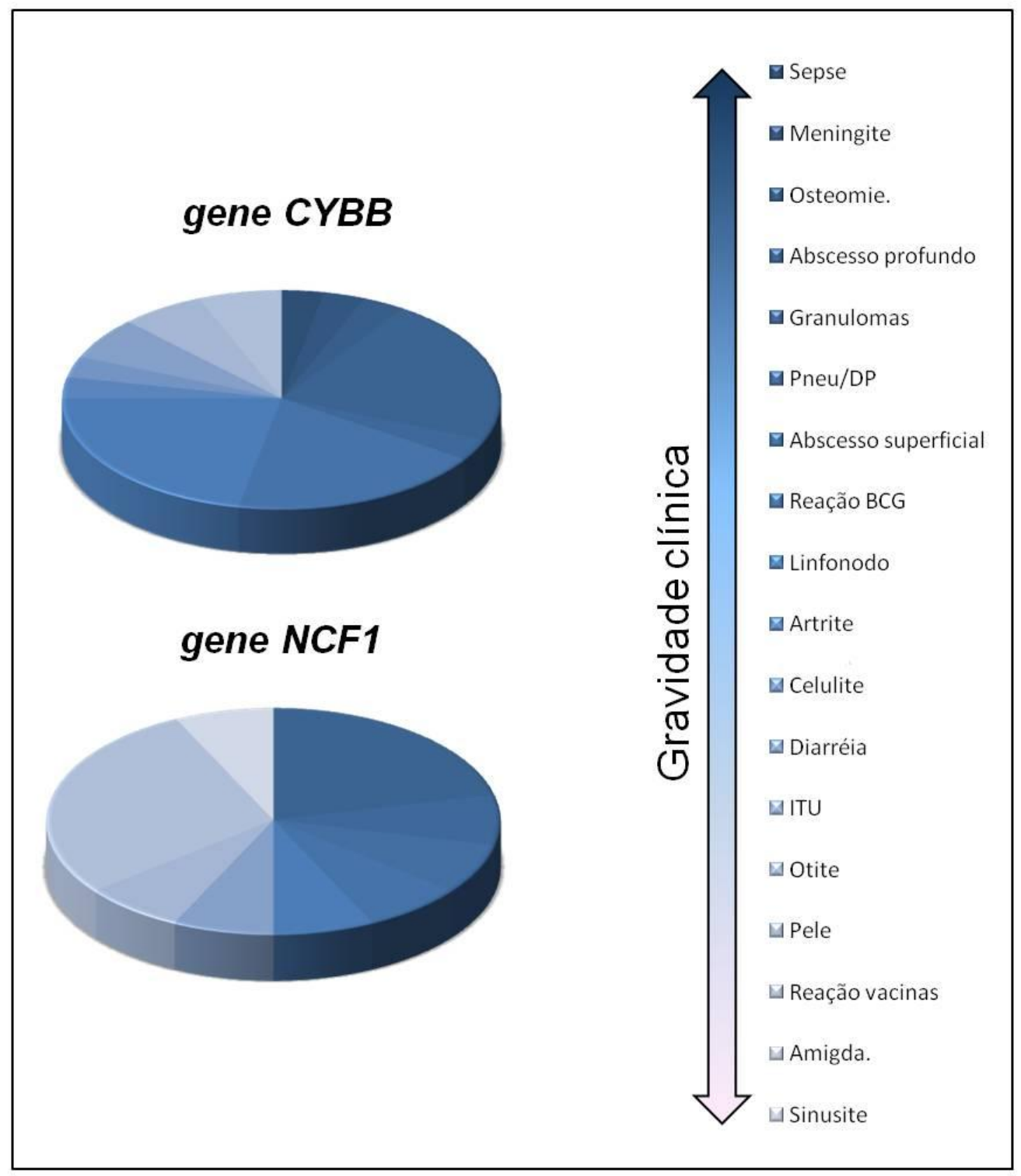

Figura 19. Análise cruzada da gravidade clínica entre os diferentes genes (CYBB / NCF1). O gráfico gradual mostra através do cruzamento entre os pontos e escala gradual monocromática comparando gravidade clínica entre os genes $C Y B B$ e $N C F 1$. O grupo com mutações no gene $N F C l$ visualmente revelou menor intensidade colorimétrica que o grupo com mutações, no gene $C Y B B$, indicando menor intensidade clínica. 


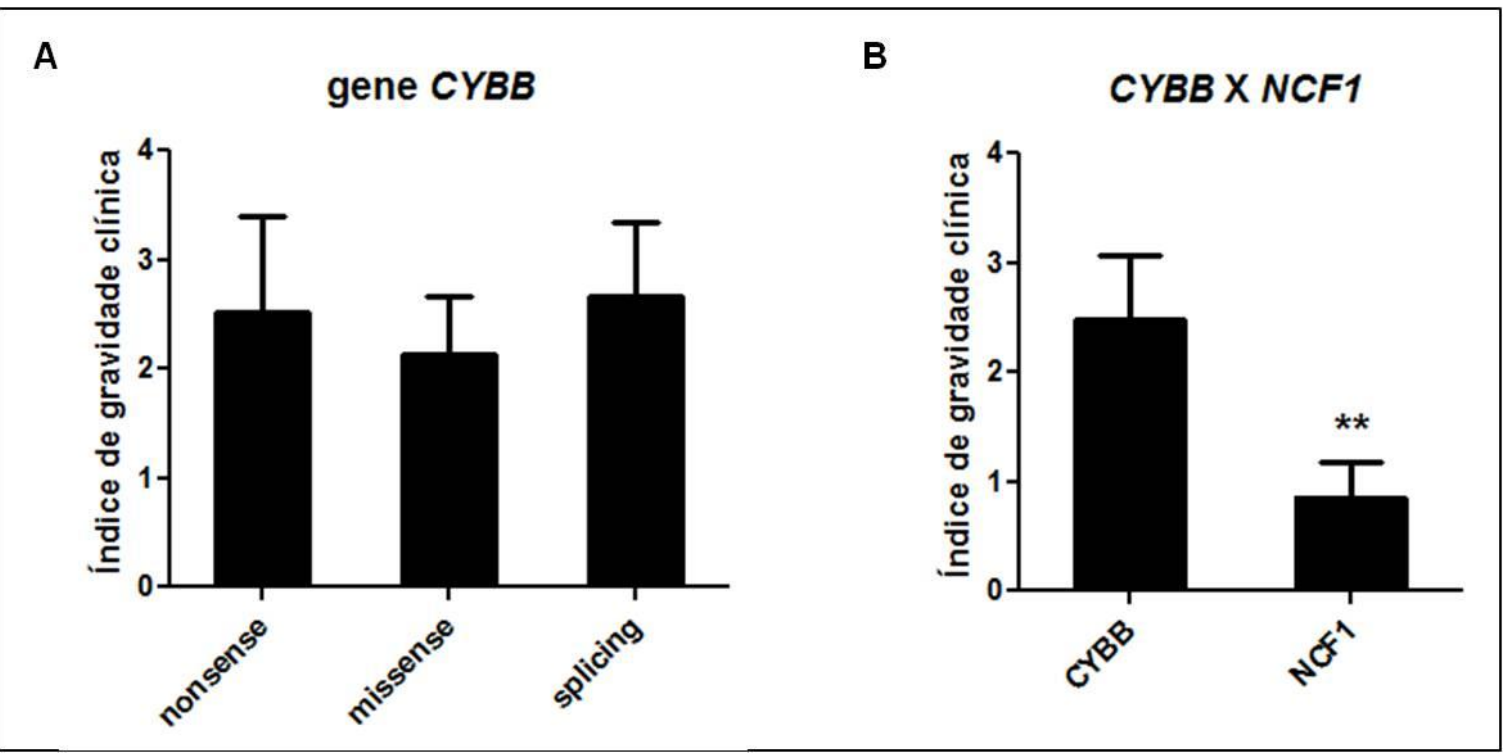

Figura 20. Análise do Índice de Gravidade Clínica entre os diferentes genótipos. A: O gráfico de barras mostra comparação dos índices de gravidade clínica entre mutações no gene $C Y B B$ ("nonsense", "missense" e "splicing") sem diferença significativa entre eles, KruskalWallis test, seguido de Dunn's Multiple Comparison Test; B: O gráfico de barras mostra comparação entre mutações em diferentes genes (CYBB e NCF1) mostrando diferença significativa no índice de gravidade clínica, Mann Whitney test; $p=0,0022(* *)$, sendo considerado significativo $p<0,05$.

Quando analisamos os dados clínicos dos principais pacientes deste estudo, constatamos dentre as principais manifestações clínicas que abscessos, linfadenite e principalmente pneumonia, são extremamente comuns entre os pacientes DGC, seja com DGC ligada ao X (P1 a P10) ou com DGC autossômica (P1a e P2a), sendo o Staphyloccocus aureus um dos principais patógenos envolvidos nas infecções, isolado principalmente da pele e do fígado (Tabela 4). 
Tabela 4 - Diagnóstico e Manifestações clínicas dos pacientes DGC

\begin{tabular}{|c|c|c|c|c|}
\hline Paciente & $\begin{array}{c}1^{a} \text { manifestação } \\
\text { (meses) }\end{array}$ & $\begin{array}{c}\begin{array}{c}\text { Diagnóstico } \\
\text { (meses) }\end{array} \\
\end{array}$ & $\begin{array}{c}\text { Principais manifestações } \\
\text { clínicas }\end{array}$ & Patógenos isolados \\
\hline $\mathrm{P} 1$ & 24 & 72 & $\begin{array}{c}\text { Pneumonia, otite, } \\
\text { amigdalite, Abcesso } \\
\text { hepático }\end{array}$ & $\begin{array}{c}\text { Staphylococcus aureus } \\
\text { (Fígado) }\end{array}$ \\
\hline $\mathrm{P} 2$ & - & 60 & $\begin{array}{l}\text { Pneumonia, Abscessos } \\
\text { hepático e de pele, diabete } \\
\text { tipo } 2\end{array}$ & - \\
\hline P3 & - & - & $\begin{array}{c}\text { Pneumonia, Abscessos } \\
\text { hepático e de pele, } \\
\text { linfadenite }\end{array}$ & - \\
\hline $\mathrm{P} 4$ & - & - & $\begin{array}{c}\text { Pneumonia, Abscessos } \\
\text { hepático e de pele, } \\
\text { linfadenite }\end{array}$ & - \\
\hline P5 & - & - & $\begin{array}{l}\text { Pneumonia, Abscessos } \\
\text { hepático e de pele, } \\
\text { linfadenite }\end{array}$ & - \\
\hline P6 & 1 & 1,5 & $\begin{array}{l}\text { Pneumonia, sepse, } \\
\text { linfadenite, Abscesso } \\
\text { pulmonar }\end{array}$ & $\begin{array}{c}\text { Klebsiela pneumoniae } \\
\text { and Serratia marcences } \\
\text { (linfonodo); Candida } \\
\text { parapsilossis }\end{array}$ \\
\hline P7 & 1 & 4 & $\begin{array}{c}\text { Pneumonia, granuloma, } \\
\text { piodermite }\end{array}$ & $\begin{array}{c}\text { Staphyloccocus aureus } \\
\text { (Pele) }\end{array}$ \\
\hline P8 & 7 & 24 & $\begin{array}{c}\text { Pneumonia, } \\
\text { lifonodomegalia, reação à } \\
\text { vacina }\end{array}$ & $\begin{array}{c}\text { Local reaction to BCG } \\
\text { vaccine }\end{array}$ \\
\hline P9 & 5 & 12 & $\begin{array}{l}\text { Pneumonia, adenite } \\
\text { cervical, linfadenite }\end{array}$ & - \\
\hline $\mathrm{P} 10$ & 9 & 12 & $\begin{array}{l}\text { Pneumonia, linfadenite, } \\
\text { amigdalite, piodermite, } \\
\text { granulomas }\end{array}$ & E. coli (Trato urinário) \\
\hline P1a & 9 & 168 & $\begin{array}{c}\text { Pneumonia, otite, } \\
\text { piodermite, abscesso } \\
\text { hepático }\end{array}$ & $\begin{array}{l}\text { Staphyloccocus aureus } \\
\text { (Pele, Fígado) }\end{array}$ \\
\hline $\mathrm{P} 2 \mathrm{a}$ & 31 & 121 & $\begin{array}{c}\text { Pneumonia, granuloma, } \\
\text { piodermite }\end{array}$ & $\begin{array}{c}\text { Staphyloccocus aureus } \\
\text { (Pele) }\end{array}$ \\
\hline
\end{tabular}

Investigando todos os pacientes DGC encaminhados ao nosso laboratório descritos anteriormente nas tabelas 2 e 3, comparamos entre os grupos a idade média da primeira manifestação clínica e idade média de diagnóstico, e verificamos que entre os grupos $C Y B B$ "nonsense", $C Y B B$ "missense" e $C Y B B$ "splicing", não houve diferença estatística significativa (Figura 21). Porém, quando comparamos os grupos com mutações em genes distintos, $C Y B B$ e $N C F 1$, este último grupo apresentou a média de idade de primeira manifestação clínica e de diagnóstico superior e estatisticamente significativa (Figura 22). 


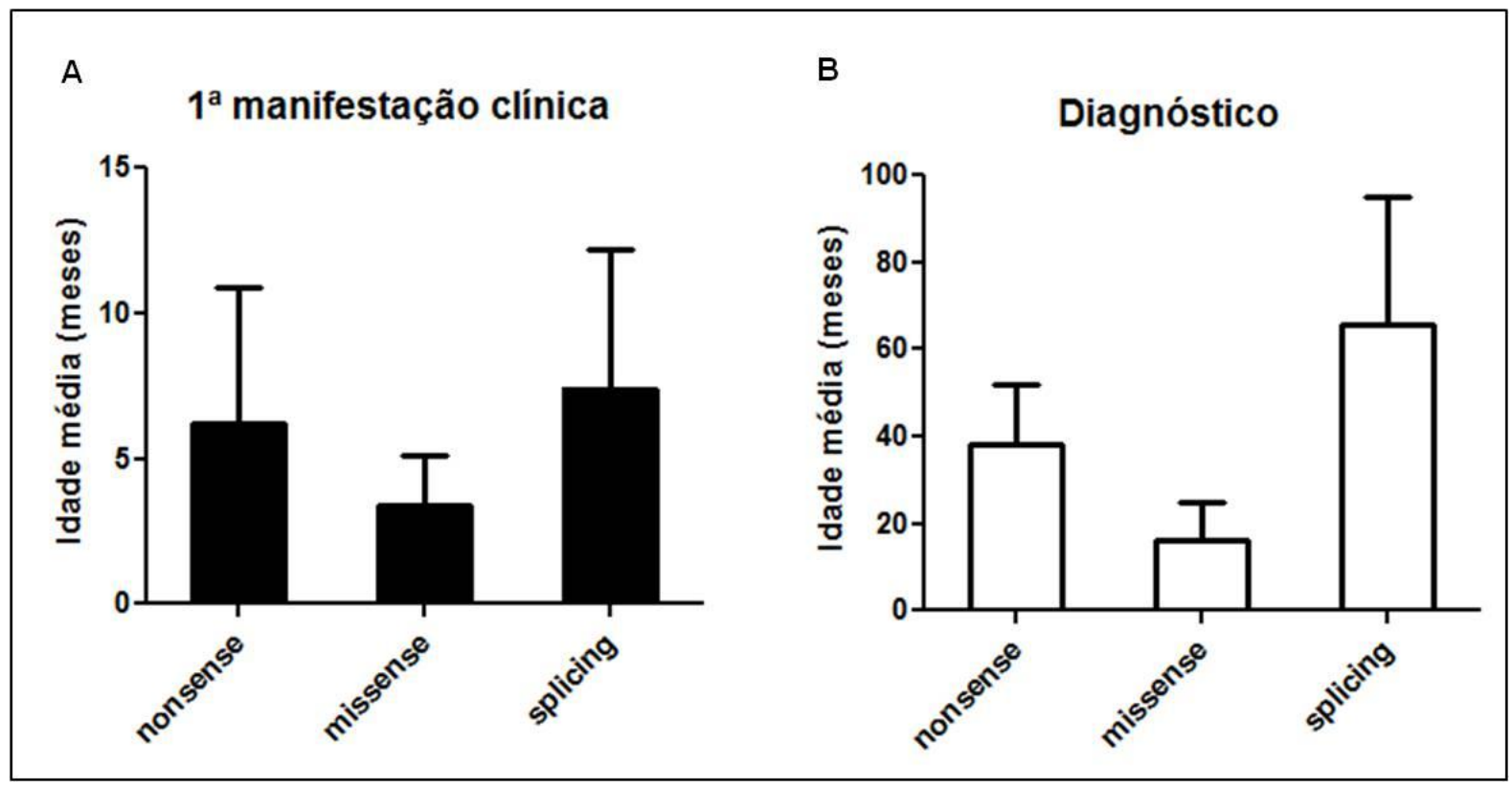

Figura 21. Gráfico comparando as médias de idade (meses) entre diferentes mutações no gene $\boldsymbol{C Y B B}$. A: Diferentes tipos de mutações ("nonsense", "missense" e "splicing") são comparados com relação as médias de idade em que ocorreu a primeira manifestação clínica e B: idade média de diagnóstico. Sem diferença estatística em ambos os gráficos.

A

$1^{\mathrm{a}}$ manifestação clínica

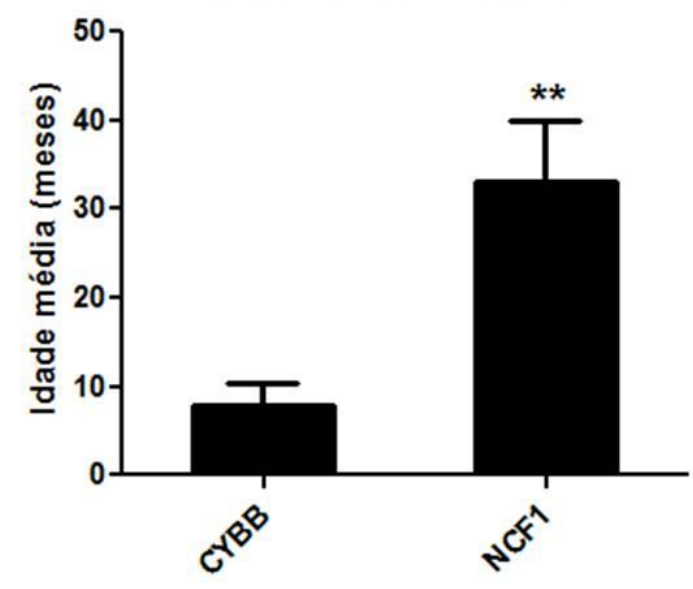

B

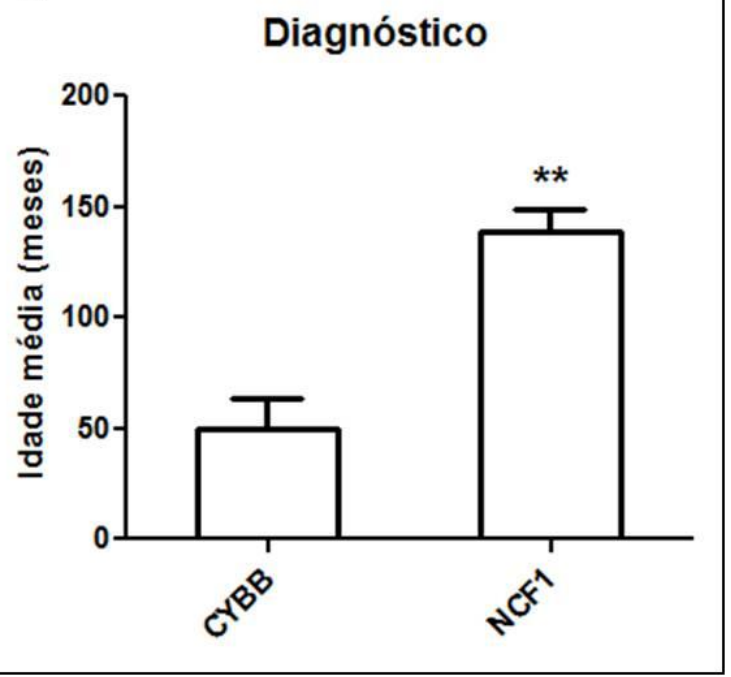

Figura 22. Gráfico comparando as médias de idade (meses) entre os genes CYBB e NCF1. A: Os dois genes mais importantes na DGC são comparados com relação as médias de idade em que ocorreu a primeira manifestação clínica e B: as médias de idade de diagnóstico. Ambos os gráficos mostram diferenças significativas na idade da primeira manifestação clínica $p=0,0012(* *)$ e diagnóstico $p=0,0064(* *)$, considerados tardios no grupo dos pacientes que apresentam mutação no gene $N C F 1$ comparado ao grupo com mutações no gene $C Y B B$. Valor considerado significativo $p<0,05$. 


\section{DISCUSSÃO}

Nos últimos 10 anos, o método de triagem de mutações dHPLC foi discutido e apreciado por muitos grupos de pesquisa pela sua sensibilidade e precisão na detecção de mutações com cerca de 96 a 100\% de sensibilidade. Em contrapartida, outros trabalhos mostram que o SSCP oferece precisão de 85\% (Ravnik-Glavac et al., 1994), ou até mesmo $50 \%$ (Liu et al., 1996). Uma circunstância agravante no uso do método SSCP, uma das principais técnicas utilizadas para triagem de mutações na América Latina atualmente, são os resultados falsos negativos apresentados (Buckley, 2006), atrasando o diagnóstico e melhor direcionamento no tratamento dos doentes e devido aconselhamento genético para as famílias. Investigações sobre as mutações no gene $C F T R$, cuja falha leva à fibrose cística, mostraram que o método dHPLC é altamente preciso, rápido e muito eficiente (Ravnik-Glavac et al., 2002), assim como mostramos neste projeto. Por outro lado, um grupo de pesquisadores avaliou vários métodos de triagem de mutações, entre eles dHPLC e SSCP, pesquisando mutações de todos os tipos, concluindo que todos os métodos eram mensuráveis para este tipo de investigação (Rohlin et al., 2009). O método dHPLC requer um investimento de capital em equipamento. No entanto, uma importante vantagem do dHPLC é que depois destas despesas iniciais, as despesas de funcionamento são baixas. A amplificação do PCR não requer reagentes especiais tais como oligos fluorescentes ou biotinilados ou mesmo radioisótopos, e não são necessárias enzimas ou produtos químicos para a manipulação do pós PCR. Despesas de funcionamento são, portanto, dependentes principalmente do preço da coluna, que tem uma vida média de 5000 análises (O'donovan et al., 1998). Aplicamos este método, tendo como inspiração um trabalho que sugere o método dHPLC como ferramenta de diagnóstico prénatal e que mostrou com sucesso a avaliação do paciente com DGC ligada ao X e mães portadoras, indicando que o método dHPLC, que foi realizado em condições otimizadas, é altamente preciso, rápido e eficiente para detectar tais doenças com herança ligada ao $\mathrm{X}$ (Chien et al., 2003).

Em geral, durante a nossa investigação molecular no gene $C Y B B$, sete diferentes mutações foram elucidadas, sendo quatro delas inéditas na literatura, que interessantemente foram reveladas apenas com o método dHPLC, apresentando a evolução dos estudos, apesar de sua complexidade. O uso do dHPLC para triagem de mutações no gene $C Y B B$ provou ser um método confiável para a detecção de mutações num gene extenso e com heterogeneidade genética. Assim, foi possível resolver com mais clareza e acelerar os casos da DGC, apesar 
dos desafios que o gene complexo como o $C Y B B$, com mais de 500 diferentes casos de mutações descritos na literatura, sendo mais de 200 delas exclusivas de cada família, sendo necessária uma sistemática de estudo e investigação caso a caso, cada uma das famílias. Com este método sensível reduzimos o número de amostras a serem encaminhadas para sequenciamento, fornecendo vantagem na análise do gene $C Y B B$, agilizando o esclarecimento dos casos. Nos pacientes 1 e 2 identificamos a mutação c.688 C>T (exon 7), uma mutação do tipo "nonsense" que resulta num códon de parada prematuro localizado no domínio Nterminal da gp91-phox / R226X. Nos pacientes 3, 4 e 5 identificamos a mutação c.880 C>T (exon 8), uma mutação do tipo "nonsense" que resulta num códon de parada prematuro localizado no domínio FADBR da gp91-phox / R290X. No paciente 6 identificamos uma mutação inédita c.904 InsC (exon 9), uma inserção que causa um "frameshift" que leva a um codon de parada prematuro localizado no domínio FADBR da gp91-phox / T302fsX46. No paciente 7 identificamos uma mutação inédita c.141+5 G> T (intron 2), uma substituição de um nucleotídeo no sítio de "splicing" que resulta na deleção completa do exon 2 nos transcritos maduros da gp91-phox. No paciente 8 identificamos uma mutação inédita c.553 $\mathrm{T}>\mathrm{C}$ ( exon 6), uma mutação do tipo "missense" que resulta em troca simples de aminoácido no domínio N-terminal da gp91-phox / C185R. No paciente 9 identificamos uma mutação inédita c.665 A>T (exon 6), uma mutação tipo "missense" que resulta em troca simples de aminoácido no domínio N-terminal da gp91-phox / H222L. No paciente 10 identificamos uma mutação c.1621 T>C (exon 13), uma mutação do tipo "missense" que resulta em troca simples de aminoácido no domínio N-terminal da gp91-phox / C537R.

Este trabalho evidenciou um elevado risco de falsos negativos durante as investigações moleculares do gene $C Y B B$ quando se utiliza o método SSCP. Esses pacientes foram considerados por nós de difícil conclusão durante as investigações, consumindo muito tempo, e que foi resolvido através da utilização do método dHPLC. Este trabalho mostra a importância do investimento em métodos mais precisos, principalmente na investigação do gene $C Y B B$ na América Latina.

Assim, comparando os resultados encontrados por ambos os métodos de análise, podemos concluir que o método dHPLC foi mais sensível que o método SSCP apresentando $100 \%$ na detecção de alterações, sendo que todas as amostras investigadas foram totalmente e claramente salientadas pelo método dHPLC, ao contrário do SSCP, permitindo-nos identificar as mutações de diferentes tipos ("nonsense", "missense" e "splicing”).

Nossa maior dificuldade foi nos estudos genético-moleculares do gene NCF1. Durante o projeto elucidamos dois casos novos de delGT A47 ${ }^{\circ}$ na forma homozigota (c. 8788 del.GT / 
p.V25fsX51), mutação esta de melhor detecção apesar dos pseudogenes, porém outros dois casos não foram concluídos durante estudos moleculares devido a presença destes pseudogenes. Nestes casos, encontramos indícios de mutações heterozigotas complexas nos exon 2 e 4 do gene $N C F 1$, que não nos permitiu concluir estes casos. Ao contrário do gene $C Y B B$, o método dHPLC não foi bem sucedido nos ensaios de triagem de mutações no gene NCF1 (resultados não apresentados), sendo necessário o uso do método SSCP, utilizado neste projeto, ou mesmo técnicas mais específicas utilizadas por outros grupos, como o método do “gene scan" (Dekker et al., 2001; De Boer et al., 2002; Roos et al., 2006).

Num estudo desenvolvido pelo nosso grupo envolvendo 59 pacientes, dentre eles DGC e não DGC foram definidas algumas diferenças clínicas entre estes pacientes. Foram formados dois grupos de acordo com os resultados dos exames de NBT e/ou Superóxido. O grupo I, com 20 pacientes DGC. O grupo II, com pacientes com história clínica e laboratorial que não confirmaram o diagnóstico de DGC, com 39 pacientes (Prando-Andrade, 2003). Concluímos que os pacientes com diagnóstico bioquímico de DGC apresentam particularidades em seu quadro clínico, e os seguintes fatores apresentaram forte associação com a doença: história familiar positiva, reação vacinal à BCG, manifestações de linfadenite e abscessos hepáticos. Já a presença de infecções do trato urinário foi associada ao grupo no qual o diagnóstico de DGC não foi confirmado (Prando-Andrade, 2003).

Correlações entre manifestações clínicas e mutações têm sido analisadas em pacientes DGC, mas com a conclusão de que não há uma correlação clara entre genética e a clínica, sendo explicado pela alta heterogeneidade de mutações do gene $C Y B B$ (Von Goessel et al., 2006). Nas práticas médicas já se sabe que pacientes DGC com mutações no gene NCF1 apresentam manifestações clínicas mais brandas, mas sem definição clara em gráficos ou valores, através de estudo com análise de dados e comparados a outros pacientes com algum tipo de mutação envolvendo o sistema NADPH oxidase. Propomos neste projeto uma inovadora forma de obter correlação genótipo versus fenótipo clínico, na qual, analisamos todos os dados clínicos dos pacientes DGC com estudo genético concluído, e os separamos por tipos de mutações e ou gene $(C Y B B$ "nonsense", $C Y B B$ "missense", $C Y B B$ "splicing" e NCF1 "nonsense").

Nas análises utilizando o cruzamento de dados no gráfico monocromático gradual, comparando diferentes mutações do gene $C Y B B$, houve menor intensidade na gravidade clínica no grupo com mutação tipo "splicing" (Figura 18). Porém, utilizando análise matemática que indica cada índice de gravidade clínica, estatisticamente não houve diferença entre os grupos de diferentes tipos de mutações no gene $C Y B B$ (Figura 20A), isso mostrou 
melhor refinamento do cálculo que resulta no IGC para cada tipo de mutação envolvida. Além disso, analisando gráficos monocromáticos graduais com cruzamento de dados, mas agora comparando o grupo com mutações no gene $C Y B B$ (ligado ao $\mathrm{X}$ ) e o grupo com mutação no gene $N C F 1$ foi possível identificar visualmente uma diferença entre os grupos, com $N C F 1$ que apresentou menor intensidade de gravidade clínica que CYBB (Figura19). Interessantemente, com a análise matemática que indica o índice de gravidade clínica, estatisticamente esta diferença tornou-se mais evidente, mostrando qualidade neste tipo de análise que correlaciona genótipo e fenótipo clínico dos pacientes DGC (Figura 20B). Além disso, quando analisamos as médias de idade da primeira manifestação clínica e de diagnóstico comparando os grupos, no grupo com mutação no gene $N C F 1$, ambas as médias indicam idades mais tardias (Figure 22). Isso mostra a dificuldade na identificação e conclusão destes casos mais complexos de pacientes DGC devido à clínica mais branda apresentada no grupo com mutações no gene NCF1 indicado pelo IGC e também pelo gráfico monocromático. Em resumo, as análises utilizando gráficos monocromáticos graduais revelam resultados qualitativos desta relação entre genótipo e fenótipo clínico, com uma validade limitada ao visual e totalmente interpretativa dos gráficos. Já as análises utilizando o cálculo desenvolvido por nós para estabelecer um índice de gravidade clínica, revelam resultados quantitativos relativos à gravidade clínica de cada grupo, e que apresentam dados que permitem a estatística, garantindo confiabilidade dos dados.

Sendo assim, acreditamos ser o início de uma inovadora forma de análise que vem completar uma lacuna, estreitando o caminho entre estes dois "mundos" de conhecimento, genética e clínica. Com essa nova proposta de análise, pretendemos ajudar a entender melhor estas correlações, permitindo abordagem clínica mais adequada, quando sabemos detalhes sobre o tipo de mutação do paciente, levando a tratamentos mais eficazes para cada tipo de mutação. Esta nova forma de correlação genótipo versus fenótipo clínico na DGC revela a importância de uma avaliação mais crítica e detalhada dos quadros clínicos associando à genética destes pacientes, mostrando diferenças sutis e também relevantes entre os tipos de mutações quando estudamos melhor a clínica, permitindo tratamentos e diagnósticos "individualizados" e precisos entre os casos.

Durante o encontro do "I Latin American Society of Primary Immunodeficiencies Registry Meeting", foi discutido a proposta de um registro (banco de dados) internacional das imunodeficiências primárias, incluindo DGC, para que instituições cadastradas possam acessar dados clínicos e genéticos de pacientes remotamente. Isso mostra a importância de um banco de dados deste porte, intuindo para uma avaliação mais ampla das imunodeficiências 
primárias, permitindo inúmeras correlações, abrindo novos horizontes de possibilidades para uma nova linha de pesquisa na área clínica-genética.

Apesar de algumas dificuldades técnicas, os estudos evoluíram bem, principalmente nos estudos do gene $C Y B B$ e na nova proposta de avaliação na correlação genótipo-fenótipo clínico, promissor devido à proposta do registro internacional das imunodeficiências primárias, garantindo dados para futuras correlações.

Os resultados provenientes deste projeto pretendem contribuir para o avanço do conhecimento sobre o sistema NADPH oxidase fagocítico humano; para a construção de estratégias que permitam a identificação dos defeitos genético-moleculares relacionados à DGC e, sobretudo no desenvolvimento e diferenciação clínica especializada para cada tipo de mutação na DGC, podendo este modelo ser adaptado para o estudo de outras imunodeficiências. 


\section{CONCLUSÕES}

- O método dHPLC é mais sensível e eficaz na triagem de mutações no gene $C Y B B$, comparado ao método SSCP, permitindo elucidar casos complexos;

- Identificamos 10 (dez) casos de DGC ligado ao X, com 7 (sete) diferentes mutações no gene $C Y B B$, dos quais 4 (quatro) delas são inéditas na literatura;

- Identificamos 2 (dois) casos DGC autossômica com uma mutação comum no gene NCF1;

- Desenvolvemos uma inovadora fórmula para correlacionar genótipo versus fenótipo clínico nos pacientes DGC, demonstrado em gráficos monocromáticos graduais (qualitativo) ou pelo IGC (Índice de Gravidade Clínica / quantitativo).

- O IGC indicou claramente que pacientes com mutações no gene NCF1 apresentam menor gravidade clínica que os pacientes com mutações no gene $C Y B B$. Porém, na comparação entre os diferentes grupos com diferentes tipos de mutações no gene $C Y B B$ não houve diferença estatística significativa. 


\section{REFERÊNCIAS*}

Agudelo-Florez P, Lopez JA, Redher J, Carneiro-Sampaio MM, Costa-Carvalho BT, Grumach AS, Condino-Neto A. The use of reverse transcription-PCR for the diagnosis of Xlinked chronic granulomatous disease. Braz J Med Biol Res. 2004;37:625-34.

Agudelo-Florez P, Navarro S, Luttges P, Lopez JA, Norambuena X, Navarrete SC, Quezada A, Spencer M, Condino-Neto A, Cornejo de M. Report of a new mutation in CYBB gene in two patients with X linked chronic granulomatous disease. Rev Med Chil. 2006;134:965-72.

Agudelo-Florez P, Prando-Andrade CC, Lopez JA, Costa-Carvalho BT, Quezada A, Espinosa FJ, de Souza Paiva MA, Roxo P, Jr., Grumach A, Jacob CA et al. Chronic granulomatous disease in Latin American patients: clinical spectrum and molecular genetics. Pediatr Blood Cancer. 2006;46:243-52.

Altschul SF, Gish W, Miller W, Myers EW, Lipman DJ. Basic local alignment search tool. J Mol Biol. 1990;215:403-10.

Babior BM. NADPH oxidase. Curr Opin Immunol. 2004;16:42-7.

Baehner RL, Kunkel LM, Monaco AP, Haines JL, Conneally PM, Palmer C, Heerema N, Orkin SH. DNA linkage analysis of $\mathrm{X}$ chromosome-linked chronic granulomatous disease. Proc Natl Acad Sci U S A. 1986;83:3398-401.

Barese C, Copelli S, Zandomeni R, Oleastro M, Zelazko M, Rivas EM. X-linked chronic granulomatous disease: first report of mutations in patients of Argentina. J Pediatr Hematol Oncol. 2004;26:656-60.

Barese CN, Copelli SB, De Matteo E, Zandomeni R, Salgueiro F, Di Giovanni D, Heyworth $\mathrm{P}$, Rivas EM. Molecular characterization of a novel splice site mutation within the CYBB gene leading to X-linked chronic granulomatous disease. Pediatr Blood Cancer. 2005;44:4202 .

Bemiller LS, Roberts DH, Starko KM, Curnutte JT. Safety and effectiveness of long-term interferon gamma therapy in patients with chronic granulomatous disease. Blood Cells Mol Dis. 1995;21:239-47.

Berendes H, Bridges RA, Good RA. A fatal granulomatosus of childhood: the clinical study of a new syndrome. Minn Med. 1957;40:309-12.

Boyum A. Isolation of mononuclear cells and granulocytes from human blood. Isolation of monuclear cells by one centrifugation, and of granulocytes by combining centrifugation and sedimentation at 1 g. Scand J Clin Lab Invest. 1968;97:77-89.

\footnotetext{
${ }^{*}$ De acordo com:

International Committee of Medical Journal Editors. Uniform requirements for manuscripts submitted to Biomedical Journal: sample references. Available from: http://www.icmje.org [2007 May 22].
} 
Bridges RA, Berendes H, Good RA. A fatal granulomatous disease of childhood; the clinical, pathological, and laboratory features of a new syndrome. AMA J Dis Child. 1959;97:387-408.

Buckley RH. Primary immunodeficiency or not? Making the correct diagnosis. J Allergy Clin Immunol. 2006;117:756-8.

Casimir CM, Bu-Ghanim HN, Rodaway AR, Bentley DL, Rowe P, Segal AW. Autosomal recessive chronic granulomatous disease caused by deletion at a dinucleotide repeat. Proc Natl Acad Sci U S A. 1991;88:2753-7.

Chien SC, Lee CN, Hung CC, Tsao PN, Su YN, Hsieh FJ. 2003. Rapid prenatal diagnosis of $\mathrm{X}$-linked chronic granulomatous disease using a denaturing high-performance liquid chromatography (DHPLC) system. Prenat Diagn. 2003;23:1092-6.

Clark RA, Malech HL, Gallin JI, Nunoi H, Volpp BD, Pearson DW, Nauseef WM, Curnutte JT. Genetic variants of chronic granulomatous disease: prevalence of deficiencies of two cytosolic components of the NADPH oxidase system. N Engl J Med. 1989;321:647-52.

Condino-neto A, Muscara MN, Bellinati-Pires R, Carneiro-Sampaio MM, Brandao AC, Grumach AS, De Nucci G. Effect of therapy with recombinant human interferon-gamma on the release of nitric oxide by neutrophils and mononuclear cells from patients with chronic granulomatous disease. J Interferon Cytokine Res. 1996;16:357-64.

Condino-Neto A, Muscara MN, Grumach AS, Carneiro-Sampaio MM, De Nucci G. Neutrophils and mononuclear cells from patients with chronic granulomatous disease release nitric oxide. Br J Clin Pharmacol. 1993;35:485-90.

Condino-Neto A e Newburger PE. NADPH oxidase activity and cytochrome b558 content of human Epstein-Barr-virus-transformed B lymphocytes correlate with expression of genes encoding components of the oxidase system. Arch Biochem Biophys. 1998;360:158-64.

Condino-Neto A e Newburger PE. Interferon-gamma improves splicing efficiency of CYBB gene transcripts in an interferon-responsive variant of chronic granulomatous disease due to a splice site consensus region mutation. Blood. 2000;95:3548-54.

Cross AR, Heyworth PG, Rae J, Curnutte JT. A variant X-linked chronic granulomatous disease patient (X91+) with partially functional cytochrome b. J Biol Chem. 1995;270:8194200.

Cross AR, Yarchover JL, Curnutte JT. The superoxide-generating system of human neutrophils possesses a novel diaphorase activity. Evidence for distinct regulation of electron flow within NADPH oxidase by p67-phox and p47-phox. J Biol Chem. 1994;269:21448-54.

Curnutte JT. Classification of chronic granulomatous disease. Hematol Oncol Clin North Am. $1988 ; 2: 241-52$.

Curnutte JT. Chronic granulomatous disease: the solving of a clinical riddle at the molecular level. Clin Immunol Immunopathol, 1993;67: S2-15. 
Curnutte JT, Erickson RW, Ding J, Badwey JA. Reciprocal interactions between protein kinase $\mathrm{C}$ and components of the NADPH oxidase complex may regulate superoxide production by neutrophils stimulated with a phorbol ester. J Biol Chem.1994;269:10813-9.

de Boer M, de Klein A, Hossle JP, Seger R, Corbeel L, Weening RS, Roos D. 1992. Cytochrome b558-negative, autosomal recessive chronic granulomatous disease: two new mutations in the cytochrome b558 light chain of the NADPH oxidase (p22-phox). Am J Hum Genet. 1992;51:1127-35.

de Boer M, Singh V, Dekker J, Di Rocco M, Goldblatt D, Roos D. 2002. Prenatal diagnosis in two families with autosomal, p47(phox)-deficient chronic granulomatous disease due to a novel point mutation in NCF1. Prenat Diagn, 2002;22:235-40.

Dekker J, de Boer M, Roos D. 2001. Gene-scan method for the recognition of carriers and patients with $\mathrm{p} 47$ (phox)-deficient autosomal recessive chronic granulomatous disease. Exp Hematol. 2001;29:1319-25.

Di Matteo G, Giordani L, Finocchi A, Ventura A, Chiriaco M, Blancato J, Sinibaldi C, Plebani A, Soresina A, Pignata C et al. Molecular characterization of a large cohort of patients with Chronic Granulomatous Disease and identification of novel CYBB mutations: an Italian multicenter study. Mol Immunol. 2009;46:1935-41

Dias-Da-Motta P, Arruda VR, Muscara MN, Saad ST, De Nucci G, Costa FF, Condino-Neto A. The release of nitric oxide and superoxide anion by neutrophils and mononuclear cells from patients with sickle cell anaemia. Br J Haematol. 1996;93:333-40.

Dinauer MC, Lekstrom-Himes JA, Dale DC. Inherited Neutrophil Disorders: Molecular Basis and New Therapies. Hematology (Am Soc Hematol Educ Program). 2000; 303-318

Dinauer MC, Pierce EA, Bruns GA, Curnutte JT, Orkin SH. Human neutrophil cytochrome b light chain (p22-phox). Gene structure, chromosomal location, and mutations in cytochromenegative autosomal recessive chronic granulomatous disease. J Clin Invest. 1990;86:1729-37.

Errante PR, Frazao JB, Condino-Neto A. The use of interferon-gamma therapy in chronic granulomatous disease. Recent Pat Antiinfect Drug Discov. 2008;3:225-30.

Ewing B e Green P. Base-calling of automated sequencer traces using phred. II. Error probabilities. Genome Res. 1998;8:186-94.

Ewing B, Hillier L, Wendl MC, Green P. Base-calling of automated sequencer traces using phred. I. Accuracy assessment. Genome Res. 1998;8:175-85.

Forrest CB, Forehand JR, Axtell RA, Roberts RL, Johnston RB, Jr. Clinical features and current management of chronic granulomatous disease. Hematol Oncol Clin North Am. 1988;2:253-66.

Gordon D, Abajian C, Green P. Consed: a graphical tool for sequence finishing. Genome Res, 1998;8:195-202. 
Gorlach A, Lee PL, Roesler J, Hopkins PJ, Christensen B, Green ED, Chanock SJ, Curnutte JT. A p47-phox pseudogene carries the most common mutation causing p47-phox- deficient chronic granulomatous disease. J Clin Invest. 1997;100:1907-18.

Heyworth PG, Cross AR, Curnutte JT. Chronic granulomatous disease. Curr Opin Immunol. 2003; 15:578-84.

Heyworth PG, Curnutte JT, Rae J, Noack D, Roos D, van Koppen E, Cross AR Hematologically important mutations: X-linked chronic granulomatous disease (second update). Blood Cells Mol Dis. 2001;27:16-26.

Heyworth PG, Noack D, Cross AR. Identification of a novel NCF-1 (p47-phox) pseudogene not containing the signature GT deletion: significance for A47 degrees chronic granulomatous disease carrier detection. Blood. 2002;100:1845-51.

Holland SM. Chronic granulomatous disease. Clin Rev Allergy Immunol. 2010;38:3-10.

Holmes B, Page AR, Good RA. Studies of the metabolic activity of leukocytes from patients with a genetic abnormality of phagocytic function. J Clin Invest. 1967;46:1422-32.

Holmes B, Quie PG, Windhorst DB, Good RA. Fatal granulomatous disease of childhood. An inborn abnormality of phagocytic function. Lancet. 1966;1:1225-8.

Horwitz ME, Barrett AJ, Brown MR, Carter CS, Childs R, Gallin JI, Holland SM, Linton GF, Miller JA, Leitman SF et al. Treatment of chronic granulomatous disease with nonmyeloablative conditioning and a T-cell-depleted hematopoietic allograft. N Engl J Med. 2001;344:881-8.

Iwata M, Nunoi H, Yamazaki H, Nakano T, Niwa H, Tsuruta S, Ohga S, Ohmi S, Kanegasaki S, Matsuda I. Homologous dinucleotide (GT or TG) deletion in Japanese patients with chronic granulomatous disease with p47-phox deficiency. Biochem Biophys Res Commun. 1994;199:1372-7.

Johnston-Junior RB. Clinical aspects of chronic granulomatous disease. Curr Opin Hematol, 2001;8:17-22.

Jurkowska M, Bernatowska E, Bal J. Genetic and biochemical background of chronic granulomatous disease. Arch Immunol Ther Exp (Warsz). 2004;52:113-20.

Kamani N, August CS, Campbell DE, Hassan NF, Douglas SD. Marrow transplantation in chronic granulomatous disease: an update, with 6-year follow-up. J Pediatr. 1988;113:697700 .

Kang EM e Malech HL. Advances in treatment for chronic granulomatous disease. Immunol Res. 2009;43:77-84.

Landing BH e Shirkey HS. A syndrome of recurrent infection and infiltration of viscera by pigmented lipid histiocytes. Pediatrics, 1957;20:431-8. 
Lew PD, Southwick FS, Stossel TP, Whitin JC, Simons E, Cohen HJ. A variant of chronic granulomatous disease: deficient oxidative metabolism due to a low-affinity NADPH oxidase. N Engl J Med. 1981;305:1329-33.

Lewis EM, Singla M, Sergeant S, Koty PP, McPhail LC. X-linked chronic granulomatous disease secondary to skewed $\mathrm{X}$ chromosome inactivation in a female with a novel CYBB mutation and late presentation. Clin Immunol. 2008;129:372-80.

Liu Q, Feng J, Sommer SS. Bi-directional dideoxy fingerprinting (Bi-ddF): a rapid method for quantitative detection of mutations in genomic regions of 300-600 bp. Hum Mol Genet. 1996;5:107-14.

Marciano BE, Wesley R, De Carlo ES, Anderson VL, Barnhart LA, Darnell D, Malech HL, Gallin JI, Holland SM. Long-term interferon-gamma therapy for patients with chronic granulomatous disease. Clin Infect Dis. 2004;39:692-9.

Margolis DM, Melnick DA, Alling DW, Gallin JI. Trimethoprim-sulfamethoxazole prophylaxis in the management of chronic granulomatous disease. J Infect Dis. 1990;162:7236.

Martire B, Rondelli R, Soresina A, Pignata C, Broccoletti T, Finocchi A, Rossi P, Gattorno M, Rabusin M, Azzari C et al. Clinical features, long-term follow-up and outcome of a large cohort of patients with Chronic Granulomatous Disease: an Italian multicenter study. Clin Immunol. 2008;126:-64.

Matute JD, Arias AA, Wright NA, Wrobel I, Waterhouse CC, Li XJ, Marchal CC, Stull ND, Lewis DB, Steele M et al. A new genetic subgroup of chronic granulomatous disease with autosomal recessive mutations in 40 phox and selective defects in neutrophil NADPH oxidase activity. Blood. 2009;114:3309-15.

Mccord JM e Fridovich I. Superoxide dismutase. An enzymic function for erythrocuprein (hemocuprein). J Biol Chem. 1969a;244:6049-55.

Mccord JM e Fridovich I. The utility of superoxide dismutase in studying free radical reactions. I. Radicals generated by the interaction of sulfite, dimethyl sulfoxide, and oxygen. $\mathrm{J}$ Biol Chem. 1969b;244:6056-63.

Movahedi M, Aghamohammadi A, Rezaei N, Farhoudi A, Pourpak Z, Moin M, Gharagozlou M, Mansouri D, Arshi S, Atarod L et al. Gastrointestinal manifestations of patients with chronic granulomatous disease. Iran J Allergy Asthma Immunol. 2004;3:83-7.

Newburger PE, Luscinskas FW, Ryan T, Beard CJ, Wright J, Platt OS, Simons ER, Tauber AI. Variant chronic granulomatous disease: modulation of the neutrophil defect by severe infection. Blood. 1986;68:914-9.

Nilsson K, Klein G, Henle W, Henle G. The establishment of lymphoblastoid lines from adult and fetal human lymphoid tissue and its dependence on EBV. Int J Cancer. 1971;8:443-50.

Noack D, Rae J, Cross AR, Ellis BA, Newburger PE, Curnutte JT, Heyworth PG. Autosomal recessive chronic granulomatous disease caused by defects in NCF-1, the gene encoding the 
phagocyte p47-phox: mutations not arising in the NCF-1 pseudogenes. Blood. 2001;97:30511.

Ochs HD e Igo RP. The NBT slide test: a simple screening method for detecting chronic granulomatous disease and female carriers. J Pediatr. 1973;83:77-82.

O'Donovan MC, Oefner PJ, Roberts SC, Austin J, Hoogendoorn B, Guy C, Speight G, Upadhyaya M, Sommer SS, McGuffin P. Blind analysis of denaturing high-performance liquid chromatography as a tool for mutation detection. Genomics. 1998;52:44-9.

Oh HB, Park JS, Lee W, Yoo SJ, Yang JH, Oh SY. Molecular analysis of X-linked chronic granulomatous disease in five unrelated Korean patients. J Korean Med Sci. 2004;19:218-22.

Oliveira-Júnior EB, Prando C, Alvaro Lopez J, Arango JC, Buzolin M, Rehder J, Formighier E, Pedroza LA, Frazão JB, Dantas VM, Costa-Carvalho BT, Grumach AS, Bustamante J, Condino-Neto A. DHPLC is more Effective than SSCP for Screening Mutations in CYBB gene: Report of Four New Mutations Leading to X-Linked Chronic Granulomatous Disease. Human Mutation. In press.

Parkos CA, Dinauer MC, Walker LE, Allen RA, Jesaitis AJ, Orkin SH. Primary structure and unique expression of the 22-kilodalton light chain of human neutrophil cytochrome b. Proc Natl Acad Sci U S A. 1988;85:3319-23.

Patino PJ, Perez JE, Lopez JA, Condino-Neto A, Grumach AS, Botero JH, Curnutte JT, Garcia de Olarte D. Molecular analysis of chronic granulomatous disease caused by defects in gp91-phox. Hum Mutat. 1999;13:29-37.

Patino PJ, Rae J, Noack D, Erickson R, Ding J, de Olarte DG, Curnutte JT. Molecular characterization of autosomal recessive chronic granulomatous disease caused by a defect of the nicotinamide adenine dinucleotide phosphate (reduced form) oxidase component p67phox. Blood. 1999;94:2505-14.

Prando-Andrade C, Agudelo-Florez P, Lopez JA, Paiva MA, Costa-Carvalho BT, CondinoNeto A. Autosomal chronic granulomatous disease: case report and mutation analysis of two Brazilian siblings. J Pediatr (Rio J). 2004;80:425-8.

Prando-Andrade C, Grumach A, Condino-Neto A. Aspectos Clínicos de Pacientes Sob Suspeita de Imunodeficiência Fagocitária. [Dissertação (Mestrado em saúde da criança e do adolescente)] São Paulo (Brasil): Faculdade de Ciências Médicas da Universidade Estadual de Campinas; 2003.

Rae J, Newburger PE, Dinauer MC, Noack D, Hopkins PJ, Kuruto R, Curnutte JT. X-Linked chronic granulomatous disease: mutations in the CYBB gene encoding the gp91-phox component of respiratory-burst oxidase. Am J Hum Genet. 1998;62:1320-31.

Ravnik-Glavac M, Atkinson A, Glavac D, Dean M. DHPLC screening of cystic fibrosis gene mutations. Hum Mutat. 2002;19:374-83. 
Ravnik-Glavac M, Glavac D, Dean M. Sensitivity of single-strand conformation polymorphism and heteroduplex method for mutation detection in the cystic fibrosis gene. Hum Mol Genet. 1994;3:801-7.

Rohlin A, Wernersson J, Engwall Y, Wiklund L, Bjork J, Nordling M. Parallel sequencing used in detection of mosaic mutations: comparison with four diagnostic DNA screening techniques. Hum Mutat. 2009;30:1012-20.

Roos D, de Boer M, Koker MY, Dekker J, Singh-Gupta V, Ahlin A, Palmblad J, Sanal O, Kurenko-Deptuch M, Jolles $\mathrm{S}$ et al. Chronic granulomatous disease caused by mutations other than the common GT deletion in NCF1, the gene encoding the p47phox component of the phagocyte NADPH oxidase. Hum Mutat. 2006;27:1218-29.

Roos D, de Boer M, Kuribayashi F, Meischl C, Weening RS, Segal AW, Ahlin A, Nemet K, Hossle JP, Bernatowska-Matuszkiewicz E et al. Mutations in the X-linked and autosomal recessive forms of chronic granulomatous disease. Blood. 1996;87:1663-81.

Rothe G, Oser A, Valet G. Dihydrorhodamine 123: a new flow cytometric indicator for respiratory burst activity in neutrophil granulocytes. Naturwissenschaften. 1988;75:354-5.

Segal BH e Holland SM. Primary phagocytic disorders of childhood. Pediatr Clin North Am. 2000;47:1311-38.

Segal BH, Leto TL, Gallin JI, Malech HL, Holland SM. Genetic, biochemical, and clinical features of chronic granulomatous disease. Medicine (Baltimore), 2000;79:170-200.

Segal BH, Sakamoto N, Patel M, Maemura K, Klein AS, Holland SM, Bulkley GB. Xanthine oxidase contributes to host defense against Burkholderia cepacia in the p47(phox-/-) mouse model of chronic granulomatous disease. Infect Immun. 2000;68:2374-8.

Segal ML, Fertel RH, Kraut EH, Sagone AL. The role of reactive oxygen species in thromboxane b2 generation by polymorphonuclear leukocytes. J Lab Clin Med. 1983;102:788-94.

Seger RA. Modern management of chronic granulomatous disease. $\mathrm{Br} \mathrm{J}$ Haematol. 2008;140:255-66.

Seger RA, Gungor T, Belohradsky BH, Blanche S, Bordigoni P, Di Bartolomeo P, Flood T, Landais $\mathrm{P}$, Muller S, Ozsahin $\mathrm{H}$ et al. Treatment of chronic granulomatous disease with myeloablative conditioning and an unmodified hemopoietic allograft: a survey of the European experience, 1985-2000. Blood. 2002;100:4344-50.

Soncini E, Slatter MA, Jones LB, Hughes S, Hodges S, Flood TJ, Barge D, Spickett GP, Jackson GH, Collin MP et al. Unrelated donor and HLA-identical sibling haematopoietic stem cell transplantation cure chronic granulomatous disease with good long-term outcome and growth. Br J Haematol. 2009;145:73-83.

Stasia MJ e Li XJ. Genetics and immunopathology of chronic granulomatous disease. Semin Immunopathol. 2008;30:209-35. 
Tauber AI, Borregaard N, Simons E, Wright J. Chronic granulomatous disease: a syndrome of phagocyte oxidase deficiencies. Medicine (Baltimore). 1983;62:286-309.

Vazquez N, Lehrnbecher T, Chen R, Christensen BL, Gallin JI, Malech H, Holland S, Zhu S, Chanock SJ. Mutational analysis of patients with p47-phox-deficient chronic granulomatous disease: The significance of recombination events between the p47-phox gene (NCF1) and its highly homologous pseudogenes. Exp Hematol. 2001;29:234-43.

Volkman DJ, Buescher ES, Gallin JI, Fauci AS. B cell lines as models for inherited phagocytic diseases: abnormal superoxide generation in chronic granulomatous disease and giant granules in Chediak-Higashi syndrome. J Immunol. 1984;133:3006-9.

Volpp BD e Lin Y. In vitro molecular reconstitution of the respiratory burst in B lymphoblasts from p47-phox-deficient chronic granulomatous disease. J Clin Invest, 1993;91:201-7.

von Goessel H, Hossle JP, Seger R, Gungor T. Characterization of 17 new cases of X-linked chronic granulomatous disease with seven novel mutations in the CYBB gene. Exp Hematol. 2006;34:528-35.

Weening RS, Adriaansz LH, Weemaes CM, Lutter R, Roos D. Clinical differences in chronic granulomatous disease in patients with cytochrome b-negative or cytochrome b-positive neutrophils. J Pediatr, 1985;107:102-4.

Winkelstein JA, Marino MC, Johnston RB, Jr., Boyle J, Curnutte J, Gallin JI, Malech HL, Holland SM, Ochs H, Quie P et al. Chronic granulomatous disease. Report on a national registry of 368 patients. Medicine (Baltimore). 2000;79:155-69.

Xiao W e Oefner PJ. Denaturing high-performance liquid chromatography: A review. Hum Mutat. 2001;17:439-74.

Xiao W, Stern D, Jain M, Huber CG, Oefner PJ. Multiplex capillary denaturing highperformance liquid chromatography with laser-induced fluorescence detection. Biotechniques. 2001;30:1332-8. 


\section{ANEXOS}

\section{ANEXO A - Artigo no prelo (Olveira-Júnior, EB)}

\section{DHPLC is more Effective than SSCP for Screening Mutations in CYBB gene: Report of Four New Mutations Leading to X-Linked Chronic Granulomatous Disease}

Edgar Borges de Oliveira-Júnior ${ }^{1}$; Carolina Cardoso de Mello Prando ${ }^{4}$; Juan Alvaro Lopez ${ }^{3}$; Julian Camilo Arango ${ }^{3}$ :Márcia Buzolin ${ }^{2}$; Jussara Rehder ${ }^{2}$; Eduardo Formighier ${ }^{2}$; Luis Alberto Pedrozal ; Josias Brito Frazão ${ }^{l}$; Vera Maria Dantas ${ }^{9}$; Beatriz Tavarez. CostaCarvalho $^{5}$; Anete Sevciovic Grumach ${ }^{6 ;}$ Pérsio Roxo-Júnior ${ }^{10}$; Jacinta Bustamante ${ }^{7,8}$; Antonio Condino-Neto ${ }^{1}$

1 - Department of Immunology, Institute of Biomedical Sciences, University of Sao Paulo-SP, Brazil 2 - Center for Investigation in Pediatrics, State University of Campinas Medical School, Campinas-SP, Brazil, 3 - Department of Immunology, University of Antioquia Medical School, Medellín, Colombia, 4 - Laboratory of Human Genetics of Infectious Diseases, Rockefeller Branch, The Rockefeller University, New York-NY, USA, 5- Division of Allergy, Immunology, and Rheumatology, Department of Pediatrics, Federal University of Sao Paulo Medical School, Sao Paulo - SP, Brazil; 6- Department of Dermatology, University of Sao Paulo Medical School, Sao Paulo - SP, Brazil; 7- Laboratory of Human Genetics of Infectious Diseases, Necker Branch, Institut National de la Santé et de la Recherche Médicale, U550, Paris, France, EU; 8- Paris René Descartes University, Necker Medical School, Paris, France, EU; 9- Hospital of Pediatrics Federal University of Rio Grande do Norte; 10- University of Medicine of Ribeirão Preto - University of São Paulo-SP, Brazil.

\section{KEY WORDS: CYBB gene; SSCP; dHPLC; Screening mutation; Novel Mutations}

*Corresponding to Antonio Condino-Neto, MD, PhD; Department of Immunology - Institute of Biomedical Sciences; University of São Paulo; Brazil

E-mail: condino@icb.usp.br 
ABSTRACT: Chronic granulomatous disease (CGD) is a primary immunodeficiency characterized by early onset of recurrent and severe infections, affecting the body barriers. In these patients, phagocytes present a failure in the respiratory burst characterized by the total absence or low levels of reactive oxygen species production caused by a deficiency of the NADPH oxidase system, and a severe microbicidal defect. Mutations affecting one of the components of the NADPH oxidase system lead to CGD. The most frequent is the X-linked form due to mutations in gp91phox (NOX2), encoded by $C Y B B$ gene. SSCP is a method for screening mutations widely used in investigating the $C Y B B$ gene, mostly in Latin America due to its low cost. dHPLC is a method that has been described and used for detection of mutations in PCR products high-performance liquid chromatography under partially denaturing conditions. We compared the efficacy of dHPLC (denaturing high-performance liquid chromatography) and SSCP (Single Strand Conformation Polymorphism) for screening mutations in $C Y B B$ gene in 12 patients with $\mathrm{X}$-linked chronic granulomatous disease (CGD). We found seven different mutations, four of which are original. Interestingly, the four novel mutations were identified only by dHPLC screening. Both methods detected the following alterations: R226X and R290X CYBB mutations. However, the novel mutations T302fsX46, $141+5 \mathrm{G}>\mathrm{T}, \mathrm{C} 185 \mathrm{R}$ and H222L, were only detected by dHPLC. We concluded that dHPLC revealed the high sensitivity and proved to be a reliable method for screening mutations and polymorphisms in an extensive gene and with a lot of genetic heterogeneity, as it happens in the $C Y B B$ gene. 


\section{Introduction}

Chronic granulomatous disease (CGD) is a primary immunodeficiency characterized by early onset of recurrent and severe infections, affecting the body barriers such as lymph nodes, lungs, intestine and eventually deep structures including bones, liver, spleen and other organs. In these patients, phagocytes present a failure in the respiratory burst characterized by the total absence or low levels of reactive oxygen species production caused by a deficiency of the NADPH (Nicotinamide adenine dinucleotide phosphate) oxidase system, and a severe microbicidal defect. The most frequent pathogens are Staphylococcus aureus, Burkholderia capacia, Aspergillus fumigates. (Martire, et al., 2008; Winkelstein, et al., 2000). A method called denaturing high-performance liquid chromatography (dHPLC) has been described elsewhere (O'Donovan, et al., 1998; Underhill, et al., 1997), in brief, depends upon the detection of heteroduplexes in PCR products by ion-pair reversephase high-performance liquid chromatography under partially denaturing conditions. When the PCR amplicon does not contain a mutation, the sense strand and the anti-sense strand of the PCR amplicons are completely complementary to each other. In this case, the molecule is referred to as a homoduplex. When a patient is heterozygous for a mutation, the mutant sense and antisense strands will not only form a homoduplex, but also heteroduplex with their corresponding wild type sense and anti-sense strands upon re-naturation of the denatured PCR product. The physicochemical difference between a homoduplex and heteroduplex can be detected by HPLC using a reversed-phase chromatography column. The differential retention of homoduplex and heteroduplex DNA on the column after partial denaturation indicates the presence of a mutation. The temperature of the column determines sensitivity, and the optimal temperature is predicted by a mathematical formula based on the amplicon sequence; the output of this formula can be calculated using a computer program. Single-nucleotide 
substitutions, deletions, and insertions have been successfully detected within 5-6 min using on-line UV or fluorescence monitoring. Numerous articles have been published describing the successful use of this method to detect mutations in various diseases including CGD (Bagwell, et al., 2004; Balogh, et al., 2004; Biggin, et al., 2005; Chien, et al., 2003; Di Matteo, et al., 2009; Flanagan, et al., 2004; Lam, 2002; Ravnik-Glavac, et al., 2002).

Mutations affecting one of the components of the NADPH oxidase system lead to CGD. The most frequent is the X-linked form (OMIM 306400; 60\% of the cases) due to mutations in gp91phox (NOX2), encoded by $C Y B B$ gene. This gene spans approximately $30 \mathrm{kB}$ in the human genomic DNA and presents 13 exons (Royer-Pokora, et al., 1986). This gene subject to a strong genetic heterogeneity, 380 different mutations was already described in this gene (Heyworth, et al., 2001; Rae, et al., 1998). Considering the size and genetic heterogeneity affecting $C Y B B$, screening of X-linked CGD may be frequently complex and troublesome. In this paper we compared the efficacy of dHPLC and SSCP for the initial screening of $C Y B B$ mutations in 12 CGD cases. 


\section{Materials and Methods}

\section{Patients}

We selected 10 patients with suspected X-linked CGD evaluated by clinical phenotype (Table I) and three diagnostic tests showing defective phagocyte respiratory burst function: NBT test, a quantitative assay based on the reduction of "nitro blue tetrazolium" by superoxide (Ochs and Igo, 1973); Cytocrome c reduction test, a qualitative assay which is reduced directly by superoxide and measured by spectrophotometry as previously described (McCord and Fridovich, 1969) and modified by Condino-Neto et al. (Condino-Neto, et al., 1996; Condino-Neto, et al., 1993); and DHR test measuring $\mathrm{H}_{2} \mathrm{O}_{2}$ by Cytometry (Rothe, et al., 1988). Because these patients are males, and NBT tests revealing carrier mothers, which indicated $\mathrm{X}$-linked inheritance, we suggest direct investigation of the $C Y B B$ gene. These patients were sent to molecular investigation using two different tests for screening mutations, SSCP and dHPLC. In this study we have included as controls two patients with previously defined mutations in the $C Y B B$ gene.

This study was approved by the Ethics Committee of Institute of Biomedical Sciences, University of São Paulo, according to the Helsinki Convention, and the Ministry of Health in Brazil. 


\section{RNA and DNA isolation for PCR}

All DNA samples were extracted from peripheral whole blood using a Puregene DNA Isolation Kit (Gentra Systems, Inc., Minneapolis, MN, USA) according to the manufacturer's instructions. PCR techniques for the DNA fragments provided were performed in a total volume of $50 \mu \mathrm{L}$ containing $50 \mathrm{ng}$ of genomic DNA, $0.3 \mu \mathrm{M}$ of each primer, $250 \mu \mathrm{M} \mathrm{dNTPs}$, 0.5 units of Taq DNA polymerase enzyme recombinant, and $2.5 \mu \mathrm{L}$ of $10 \mathrm{x}$ buffer PCR (10 $\mathrm{mM}$ tris- $\mathrm{HCl}, \mathrm{pH}=8.3,50 \mathrm{mM} \mathrm{KCl}$ ), in $2 \mathrm{mM} \mathrm{MgCl}_{2}$ as provided by the manufacturer. Amplification was performed in a multiblock system thermocycler (Applied Biosystems GeneAmp® PCR System 9100). PCR amplification was performed with an initial denaturation step at $95^{\circ} \mathrm{C}$ for $3 \mathrm{~min}$, followed by 30 cycles consisting of denaturation at $95^{\circ}$ $\mathrm{C}$ for $30 \mathrm{sec}$., annealing at $56^{\circ} \mathrm{C}-60{ }^{\circ} \mathrm{C}$ for $45 \mathrm{sec}$, and extension at $72^{\circ} \mathrm{C}$ for $1 \mathrm{~min}$. , and then a final extension step at $72^{\circ} \mathrm{C}$ for $10 \mathrm{~min}$. We used 13 pairs of primers, one for each exon of the gene $C Y B B$ introns flanking the edges (Table II). Total mRNA was extracted with reagent TRIZOL® (Invitrogem) following instructions of the manufacture. The samples were conserved to $-80^{\circ} \mathrm{C}$ until your use. The cDNA was obtained being used the kit SuperScript III® RT (Invitrogem), following the manufacturer's instructions. For the PCR assay we used one pair of oligos (Exons 1-5 Fwd.: 5 ' - T GAG GGG CTC TCC ATT TTT GTC TO-3 ' / Rev.: 5 ' - AG TTC AGA GAG TGC TAC TGA TIES -3).

\section{SSCP Analysis}

A total of $30 \mu$ PCR reaction was mixed with formamide dye solution (98\% formamide, $20 \mathrm{~mm}$ ethylene diamine tetra-acetic acid (EDTA), Cyanole xylene $0.05 \%$ and $0.05 \%$ bromophenol blue). Samples were heated to $98^{\circ} \mathrm{C}$ for 8 minutes and immediately set on ice. 
Electrophoretic separation was performed using the system kits (Bio Rad - Mini TransferBlot ${ }^{\circledR}$ Eletrophoretic Transfer Cell) and using a polyacrylamide gel of $10 \%$. A total of $20 \mu 1$ of each sample was applied on the gel ran at $200 \mathrm{~V}$ for $5 \mathrm{~h}$ to $2 \mathrm{~h} 30 \mathrm{~min}$ depending on the exon studied. After SYBR® Gold nucleic acid gel stain (Invitrogem® ${ }^{\circledR}$ S11494) was used to visualize the DNA fragments and as negative control undenatured samples were used.

\section{dHPLC Analysis}

For dHPLC screening test we used the Transgenomic Wave Nucleic Acid Fragment Analysis System (Transgenomic Inc., San Jose, CA, USA), a heteroduplexes analysis. A denaturing high-performance liquid chromatography was carried out on automated HPLC instrument equipped with a DNASep column (Transgenomic Inc., San Jose, CA, USA). Each PCR product ( $15 \mathrm{ul}$ ) was denatured for $8 \mathrm{~min}$ at $95^{\circ} \mathrm{C}$ and followed by gradual re-annealing from room temperature over a period of 40 min prior to analysis. PCR products were injected into a pre-heated column and separated at a flow rate of $1.5 \mathrm{ml} / \mathrm{min}$ through a $2 \%$ linear acetonitrile gradient. The elution buffer consisted of buffer A, 0.1M triethylammonium acetate (TEAA, Transgenomic Inc., Crewe, UK), and buffer B, 0.1M TEAA with 25\% acetonitrile, and the gradient slope was an increase of $2 \%$ of buffer B per min. The oven temperatures for optimal heteroduplex separation were determined using Wavemaker software (Transgenomic), which gives a computer-assisted determination of melting profile and analytical conditions for each fragment. A volume of $5 \mu 1$ was injected for analysis of each PCR run. HD fragments can be observed as separate peaks or as a shoulder on the leading edge of homoduplex peaks, or as broader peaks than the wt DNA peak. The analysis of an individual sample took 8 min, including regeneration and equilibration of the column after each analysis. We use the same samples of PCR product used in SSCP. 


\section{Sequencing}

PCR products were purified by solid-phase extraction, and bidirectionally sequenced using the Applied Biosystems Taq DyeDeoxy terminator cycle sequencing kit (Applied Biosystems, Foster City, CA) according to the manufacturer's instructions. Sequencing reactions were separated on an Applied Biosystems 3100 sequencer.

\section{Results}

We investigated a total of 12 cases of patients with clinical and Biochemical diagnosis of CGD. We used two different techniques for initial screening in the search for mutations, SSCP and dHPLC (Table III). We show 7 different mutations, 4 of which are original in the literature. Interestingly, the 4 novel mutations were identified only by dHPLC method, revealing the high sensitivity of this technique. During the molecular investigation, we found by both techniques the following mutations: c.688 C>T R226X (exon 7), a nonsense mutation in patients 1 and 2 (Figure 1) and c.880 C>T R290X (exon 8), a nonsense mutation in patients 3, 4 and 5 (Figure 2). Furtheremore, we found four novel mutations in the $C Y B B$ gene: c.904 InsC / T302fsX46 (exon 9), a insertion (frameshift) mutation in patient 6 (Figure 3); c.141 +5 G> T (intron 2), a splice site substitution in patient 7 (Figure 4); c.553 T> C / C185R ( exon 6), a missense substitution in patient 8 (Figure 5) and c.665 A> T / H222L (exon 6), a missense substitution in patient 9 (Figure 6) c.1621 T>C / C537R (exon 13), a missense substitution in patient 10 (Figure 7) that generates a substitution of amino acids (C537R) in an area totally conserved among all the analyzed species (Figure 7C), only dHPLC technique could reveal these mutations. We also performed an analysis by dHPLC investigating two CGD cases confirmed by our group and collaborators using SSCP, patient 11 (exon 3) - c.229 
C>T / R73X (Agudelo-Florez, et al., 2006) and patient 12 (exon 5) - c. 481 C>T / R157X (Patino, et al., 1999), which served as our positive controls during the standardization of dHPLC, validating this technique for $C Y B B$ gene analysis (Figure 8). We complemented our molecular analysis of patient 7 with the transcripts analysis (cDNA amplified) by electrophoresis gel and sequencing of those fragment, because of the mutation characteristics (intron border), culminating in the complete deletion of exon 2 in the transcript (Figure 4D). The phylogenetic comparison among species (gp91phox), a missense substitution that affects the patient 8 generates an amino acid exchange in a semi-conserved among species in general, but is highly conserved between mammals (Figure 5D). The missense substitution that affects the patient 9 generates an exchange of amino acid in a highly conserved region (Figure 6D).

\section{Discussion}

Over the last 10 years, the method of screening mutations, dHPLC, has been discussed and appreciated by many research groups for their sensitivity and accuracy in detecting mutations around 96 to $100 \%$. While some work shows that the SSCP offers precision of $85 \%$ (Ravnik-Glavac, et al., 1994), or even 50\% (Liu, et al., 1996). An aggravating circumstance in the use of the SSCP, one of the main techniques used for screening mutations in Latin America nowadays, are false-negative results (Buckley, 2006), delaying diagnosis and better treatment of patients and genetic counseling for families. An investigation about mutations in the CFTR gene responsible for cystic fibrosis showed that dHPLC is highly accurate, fast and very efficient (Ravnik-Glavac, et al., 2002). On the other hand, a group of researchers evaluated several methods for screening mutations, among them dHPLC and SSCP to search mutations of all type, concluding that all methods were measurable for this type of research (Rohlin, et al., 2009). dHPLC requires a capital investment in equipment. However, an 
important advantage of dHPLC is that after capital expenditure, the running costs are low. PCR amplification requires no special reagents such as fluorescent or biotinylated primers or radioisotopes, and aren't required enzymes or chemicals for post-PCR manipulation. Running costs are therefore dependent mainly upon the price of the column, which has an average lifetime of 5,000 analyses (O'Donovan, et al., 1998). We accomplished this method, having as inspiration a published work that suggests dHPLC as tool of prenatal diagnosis, and shows with success the evaluation of patient CGD-X and carrier mothers, indicating that the dHPLC method, which was carried out under optimized conditions, is a highly accurate, rapid, and efficient technique for detecting such inherited X-linked disease (Chien, et al., 2003).

In general, during our molecular investigation on $C Y B B$ gene, seven different mutations were elucidated, being four of them unpublished in the literature revealed only with the dHPLC, showing evolution in the studies, in spite of your complexity (Table III). The use of the dHPLC for screening mutations proved to be a reliable method in the detection of mutations in an extensive gene and with genetic heterogeneity, $C Y B B$ gene. Thus, was possible to resolve with more clarity and speed the CGD cases in spite the challenges that the $C Y B B$ gene submits us by being an extensive and complex gene with more than 400 cases of different already described mutations in the literature, and 300 of them are exclusive, being necessary to study in each case, each one of the families. We used a sensitive method and we reduced the number of samples to be sequenced, providing advantage in the analysis of the $C Y B B$ gene.

We can conclude that in this work we demonstrated that there is a high risk of falsenegative during molecular investigations in the $C Y B B$ gene using the $\mathrm{SSCP}$, these patients were considered by us of difficult conclusion during investigations, consuming a long time, and which was resolved through the use of dHPLC method. This work shows the importance of investment in more refined methods mainly in research of gene $C Y B B$ in Latin America, 
alerting to the cases of difficult conclusion and that leads to false negatives during molecular investigations using SSCP. We implement the dHPLC method in our lab, with this we found new cases and mutations which allowed genetic counseling to families and publication of these new genetic defects.

Thus, comparing the results found by both screening methods, we can conclude that the dHPLC was more sensitive than SSCP (Figure 1-7, A and B) showing be 100\% secure, being all samples investigated have been fully and clearly highlighted by method dHPLC, unlike SSCP, allowing us to identify mutations of different types, such as nonsense, missense, insertion and splice site mutations.

\section{Acknowledgments}

The authors thank FAPESP and CNPq for financial support and the patients and their families for their participation in the study.

\section{References}

Agudelo-Florez P, Prando-Andrade CC, Lopez JA, Costa-Carvalho BT, Quezada A, Espinosa FJ, de Souza Paiva MA, Roxo P, Jr., Grumach A, Jacob CA and others. 2006. Chronic granulomatous disease in Latin American patients: clinical spectrum and molecular genetics. Pediatr Blood Cancer 46(2):243-52.

Bagwell AM, Bailly A, Mychaleckyj JC, Freedman BI, Bowden DW. 2004. Comparative genomic analysis of the HNF-4alpha transcription factor gene. Mol Genet Metab 81(2):112-21.

Balogh K, Patocs A, Majnik J, Racz K, Hunyady L. 2004. Genetic screening methods for the detection of mutations responsible for multiple endocrine neoplasia type 1. Mol Genet Metab 83(1-2):74-81.

Biggin A, Henke R, Bennetts B, Thorburn DR, Christodoulou J. 2005. Mutation screening of the mitochondrial genome using denaturing high-performance liquid chromatography. Mol Genet Metab 84(1):61-74.

Buckley RH. 2006. Primary immunodeficiency or not? Making the correct diagnosis. J Allergy Clin Immunol 117(4):756-8. 
Chien SC, Lee CN, Hung CC, Tsao PN, Su YN, Hsieh FJ. 2003. Rapid prenatal diagnosis of $\mathrm{X}$-linked chronic granulomatous disease using a denaturing high-performance liquid chromatography (dHPLC) system. Prenat Diagn 23(13):1092-6.

Condino-neto A, Muscara MN, Bellinati-Pires R, Carneiro-Sampaio MM, Brandao AC, Grumach AS, De Nucci G. 1996. Effect of therapy with recombinant human interferon-gamma on the release of nitric oxide by neutrophils and mononuclear cells from patients with chronic granulomatous disease. J Interferon Cytokine Res 16(5):357-64.

Condino-Neto A, Muscara MN, Grumach AS, Carneiro-Sampaio MM, De Nucci G. 1993. Neutrophils and mononuclear cells from patients with chronic granulomatous disease release nitric oxide. Br J Clin Pharmacol 35(5):485-90.

Di Matteo G, Giordani L, Finocchi A, Ventura A, Chiriaco M, Blancato J, Sinibaldi C, Plebani A, Soresina A, Pignata C and others. 2009. Molecular characterization of a large cohort of patients with Chronic Granulomatous Disease and identification of novel CYBB mutations: an Italian multicenter study. Mol Immunol 46(10):1935-41.

Flanagan JM, Tighe O, C ON, Naughten E, Mayne PD, Croke DT. 2004. Identification of sequence variation in the galactose-1-phosphate uridyl transferase gene by dHPLC. Mol Genet Metab 81(2):133-6.

Heyworth PG, Curnutte JT, Rae J, Noack D, Roos D, van Koppen E, Cross AR. 2001. Hematologically important mutations: X-linked chronic granulomatous disease (second update). Blood Cells Mol Dis 27(1):16-26.

Lam CW. 2002. First application of denaturing high-performance liquid chromatography (dHPLC) for prenatal diagnosis of genetic disease. Prenat Diagn 22(1):79-80.

Liu Q, Feng J, Sommer SS. 1996. Bi-directional dideoxy fingerprinting (Bi-ddF): a rapid method for quantitative detection of mutations in genomic regions of 300-600 bp. Hum Mol Genet 5(1):107-14.

Martire B, Rondelli R, Soresina A, Pignata C, Broccoletti T, Finocchi A, Rossi P, Gattorno M, Rabusin M, Azzari C and others. 2008. Clinical features, long-term follow-up and outcome of a large cohort of patients with Chronic Granulomatous Disease: an Italian multicenter study. Clin Immunol 126(2):155-64.

McCord JM, Fridovich I. 1969. The utility of superoxide dismutase in studying free radical reactions. I. Radicals generated by the interaction of sulfite, dimethyl sulfoxide, and oxygen. J Biol Chem 244(22):6056-63.

Ochs HD, Igo RP. 1973. The NBT slide test: a simple screening method for detecting chronic granulomatous disease and female carriers. J Pediatr 83(1):77-82.

O'Donovan MC, Oefner PJ, Roberts SC, Austin J, Hoogendoorn B, Guy C, Speight G, Upadhyaya M, Sommer SS, McGuffin P. 1998. Blind analysis of denaturing highperformance liquid chromatography as a tool for mutation detection. Genomics 52(1):44-9.

Patino PJ, Perez JE, Lopez JA, Condino-Neto A, Grumach AS, Botero JH, Curnutte JT, Garcia de Olarte D. 1999. Molecular analysis of chronic granulomatous disease caused by defects in gp91-phox. Hum Mutat 13(1):29-37.

Rae J, Newburger PE, Dinauer MC, Noack D, Hopkins PJ, Kuruto R, Curnutte JT. 1998. XLinked chronic granulomatous disease: mutations in the CYBB gene encoding the gp91-phox component of respiratory-burst oxidase. Am J Hum Genet 62(6):1320-31.

Ravnik-Glavac M, Atkinson A, Glavac D, Dean M. 2002. dHPLC screening of cystic fibrosis gene mutations. Hum Mutat 19(4):374-83.

Ravnik-Glavac M, Glavac D, Dean M. 1994. Sensitivity of single-strand conformation polymorphism and heteroduplex method for mutation detection in the cystic fibrosis gene. Hum Mol Genet 3(5):801-7. 
Rohlin A, Wernersson J, Engwall Y, Wiklund L, Bjork J, Nordling M. 2009. Parallel sequencing used in detection of mosaic mutations: comparison with four diagnostic DNA screening techniques. Hum Mutat 30(6):1012-20.

Rothe G, Oser A, Valet G. 1988. Dihydrorhodamine 123: a new flow cytometric indicator for respiratory burst activity in neutrophil granulocytes. Naturwissenschaften 75(7):354-5.

Royer-Pokora B, Kunkel LM, Monaco AP, Goff SC, Newburger PE, Baehner RL, Cole FS, Curnutte JT, Orkin SH. 1986. Cloning the gene for an inherited human disorder-chronic granulomatous disease--on the basis of its chromosomal location. Nature 322(6074):32-8.

Underhill PA, Jin L, Lin AA, Mehdi SQ, Jenkins T, Vollrath D, Davis RW, Cavalli-Sforza LL, Oefner PJ. 1997. Detection of numerous Y chromosome biallelic polymorphisms by denaturing high-performance liquid chromatography. Genome Res 7(10):996-1005.

Winkelstein JA, Marino MC, Johnston RB, Jr., Boyle J, Curnutte J, Gallin JI, Malech HL, Holland SM, Ochs H, Quie P and others. 2000. Chronic granulomatous disease. Report on a national registry of 368 patients. Medicine (Baltimore) 79(3):155-69.

\section{Tables}

Table I. Clinical features of patients with CGD included in this study

Table II. Oligos for PCR amplification used in the SSCP and dHPLC

Table III. Mutations in the $C Y B B$ gene in CGD patients and effectiveness of the screening mutations

\section{Figures Legends}

Figure 1. Molecular analysis in the exon 7 (patients 1 and 2), a nonsense mutation. A: SSCP revealing alteration in the race pattern in the area of the exon 7. B: dHPLC confirming molecular alteration in the exon $7\left(57^{\circ} \mathrm{C}\right.$, retention time among 3-5 minutes). $\mathrm{C}$ : Chromatogram showing the nucleotides change $\mathrm{C}>\mathrm{T}$. 
Figure 2. Molecular analysis in the exon 8 (patients 3, 4 and 5), a nonsense mutation. A: SSCP revealing alteration in the race pattern in the area of the exon 8. B: dHPLC confirming molecular alteration in the exon $8\left(58,4{ }^{\circ} \mathrm{C}\right.$, retention time among $3-5$ minutes $)$. C: Chromatogram showing the nucleotides change $\mathrm{C}>\mathrm{T}$.

Figure 3. Molecular analysis in the exon 9 (patient 6), a frameshift mutation. A: SSCP with pattern of normal race in the area of the exon 9. B: dHPLC confirming molecular alteration in the area of the exon $9\left(57,0{ }^{\circ} \mathrm{C}\right.$, retention time among 3-5 minutes). C: Chromatogram showing an insert of a nucleotide C.

Figure 4. Molecular analysis in the exon 2 (patient 7), a splicing mutation. A: SSCP with pattern of normal race in the area of the exon $2\left(56,9^{\circ} \mathrm{C}\right.$, retention time among 3-5 minutes). B: dHPLC confirming molecular alteration in the area of the exon 2. C: Chromatogram showing a nucleotide change $\mathrm{G}>\mathrm{T}$ in the border intonic of the intron 2. D: eletrophoresis in gel of agarose $2 \%$ stained with etídium bromide showing difference in the size of the products of PCR between the patient and the normal fragment evidencing deletion of the exon 2 in transcribed it of the gene $C Y B B(\mathrm{cDNA})$.

Figure 5. Molecular analysis in the exon 6 (patient 8), a missense mutation. A: SSCP with pattern of normal race in the area of the exon 6. B: dHPLC revealing molecular alteration in the exon $6\left(60,0^{\circ} \mathrm{C}\right.$, retention time among 3-5 minutes). C: Chromatogram showing a nucleotide change $\mathrm{T}>\mathrm{C}$. D: philogenetic comparison among species of the amino acids of the gp91-phox evidencing a missense mutation in the patient 8 that generates a substitution of amino acids $(\mathrm{C} 185 \mathrm{R})$ in an area semi-conserved among species, but totally conserved among the mammals. 
Figure 6. Molecular analysis in the exon 6 (patient 9), a missense mutation. A: SSCP with pattern of normal race in the area of the exon 6. B: dHPLC revealing molecular alteration in the exon $6\left(60,0{ }^{\circ} \mathrm{C}\right.$, retention time among 3-5 minutes). C: Chromatogram showing a nucleotide change $\mathrm{A}>\mathrm{T}$. D: philogenetic comparison among species of the amino acids of the gp91-phox evidencing a missense mutation in the patient 9 that generates a substitution of amino acids (H222L) in an area totally conserved among all the analyzed species.

Figure 7. Molecular analysis in the exon 13 (patient 10), a missense mutation. A: dHPLC revealing molecular alteration in the exon $13\left(58,1^{\circ} \mathrm{C}\right.$, retention time among $3-5$ minutes $)$. B: Chromatogram showing a nucleotide change T $>$ C. C: philigenetic comparison among species of the amino acids of the gp91-phox evidencing a missense mutation in the patient 10 that generates a substitution of amino acids (C537R) in an area totally conserved among all the analyzed species.

Figure 8. Additional dHPLC analysis. Results of two DGC cases cited in two different papers. We confirmed the efficiency of the method in detecting changes in the following exons on $C Y B B$ gene. A. show exon 3 analysis (patient 11) and B. show exon 5 analysis (patient 12). 
Figure 1 - Oliveira-Júnior, 2010

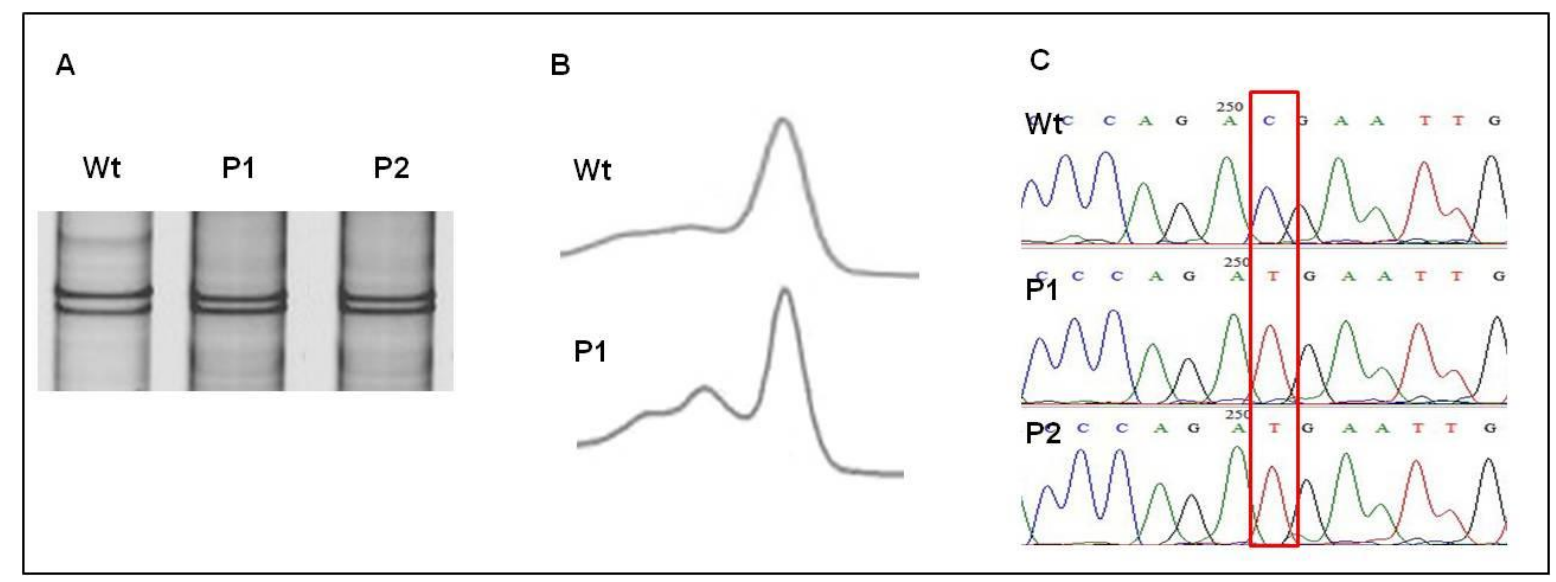

Figure 2 - Oliveira-Júnior, 2010

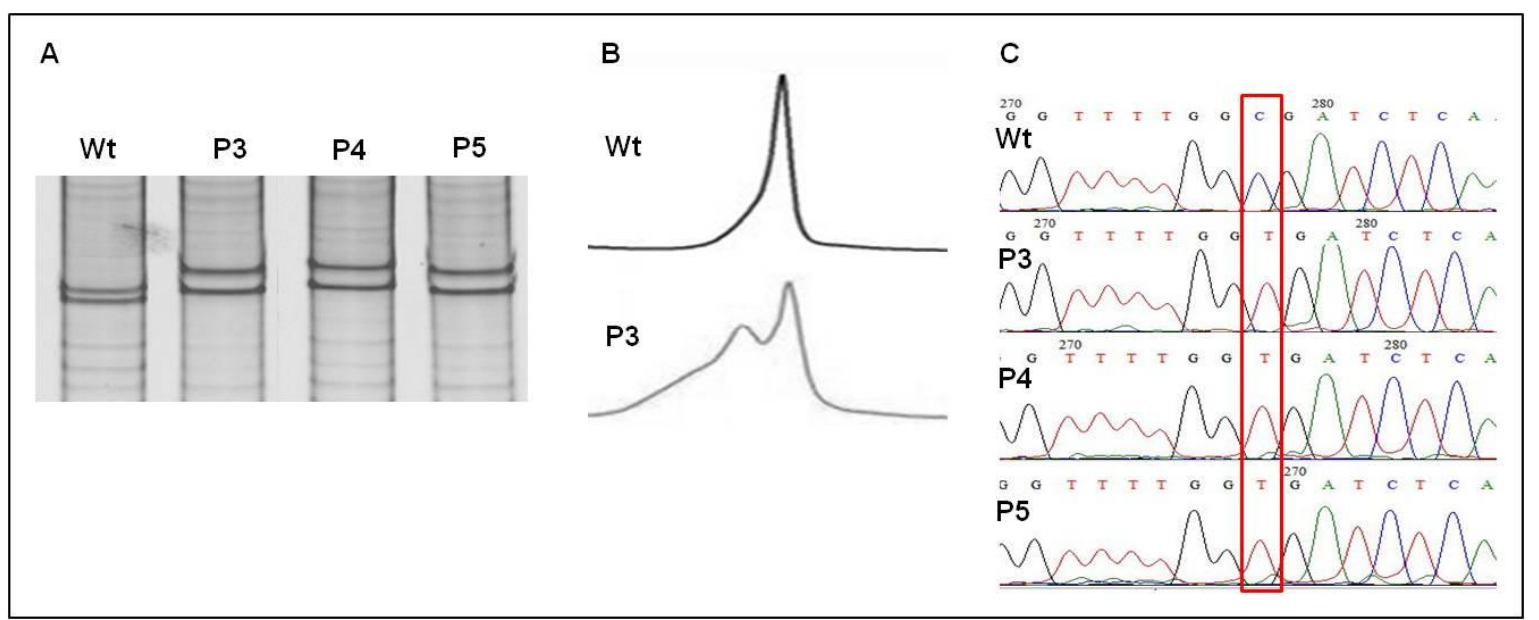

Fiagure 3 - Oliveira-Júnior, 2010

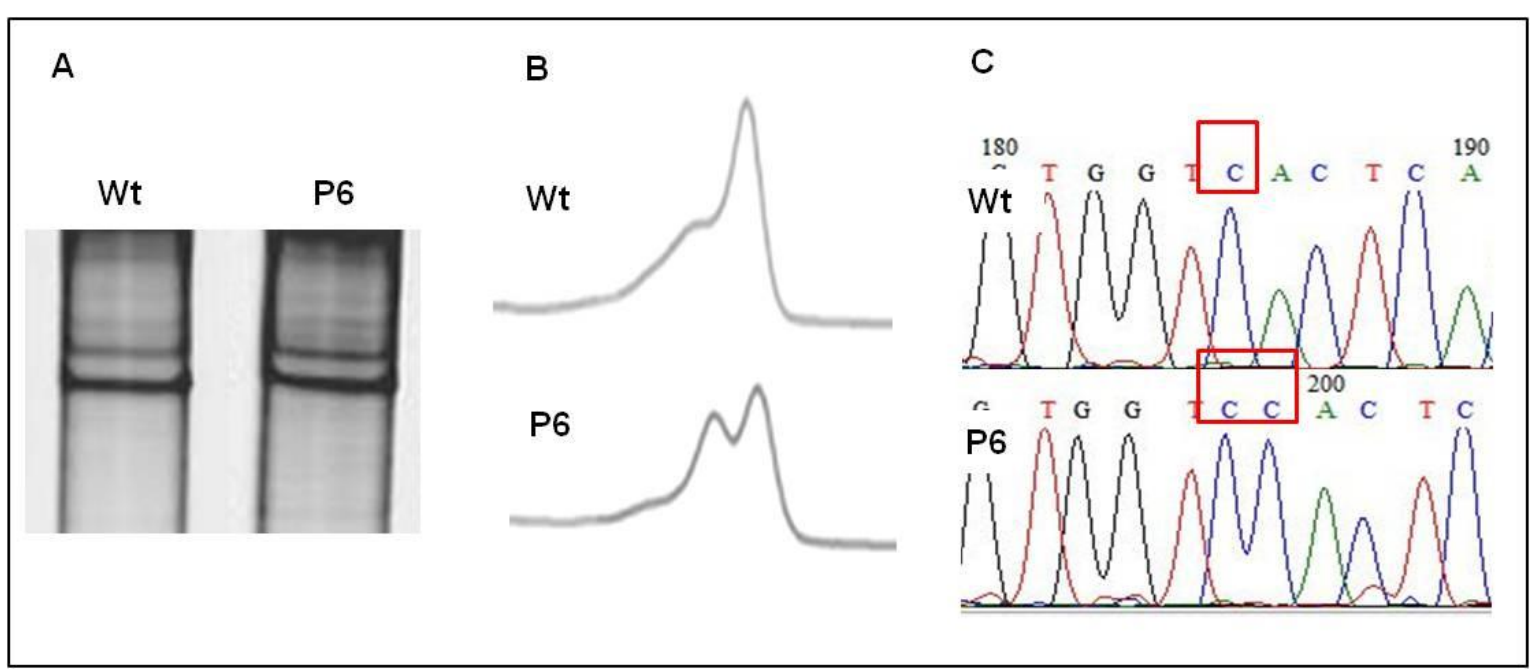


Figure 4 - Oliveira-Júnior, 2010

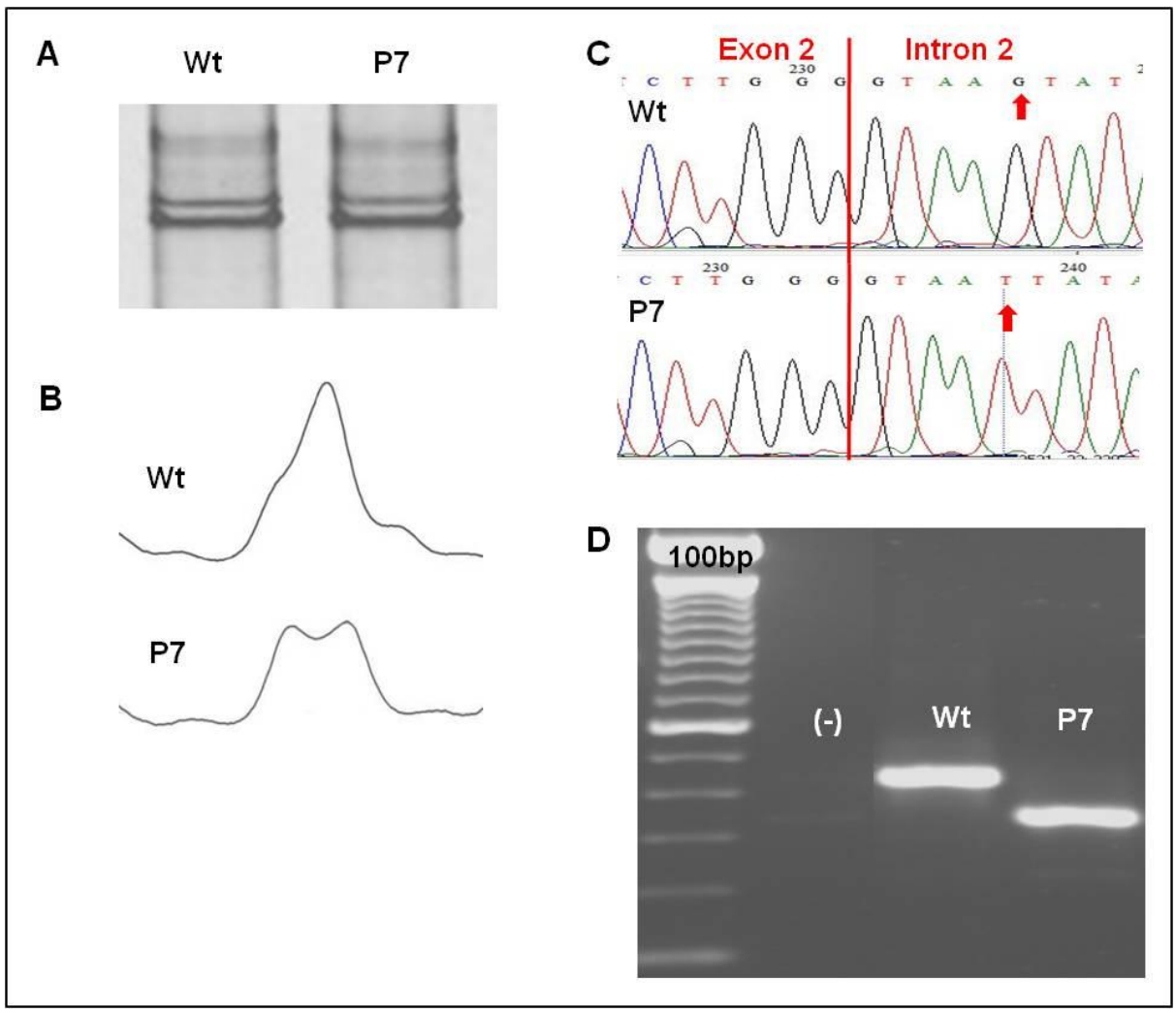

Figure 5 - Oliveira-Júnior, 2010

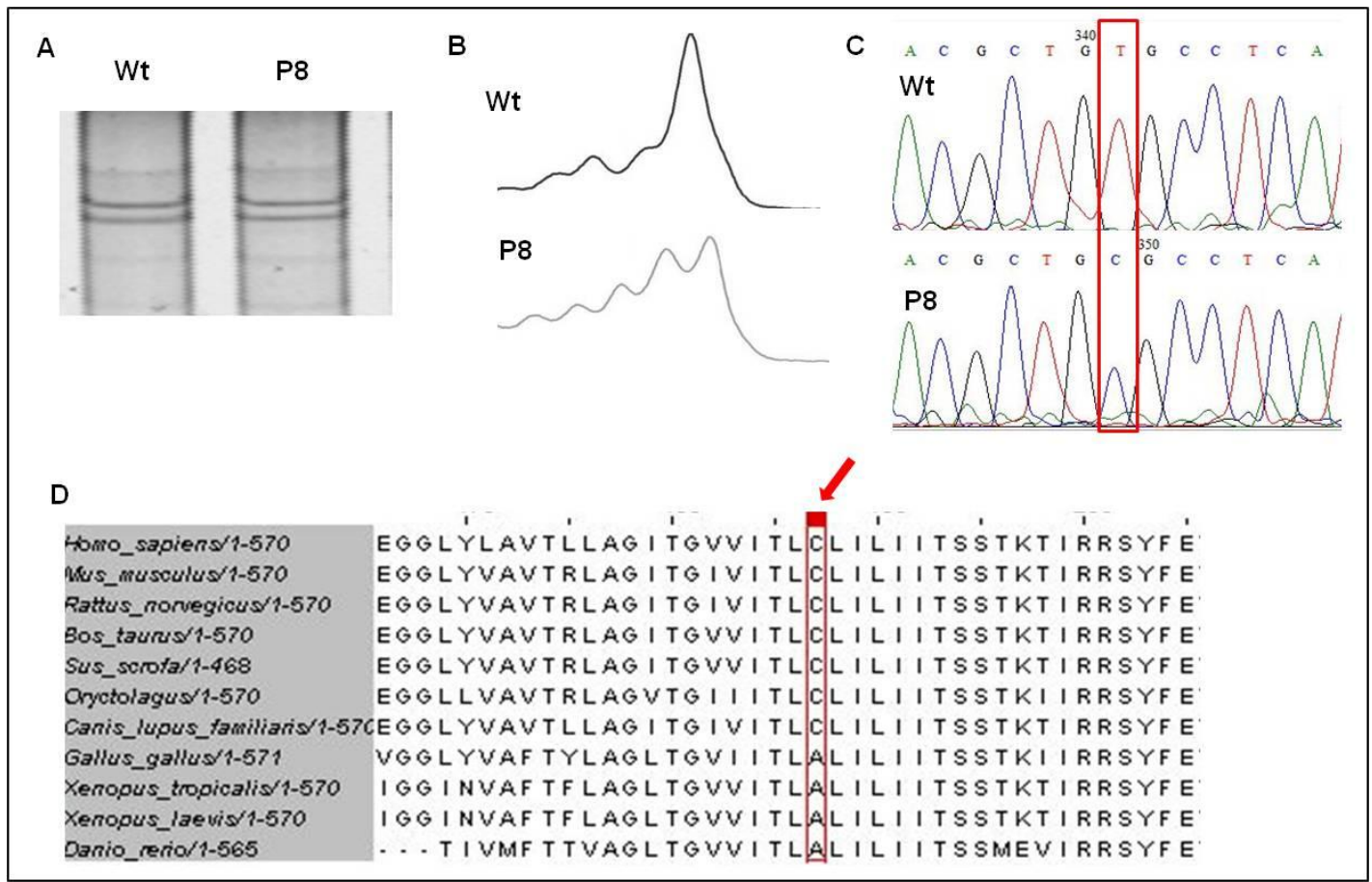


Figure 6 - Oliveira-Júnior, 2010

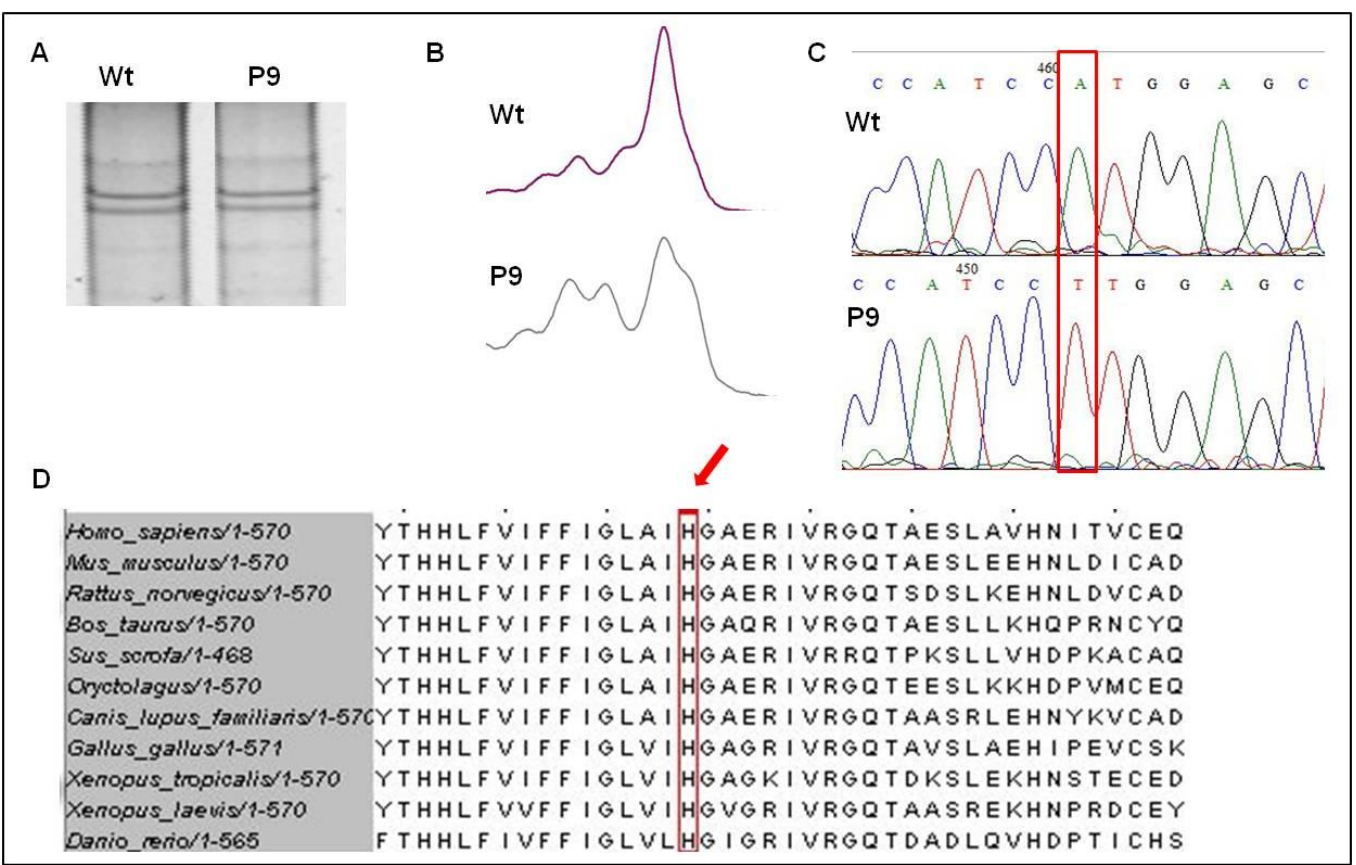

Figure 7 - Oliveira-Júnior, 2010

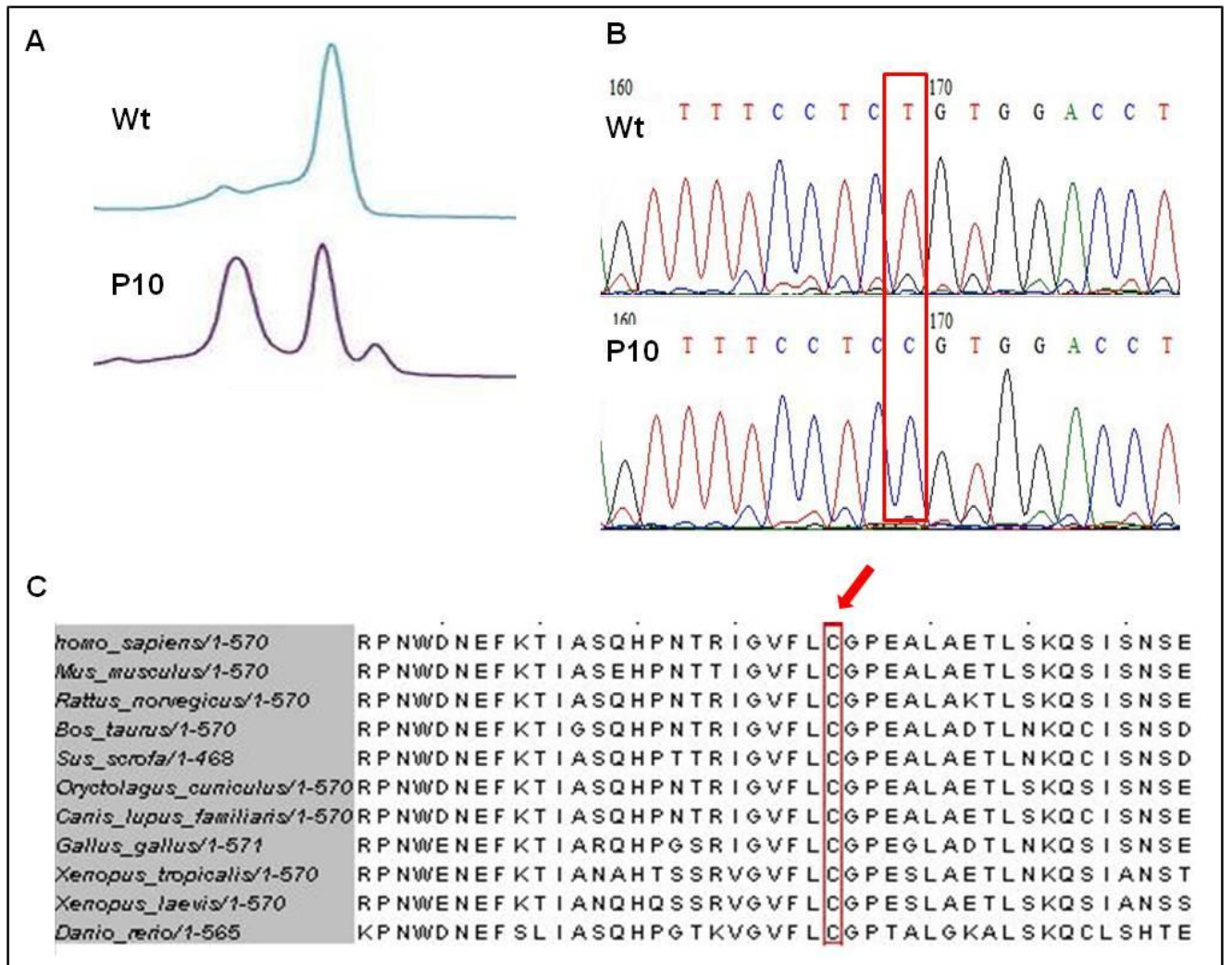


Figure 8 - Oliveira-Júnior, 2010

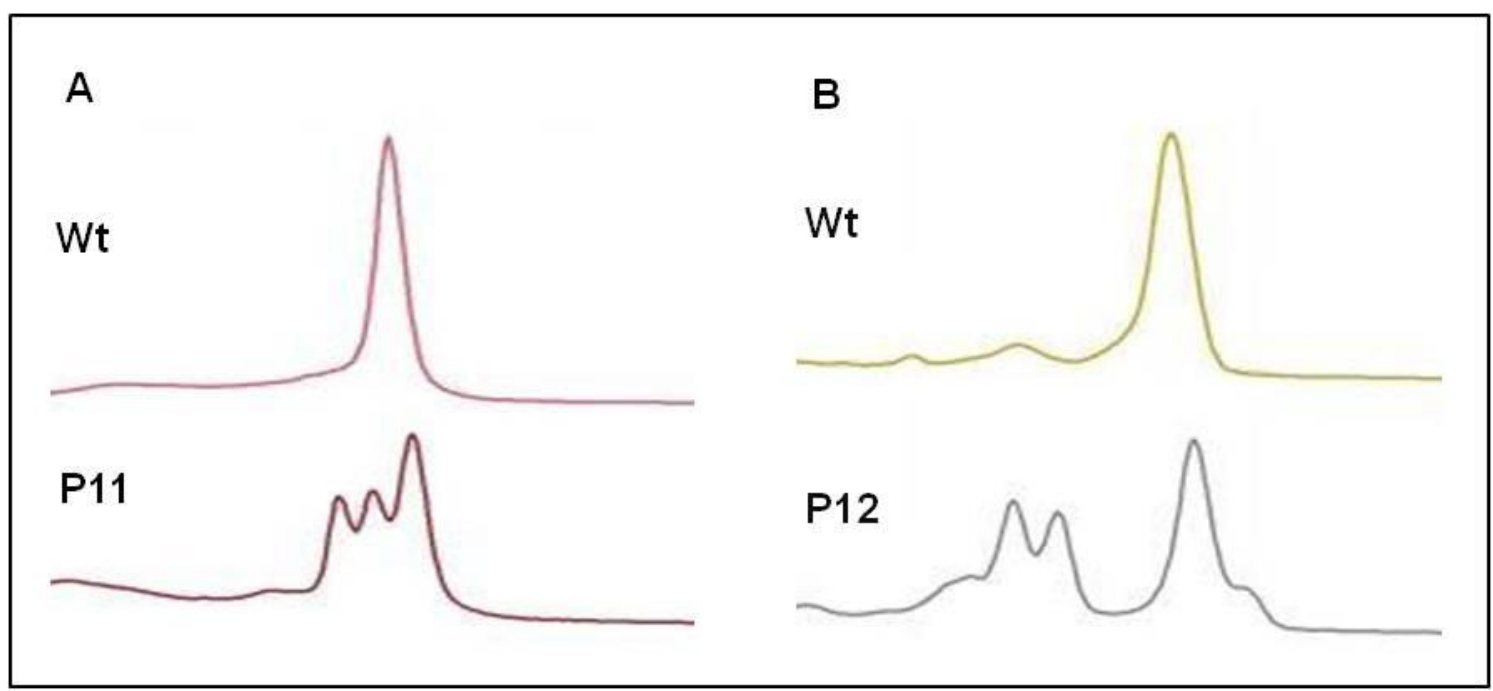

Tabela I - Oliveira-Júnior, 2010

\begin{tabular}{|c|c|c|c|c|}
\hline Patient & $\begin{array}{c}\text { First } \\
\text { manifestation } \\
\text { (months) }\end{array}$ & $\begin{array}{c}\text { Disease onset } \\
\text { (months) }\end{array}$ & Main clinical manifestations & Pathogens \\
\hline 1 & 24 & 72 & Pneumonia, otitis, tonsillitis, liver abscess & $\begin{array}{l}\text { Staphylococcus } \\
\text { aureus (Liver) }\end{array}$ \\
\hline 2 & - & 60 & $\begin{array}{l}\text { Pneumonia, liver and skin abscesses, type } \\
2 \text { diabetes }\end{array}$ & - \\
\hline 3 & - & - & $\begin{array}{c}\text { Pneumonia, liver and skin abscesses, } \\
\text { lymphadenitis }\end{array}$ & - \\
\hline 4 & - & - & $\begin{array}{l}\text { Pneumonia, liver and skin abscesses, } \\
\text { lymphadenitis }\end{array}$ & - \\
\hline 5 & - & - & $\begin{array}{l}\text { Pneumonia, liver and skin abscesses, } \\
\text { lymphadenitis }\end{array}$ & - \\
\hline 6 & 1 & 1,5 & $\begin{array}{l}\text { Pneumonia, sepsis, lymphadenitis, } \\
\text { pulmonary abscess }\end{array}$ & $\begin{array}{l}\text { Klebsiela pneumoniae } \\
\text { and Serratia } \\
\text { marcences } \\
\text { (lynphonode); } \\
\text { Candida parapsilossis }\end{array}$ \\
\hline 7 & 1 & 4 & Pneumonia, granuloma, pyoderma & $\begin{array}{l}\text { Staphyloccocus } \\
\text { aureus (Skin) }\end{array}$ \\
\hline 8 & 7 & 24 & $\begin{array}{l}\text { Pneumonia, lifonodomegalia, reaction to } \\
\text { vaccine }\end{array}$ & $\begin{array}{l}\text { Local reaction to } \mathrm{BCG} \\
\text { vaccine }\end{array}$ \\
\hline 9 & 5 & 12 & Pneumonia, cervical adenitis, lymphadenitis & - \\
\hline 10 & 9 & 12 & $\begin{array}{l}\text { Pneumonia, lymphadenitis, tonsillitis, } \\
\text { pyoderma, granulomas }\end{array}$ & E. coli (Urinary tract) \\
\hline 11 & 6 & 9 & $\begin{array}{l}\text { Pneumonia, lymphadenitis, osteomyelitis, } \\
\text { liver and skin abscesses, pyoderma }\end{array}$ & Candida sp (Skin) \\
\hline 12 & 8 & 24 & $\begin{array}{l}\text { Pneumonia, measles, inguinal adenitis, } \\
\text { gastroenteritis, ulcers on lower limbs }\end{array}$ & $\begin{array}{c}\text { Aspergillus sp (Lung); } \\
\text { Staphylococcus } \\
\text { epidermidis and } \\
\text { Staphylococcus } \\
\text { aureus (Skin) }\end{array}$ \\
\hline
\end{tabular}


Tabela II - Oliveira-Júnior, 2010

\begin{tabular}{rllcc}
\hline Exons & \multicolumn{1}{c}{$\begin{array}{c}\text { Sequence Oligos } \\
\text { Foward 5'-3' }\end{array}$} & $\begin{array}{c}\text { Sequence Oligos } \\
\text { Reverse } \mathbf{5}^{\prime}-\mathbf{3}^{*}\end{array}$ & $\begin{array}{c}\mathbf{T}^{\circ} \mathbf{C} \\
\text { annealing }\end{array}$ & $\begin{array}{c}\text { Product size } \\
\text { (bp) }\end{array}$ \\
\hline 1 & gcaaggctatgaatgctgttc & gcttggtctatttagttcc & 56 & 545 \\
2 & tgttgaggaaagagctggct & taagtgactgttgcccagga & 58 & 420 \\
3 & gggcaaaaggtcaattcagatg & tagtttgtcttagggagctcc & 56 & 466 \\
4 & tactggctgtttgacctgag & gaagtggcagaaagtgtggt & 60 & 446 \\
5 & acaactagagaggatcttaccc & tcagtgagtgaaaccctcct & 57 & 426 \\
6 & tgtctgtgagggatgattagg & tagcaattacatgggtgcatg & 58 & 566 \\
7 & acagaagtagaaattctccct & ttctgaaccaaaacagcac & 56 & 675 \\
8 & cttgtcagtacagttccccat & gatgtccagaaagaacttggc & 58 & 553 \\
9 & gtatcccttaatcagcccatc & cggtgaccacagaaatagct & 58 & 602 \\
10 & aacccaacgttggcactaag & cccttcactaataggcctac & 56 & 548 \\
11 & gtgaaatgtccagagccttc & tggcgatactaaatgagagtg & 56 & 449 \\
12 & cgaagtctccctttctagac & ggaatcttctgttgggcatg & 56 & 449 \\
13 & gctcacacaaacaggctgaa & ccatagagctccacataaatg & 58 & 498 \\
\hline
\end{tabular}

Tabela III - Oliveira-Júnior, 2010

\begin{tabular}{|c|c|c|c|c|c|c|c|c|}
\hline Patients & CGD type & Mutation & Location & Nucleotide Change & $\begin{array}{l}\text { Amino acid } \\
\text { Change }\end{array}$ & $\begin{array}{c}\text { SSCP } \\
\text { detected }\end{array}$ & $\begin{array}{c}\text { DHPLC } \\
\text { dectated }\end{array}$ & References \\
\hline 1 & $\times 91^{0}$ & Nonsense & exon 7 & $\mathrm{c} .688 \mathrm{C}>\mathrm{T}$ & R226X & yes & yes & $\begin{array}{l}\text { Heyworth et } \\
\text { al_. } 2001\end{array}$ \\
\hline 2 & $\times 91^{0}$ & Nonsense & exon 7 & c. $688 \mathrm{C}>\mathrm{T}$ & R226X & yes & - & $\begin{array}{l}\text { Heyworth et } \\
\text { al. } 2001\end{array}$ \\
\hline 3 & $\times 91^{0}$ & Nonsense & exon 8 & c. $880 \mathrm{C}>\mathrm{T}$ & R290X & yes & yes & $\begin{array}{l}\text { Heyworth et } \\
\text { al_. } 2001\end{array}$ \\
\hline 4 & $\times 91^{0}$ & Nonsense & exon 8 & $c .880 \mathrm{C}>\mathrm{T}$ & R290X & yes & - & $\begin{array}{l}\text { Heyworth et } \\
\text { al. } 2001\end{array}$ \\
\hline 5 & $\mathrm{X} 91^{\circ}$ & Nonsense & exon 8 & c. $880 \mathrm{C}>\mathrm{T}$ & R290X & yes & - & $\begin{array}{l}\text { Heyworth et } \\
\text { al. } 2001\end{array}$ \\
\hline 6 & $\times 91^{0}$ & Insertion & exon 9 & c.904 ins C * & T302fsX46* & no & yes & - \\
\hline 7 & $\times 91^{0}$ & Splice site & intron 2 & c.141+5 agt > att ${ }^{*}$ & Delete exon 2 & no & yes & - \\
\hline 8 & $\mathrm{X} 91^{+}$ & Missense & exon 6 & c.553 T>C * & $\mathrm{C} 185 \mathrm{R}^{*}$ & no & yes & - \\
\hline 9 & X91- & Missense & exon 6 & c. $665 A>T^{*}$ & $\mathrm{H} 222 \mathrm{~L}^{*}$ & no & yes & - \\
\hline 10 & $\mathrm{X} 91^{+}$ & Missense & exon 13 & c. $1621 \mathrm{~T}>\mathrm{C}$ & C537R & - & yes & $\begin{array}{l}\text { Heyworth et } \\
\text { al_. } 2001\end{array}$ \\
\hline 11 & $\times 91^{0}$ & Nonsense & exon 3 & c. $229 \mathrm{C}>\mathrm{T}$ & R73X & Ref. & yes & $\begin{array}{l}\text { Heyworth et } \\
\text { al. } 2001\end{array}$ \\
\hline 12 & $\times 91^{0}$ & Nonsense & exon 5 & C.481 C>T & R157X & Ref. & yes & $\begin{array}{l}\text { Heyworth et } \\
\text { al_2001 }\end{array}$ \\
\hline
\end{tabular}

* Novel mutation 
ANEXO B - Estudo de Pacientes com Suspeita de Imunodeficiência Primária Laboratório de Alergia e Imunodeficiências em Humanos

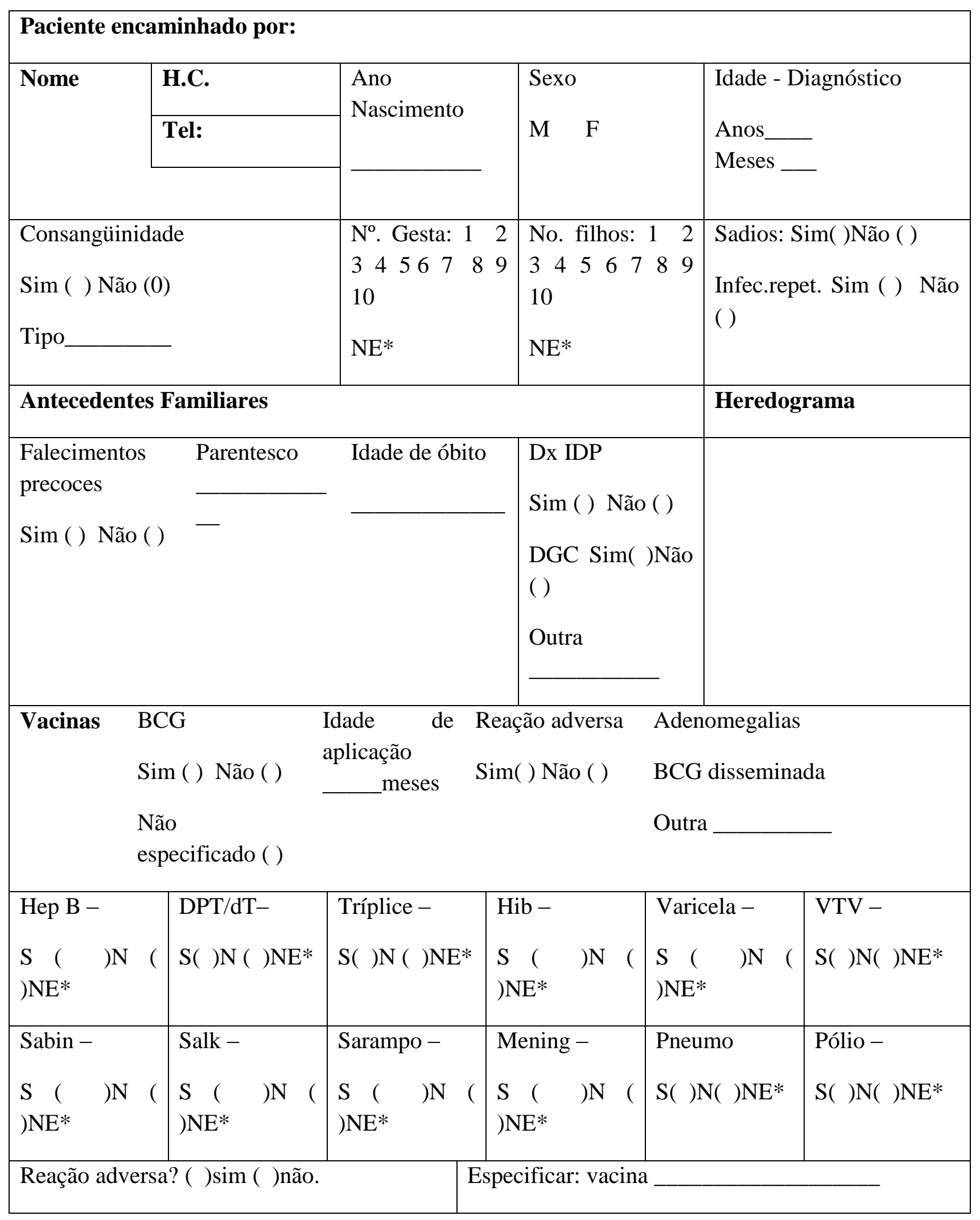




\begin{tabular}{|c|c|c|c|c|}
\hline & & & \multicolumn{2}{|c|}{ Manifestação } \\
\hline DNPM & \multicolumn{2}{|c|}{ BDNPM S( )N( )NE* } & \multicolumn{2}{|c|}{$\begin{array}{l}\text { RDNPM S( )N( )NE*. } \\
\text { Detalhar: }\end{array}$} \\
\hline DPE & $\begin{array}{l}>\mathrm{p} 90 \% \mathrm{~S}( \\
) \mathrm{N}(\mathrm{r}\end{array}$ & $<\mathrm{p} 10 \% \mathrm{~S}(\mathrm{)}$ & $>\mathrm{p} 10 \% \mathrm{e}<\mathrm{p} 90$ & $\mathrm{~S}(\mathrm{)}) \mathrm{N}(0)$ \\
\hline \multicolumn{3}{|l|}{$1^{a}$ manifestação } & \multicolumn{2}{|l|}{ Motivo de Estudo } \\
\hline $\begin{array}{l}\text { Idade } \\
\quad \text { ano } \\
\text { meses }\end{array}$ & \multicolumn{2}{|l|}{ Local } & \multicolumn{2}{|c|}{$\begin{array}{l}\text { Infec. Repetição Sim ( )Não ( ) } \\
\text { Manifest. Grave Sim ( )Não ( ) } \\
\text { História Familiar Sim ( )Não ( ) } \\
\text { Outro Sim ( } \quad \text { )Não } \quad \text { (0). Especificar: }\end{array}$} \\
\hline Manifestações & $\begin{array}{l}\text { No. de } \\
\text { episódio } \\
\text { s }\end{array}$ & $\begin{array}{l}\text { Microorg. } \\
\text { isolado } \\
\text { Sim ( )Não } \\
\text { ( ) }\end{array}$ & Microorganismo Isolado & Localização \\
\hline 1 Otite & & & & \\
\hline 2 Pneumonia & & & & \\
\hline 3 Pneumonia / DP & & & & \\
\hline 3 Amigdalite & & & & \\
\hline 4 Linfonodo & & & & \\
\hline 5 ITU & & & & \\
\hline 6 Meningite & & & & \\
\hline 7 Artrite & & & & \\
\hline 8 Osteomielite & & & & \\
\hline 9 Diarréia & & & & \\
\hline $\begin{array}{l}10 \text { Infecções de Pele } \\
\text { Especificar: }\end{array}$ & & & & \\
\hline 11 Artrite & & & & \\
\hline
\end{tabular}




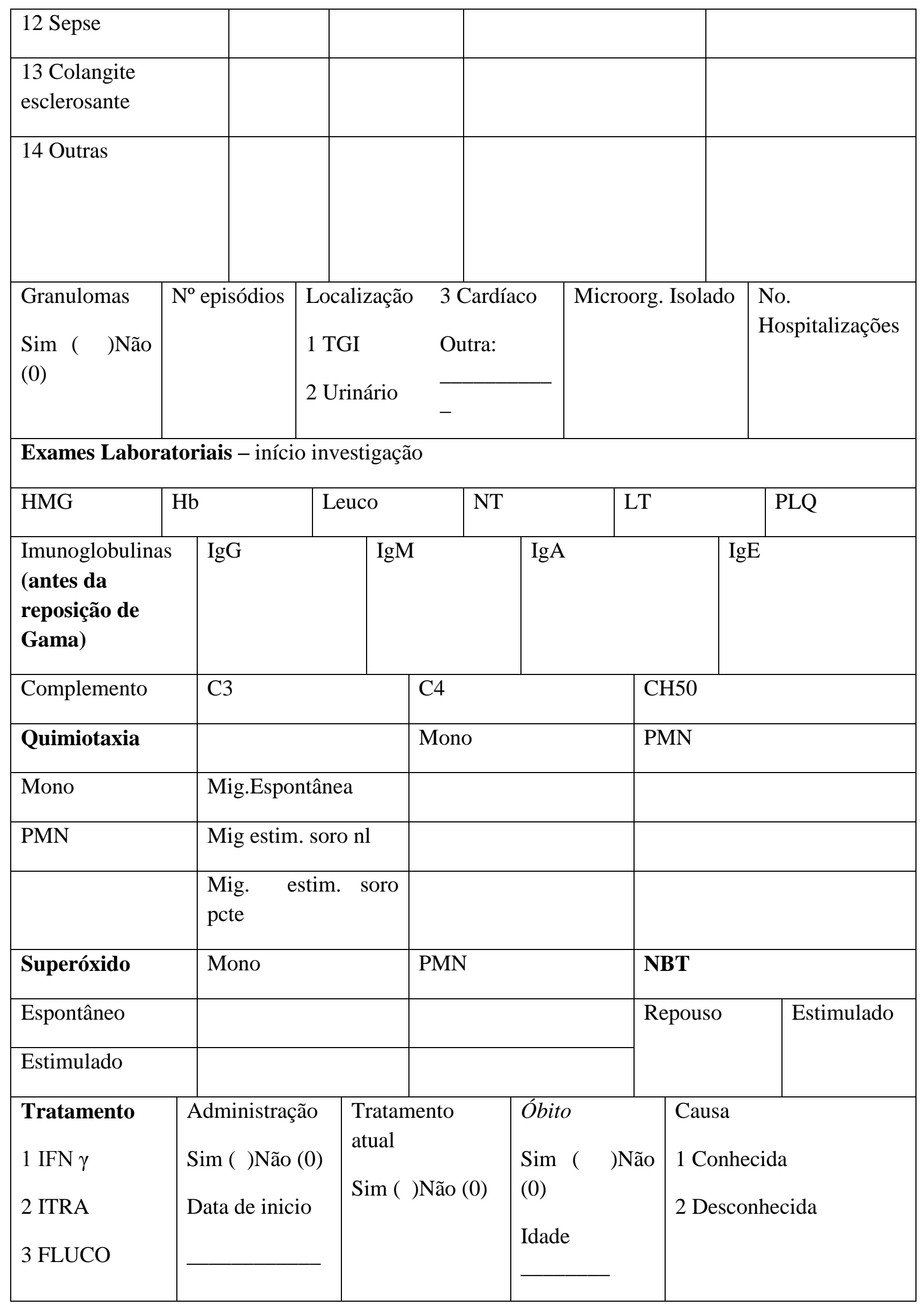




\begin{tabular}{|l|l|l|l|l|}
\hline 4 SMX +TMP & - & Autópsia & Laudo \\
5 Prednisona & & Sim ( )Não ( ) & \\
6 TMO 7 & & & & \\
Outros & & & \\
\hline
\end{tabular}

* = não especificado

OUTRAS MANIFESTACOES - LIVRE RELATO DE OCORRENCIAS 
ANEXO C.1 - Termo de Consentimento livre esclarecido (Grupo experimental)

\author{
ESTUDO: ESPECTRO CLÍNICO E DEFEITOS GENÉTICO-MOLECULARES DE \\ PACIENTES COM DOENÇA GRANULOMATOSA CRÔNICA
}

Você está sendo convidado(a) a participar do projeto de pesquisa acima citado. O documento abaixo contém todas as informações necessárias sobre a pesquisa que estaremos fazendo. Sua colaboração neste estudo será de muita importância para nós, mas se desistir a qualquer momento, isso não causará nenhum prejuízo a você.

Eu, (nome completo) portador(a) da carteira de identidade número (RG) nascido (a)

em (data, idade, estado) residente na (rua, número) na cidade de. estado de. declaro que é de minha livre e espontânea vontade que concordo em participar do estudo sobre "ESPECTRO CLÍNICO E DEFEITOS GENÉTICO-MOLECULARES DE PACIENTES COM DOENÇA GRANULOMATOSA CRÔNICA" Para isto estou disposto(a) a fornecer dados clínicos completos sobre a minha doença e doar uma amostra de $20 \mathrm{ml}$ de sangue, e declaro que obtive todas as informações necessárias, bem como todos os eventuais esclarecimentos quanto às dúvidas por mim apresentadas.

O principal objetivo deste estudo é analisar as características clínicas, imunológicas, epidemiológicas e defeitos genético-moleculares, estabelecendo correlação entre genótipo (características genéticas) $\mathrm{x}$ fenótipo (características clínicas) de pacientes com Doença Granulomatosa Crônica (DGC). 


\section{Estou ciente das seguintes informações:}

1- Uma amostra de sangue será coletada de uma veia do meu braço, e será utilizada nos experimentos científicos do projeto e não haverá sobra de material armazenada depois de terminado o estudo.

2- Os riscos da retirada de sangue são hematoma local (rouxidão), pequeno incômodo de dor no momento da coleta (introdução da agulha para retirada do sangue), algum desconforto e, raramente, tontura.

3- Não receberei qualquer remuneração para esta doação e que esta pesquisa não vai curar minha doença.

4- As informações e resultados obtidos no decorrer do estudo serão mantidos em sigilo, zelando-se pela minha privacidade não serão divulgados meus dados pessoais, mas sim científicos, nas conclusões ou publicações dos resultados desta pesquisa.

5- Tenho a liberdade de desistir ou de interromper a colaboração neste estudo no momento em que eu desejar, sem necessidade de qualquer explicação;

6- A desistência não causará nenhum prejuízo à minha saúde ou ao meu bem estar físico. Não virá interferir no atendimento ou tratamento médico;

7- Caso eu desejar, poderei pessoalmente tomar conhecimento dos resultados, ao final desta pesquisa:

( ) Desejo conhecer os resultados desta pesquisa.

( ) Não desejo conhecer os resultados desta pesquisa.

Estes estudos podem melhorar o entendimento da doença levando a formas mais eficazes de diagnóstico e tratamento no futuro. É provável que o voluntário em questão não seja beneficiário direto destes avanços. 
Quaisquer dúvidas, que possam ocorrer com relação a esse estudo, poderão ser contatados:

Dr. Antonio Condino Neto na Universidade de São Paulo, Laboratório de Imunodeficiência, Av. Prof. Lineu Prestes 1730, São Paulo - SP 05508-900, telefone (11) 30917435.

São Paulo, de de

Paciente:

Testemunha 1 :

Nome / RG / Telefone

Testemunha 2 :

Nome / RG / Telefone

Responsável pelo Projeto:

Edgar Borges de Oliveira Júnior 
ANEXO C.2 - Termo de Consentimento livre esclarecido (menores de 18 anos)

\section{ESTUDO: ESPECTRO CLÍNICO E DEFEITOS GENÉTICO-MOLECULARES DE PACIENTES COM DOENÇA GRANULOMATOSA CRÔNICA.}

Seu filho está sendo convidado a participar do presente estudo. O documento abaixo contém todas as informações necessárias sobre a pesquisa que estaremos fazendo. Leia atentamente. Caso tenha dúvidas, teremos prazer em esclarecê-las. Se concordar, o documento será assinado e só então daremos início ao estudo. Sua colaboração será muito importante para nós. Mas, se quiser desistir a qualquer momento, isto não causará nenhum prejuízo, nem a você, nem ao(à) seu (sua) filho(a).

Eu, (nome completo)

portador(a) da carteira de identidade número (RG)

abaixo assinado(a), concordo de livre e espontânea vontade que meu(minha) filho(a) nascido (a) em (data, idade, estado) residente na (rua,número) na cidade

de. estado de. seja voluntário (a) no

estudo “ESPECTRO CLÍNICO E DEFEITOS GENÉTICO-MOLECULARES DE PACIENTES COM DOENÇA GRANULOMATOSA CRÔNICA” Para isto estou disposto(a) a fornecer dados clínicos completos sobre a doença e doar uma amostra de $20 \mathrm{ml}$ de sangue do meu (minha) filho (a), e declaro que obtive todas as informações necessárias, bem como todos os eventuais esclarecimentos quanto às dúvidas por mim apresentadas.

O principal objetivo deste estudo é analisar as características clínicas, imunológicas, epidemiológicas e defeitos genético-moleculares, estabelecendo correlação entre genótipo (características genéticas) x fenótipo (características clínicas) de pacientes com Doença Granulomatosa Crônica (DGC). 
Estou ciente das seguintes informações:

1- Uma amostra de sangue será coletada de uma veia do braço do meu (minha) filho (a), que será utilizada nos experimentos científicos do projeto e não haverá sobra de material armazenada depois de terminado o estudo.

2- Os riscos da retirada de sangue são hematoma local (rouxidão), pequeno incômodo de dor no momento da coleta (introdução da agulha para retirada do sangue), algum desconforto e, raramente, tontura.

3- Não receberei qualquer remuneração para esta doação e que esta pesquisa não vai curar a doença do meu (minha) filho (a).

4- As informações e resultados obtidos no decorrer do estudo serão mantidos em sigilo, zelando-se pela privacidade do meu (minha) filho (a) e não serão divulgadas informações pessoais, mas sim científicos, nas conclusões ou publicações dos resultados desta pesquisa.

5- Tenho a liberdade de desistir ou de interromper a colaboração neste estudo no momento em que eu desejar, sem necessidade de qualquer explicação;

6- A desistência não causará nenhum prejuízo à saúde do meu (minha) filho (a) ou ao bem estar físico. Não virá interferir no atendimento ou tratamento médico;

7- Caso eu desejar, poderei pessoalmente tomar conhecimento dos resultados, ao final desta pesquisa:

( ) Desejo conhecer os resultados desta pesquisa.

( ) Não desejo conhecer os resultados desta pesquisa.

Estes estudos podem melhorar o entendimento da doença levando a formas mais eficazes de diagnóstico e tratamento no futuro. É provável que seu filho (a) em questão não seja beneficiário direto destes avanços. 
Quaisquer dúvidas, que possam ocorrer com relação a esse estudo, poderão ser contatados:

Dr. Antonio Condino Neto na Universidade de São Paulo, Laboratório de Imunodeficiência, Av. Prof. Lineu Prestes 1730, São Paulo - SP 05508-900, telefone (11) 30917435.

São Paulo, de de

Responsável pelo paciente:

Testemunha 1 :

Nome / RG / Telefone

Testemunha 2 :

Nome / RG / Telefone

Responsável pelo Projeto:

Edgar Borges de Oliveira Júnior 
ANEXO D - Oligos (dHPLC / SSCP / Sequênciamento)

Material: gDNA

Gene: $C Y B B$ (13 exons)

Proteína: gp91-phox

PRIMER 1F (-425 LA)

GCA AGG CTA TGA ATG CTG TTC

$556 \mathrm{pb}-\mathrm{Tm}: 56^{\circ} \mathrm{C}-30$ ciclos

PRIMER 1R (1 RA2)

GCT TTG GTC TAT TTT AGT TCC

PRIMER 2F

TGT TGA GGA AAG AGC TGG CT

PRIMER 2R

$420 \mathrm{pb}-\mathrm{Tm}: 58 \circ \mathrm{C}-30$ ciclos

TAA GTG ACT GTT GCC CAG GA

PRIMER 3F

CAA AGG GTC CTA GCT AGC C

Primer 3r

$466 \mathrm{pb}-\mathrm{Tm}: 56 \circ \mathrm{C}-30$ ciclos

TAG TTG TCT TAG GGA GCT CC

PRIMER 4F

TAC TGG CTG TTT GAC CTG AG

PRIMER 4R

$446 \mathrm{pb}-\mathrm{Tm}: 60 \mathrm{oc}-30$ ciclos

GAA GTG GCA GAA AGT GTG GT

PRIMER 5F

ACA ACT AGA GAG GAT CTT ACC C

PRIMER 5R

$426 \mathrm{pb}-\mathrm{Tm}: 570 \mathrm{C}-30$ ciclos

GAG AGG TCT TCA CTC ACT GA

PRIMER 6F

TGT CTG TGA GGG ATG ATT AGG

PRIMER 6R

$566 \mathrm{pb}-\mathrm{Tm}: 58 \mathrm{oc}-30$ ciclos

TAG CAA TTA CAT GGG TGC ATG 
PRIMER 7F

ACA GAA GTA GAA ATT CTC CCT

PRIMER 7R

$675 \mathrm{pb}-\mathrm{Tm}: 56 \mathrm{o}-25$ ciclos

TTC TTG AAC CAA AAC AGC AC

PRIMER 8F

CTT GTC AGT ACA GTT CCC CAT

PRIMER 8R

$553 \mathrm{pb}-\mathrm{Tm}: 58 \mathrm{o}-30$ ciclos

GAT GTC CAG AAA GAA CTT GGC

PRIMER 9F

GTA TCC CTT AAT CAG CCC ATC

PRIMER 9R

$602 \mathrm{pb}-\mathrm{Tm}: 58 \mathrm{o}-30$ ciclos

CGG TGA CCA CAG AAA TAG CT

PRIMER 10F

AAC CCA ACG TTG GCA CTA AG

PRIMER 10R

$548 \mathrm{pb}-\mathrm{Tm}: 56 \mathrm{oc}-30$ ciclos

CCC TTC ACT AAT AGG CCT AC

PRIMER 11F

GTG AAA TGT CCA GAG CCT TC

PRIMER 11R

$449 \mathrm{pb}-\mathrm{Tm}: 560 \mathrm{C}-30$ ciclos

TGG CGA TAC TAA ATG AGA GTG

PRIMER 12F

CGA AGT CTC CCT TTC TAG AC

PRIMER 12R

$449 \mathrm{pb}-\mathrm{Tm}: 56 \circ \mathrm{C}-30$ ciclos

GGA ATC TTC TGT TGG GCA TG

PRIMER 13F

GCT CAC ACA AAC AGG CTG AA

PRIMER 13R

$498 \mathrm{pb}-\mathrm{Tm}: 58 \mathrm{\circ}-30$ ciclos

CCA TAG AGC TCC ACA TAA ATG 